\title{
Imunomodulação da encefalomielite autoimune experimental pelo extrato da glândula salivar de
}

Aedes aegypti

Tese apresentada ao Programa de PósGraduação em Imunologia do Instituto de Ciências Biomédicas da Universidade de São Paulo, para obtenção do Título de Doutor em Ciências.

São Paulo 


\title{
ANDERSON DANIEL RAMOS
}

\section{Imunomodulação da encefalomielite autoimune experimental pelo extrato da glândula salivar de}

\author{
Aedes aegypti
}

Tese apresentada ao Programa de PósGraduação em Imunologia do Instituto de Ciências Biomédicas da Universidade de São Paulo, para obtenção do Título de Doutor em Ciências.

Área de concentração: Imunologia

Orientador: Prof. Dr. Anderson de Sá Nunes

Versão corrigida. A versão original eletrônica encontra-se disponível tanto na Biblioteca do ICB quanto na Biblioteca Digital de Teses e Dissertações da USP (BDTD).

São Paulo 
DADOS DE CATALOGAÇÃO NA PUBLICAÇÃO (CIP)

Serviço de Biblioteca e Informação Biomédica do

Instituto de Ciências Biomédicas da Universidade de São Paulo

reprodução não autorizada pelo autor

Ramos, Anderson Daniel.

Imunomodulação da encefalomielite autoimune experimental pelo extrato da Gândula salivar de Aedes aegypti / Anderson Daniel Ramos. -- São Paulo, 2014.

Orientador: Prof. Dr. Anderson de Sá Nunes.

Tese (Doutorado) - Universidade de São Paulo. Instituto de Ciências Biomédicas. Departamento de Imunologia. Área de concentração: Imunologia. Linha de pesquisa: Imunomodulação por componentes salivares de artrópodes hematófagos.

Versão do título para o inglês: Immunomodulation of experimental autoimmune encephalomyelitis by salivary gland extrat of Aedes aegypti.

1. Encefalomielite 2. Aedes aegypti 3. Saliva 4. Imunomoduladores 5. Artrópodes I. Nunes, Prof. Dr. Anderson de Sá II. Universidade de São Paulo. Instituto de Ciências Biomédicas. Programa de PósGraduação em Imunologia III. Título. 


\section{UNIVERSIDADE DE SÃO PAULO INSTITUTO DE CIÊNCIAS BIOMÉDICAS}

Candidato(a): $\quad$ Anderson Daniel Ramos

Título da Dissertação: Imunomodulação da encefalomielite autoimune experimental pelo extrato da glândula salivar de Aedes aegypti.

Orientador(a): $\quad$ Prof. Dr. Anderson de Sá-Nunes.

A Comissão Julgadora dos trabalhos de Defesa da Dissertação de Mestrado, em sessão pública realizada a ............................................., considerou
( ) Aprovado(a)
( ) Reprovado(a)

Presidente:

Assinatura:

Nome:

Instituição:

Examinador(a): Assinatura:

Nome:

Instituição:

Examinador(a): Assinatura:

Nome:

Instituição:

Examinador(a): Assinatura:

Nome:

Instituição:

Examinador(a): Assinatura:

Nome:

Instituição: 


\section{Certificado}

Certificamos que o protocolo registrado sob n ${ }^{\circ} \mathbf{0 1 6}$ nas fls. 125 do livro 02 para uso de animais em experimentação, sob a responsabilidade do $\operatorname{Prof}(a) \operatorname{Dr}(a))$ Anderson de Sá Nunes, Coordenador (a) da Linha de pesquisa "Efeitos do extrato de glândula salivar do mosquito Aedes aegypti em modelos animais de doenças autoimunes" do qual participam o(s) aluno(s) Anderson Daniel Ramos, Bruna Bizzarro, Michele Silva de Barros, Ciro Novaes Rosa Lino, Ceres Maciel de Miranda, está de acordo com os Princípios Éticos de Experimentação Animal adotado pela Sociedade Brasileira de Ciência de Animais de Laboratório (SBCAL) e foi aprovado pela COMISSÃO DE ÉTICA NO USO DE ANIMAIS (CEUA) em 05.03.2012, com validade de 4 anos.

São Paulo, 06 de março de 2012.
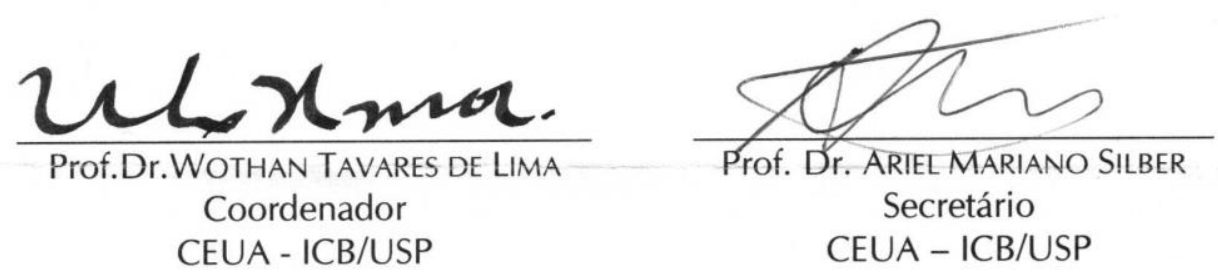


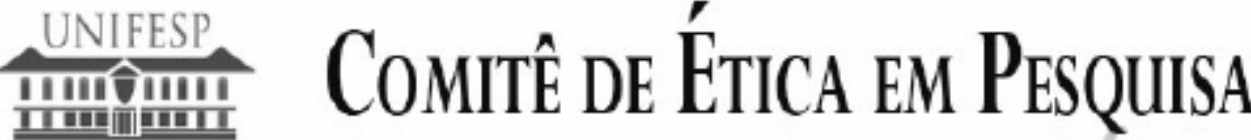

São Paulo, 15 de maio de 2014

CEUA N 7623150114

IImo(a). Sr(a)

Pesquisador(a): Anderson Daniel Ramos

Depto/Disc: Dmip-disciplina De Imunologia

Pesquisadores associados: Dr. Alexandre Salgado Basso (unifesp); Leandro Pires Araujo (unifesp); Dr. Anderson De Sá Nunes (orientador)

Título do projeto: "Imunomodulação da encefalomielite autoimune experimental pelo extrato da glândula salivar de Aedes aegypti.".

\section{Parecer Consubstanciado da Comissão de Ética no Uso de Animais UNIFESP/HSP}

Malária, dengue e febre amarela são graves doenças infecciosas transmitidas por mosquitos vetores. Para se alimentar, esses mosquitos precisam driblar a barreira da hemostasia e o sistema imunológico do hospedeiro. A saliva inoculada por esses vetores durante o repasto sanguíneo desempenha um papel importante na imunidade do hospedeiro vertebrado $e$ facilita a transmissão de doenças, pois possui componentes imunomoduladores, em sua grande maioria ainda não identificados. Assim, as atividades imunofarmacológicas do extrato de glândula salivar de mosquitos ainda carece de elucidação.

\section{ANIMAIS:}

Serão utilizados:

300 Camundongo isogênico, Fêmeas, idade: 6-10semanas

Procedência: CEDEME

Manutenção: Biotério de experimentação da Disciplina de Imunologia

\section{VIGÊNCIA DO ESTUDO:}

início previsto para: 02/2014 com término previsto para: 02/2015

A Comissão de Ética no Uso de Animais da Universidade Federal de São Paulo/Hospital São Paulo, na reunião de 13/03/2014, ANALISOU e APROVOU todos os procedimentos apresentados neste protocolo.

1. Comunicar toda e qualquer alteração do protocolo.

2. Comunicar imediatamente ao Comitê qualquer evento adverso ocorrido durante o desenvolvimento do protocolo.

3. Os dados individuais de todas as etapas da pesquisa devem ser mantidos em local seguro por 5 anos para possível auditoria dos órgãos competentes.

4. Relatórios parciais de andamento deverão ser enviados anualmente à CEUA até a conclusão do protocolo.

Atenciosamente,

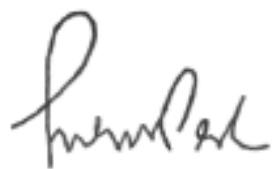

Prof. Dr. José Osmar Medina Pestana

Coordenador da Comissáo de Ética no Uso de Animais

Universidade Federal de Sao Paulo/Hospital Săo Paulo 
Dedico esta tese à Maria Luiza Raimundo que foi uma segunda mãe pra mim, me tratando como um filho e me ensinou a ser uma pessoa correta e justa. 


\section{AGRADECIMENTOS}

Gostaria de agradecer aquele que lutou, morreu e ressuscitou por nós. Obrigado Goku!

Aos meus pais, Maria Lúcia e Alaor, que sempre me incentivaram e me apoiaram durante toda a minha vida, dando todo o suporte, tanto financeiro como emocional.

Aos meus irmãos, Adriano e Alexsandro, que sempre me apoiaram e foram exemplos de pessoas durante minha vida.

Ao meu orientador Prof. Dr. Anderson de Sá Nunes, pela oportunidade de fazer parte do seu grupo de pesquisa e desenvolver este trabalho, pelos enormes ensinamentos, por ser um exemplo de pesquisador a ser seguido.

À Prof.(a) Dr.(a) Sonia Jancar, por todo o apoio e ajuda durante a troca de orientação.

Ao Dr. Alexandre Salgado Basso e seu aluno Leandro Araújo, que tornaram possível a realização deste trabalho, pela colaboração, ajuda com os experimentos e discussão dos resultados.

Aos membros da banca de qualificação Dr. Niels Olsen Saraiva Câmara, Dr. Alexandre Steiner e Dr. Joilson de Oliveira Martins, pela contribuição com a discussão e pelas críticas e sugestões para a melhora deste trabalho.

À minha namorada Marília por todo apoio e carinho durante todo o desenvolvimento desse projeto, por escutar meus desabafos, entender os fins de semana e horários de experimentos.

Aos meus sogros, Maria Aparecida e Tadeu, que me acolheram e sempre que possível me ajudam.

A minha prima Daiane e seu marido Leonardo, por estarem sempre dispostos quando precisei.

À Profa. Dra. Margareth de Lara Capurro Guimarães do Departamento de Parasitologia do ICB/USP por manter seu laboratório sempre aberto, e por ceder os mosquitos Aedes aegypti.

Aos colegas do laboratório de Imunologia Experimental, Michele, Bruna, Ciro, Priscila, Eliane, Sandra e Daniele por toda ajuda, não só nos experimentos mas também com conversas, discussões de resultados e por fazerem os momentos no laboratório mais descontraídos.

Aos colegas de demais laboratórios, Mariana Koga, Luciano, Matheus, Matheuzinho, Edson, Lidiane, Fernanda Bruni, Evilin, Luciana, Esther, Bianca, Davi, Bruno, Maysa, Simone, Aleida, Junior, Luciana, Fernanda Rofa, Marlise pela ajuda em algum momento, seja em experimentos ou apenas em conversas.

Às secretárias Eni, Jotelma e Amanda por toda ajuda com a parte burocrática.

Ao CNPq e a FAPESP pelo apoio financeiro.

Até mais, e obrigado pelos peixes! 


\section{LEARNING TO FLY (Pink Floyd)}

Into the distance a ribbon of black

Stretched to the point of no turning back

A flight of fancy on a windswept field

Standing alone my senses real

A fatal attraction holding me fast how

Can I escape this irresistible grasp?

Can't keep my eyes from the circling skies

Tongue tied and twisted Just an earth bound misfit I

Ice is forming on the tips of my wings

Unheeded warnings I thought I thought of everything

No navigator to find my way home

Unladened, empty and turned to stone

A soul in tension that's learning to fly

Condition grounded but determined to try

Can't keep my eyes from the circling skies

Tongue-tied and twisted just an earth-bound misfit, I

Above the planet on a wing and a prayer,

My grubby halo, a vapour trail in the empty air,

Across the clouds I see my shadow fly

Out of the corner of my watering eye

A dream unthreatened by the morning light

Could blow this soul right through the roof of the night

There's no sensation to compare with this

Suspended animation, A state of bliss

Can't keep my mind from the circling skies

Tongue-tied and twisted just an earth-bound misfit, I 
"O lado bom da ciência é que ela é verdade, quer você acredite ou não."

"Mesmo que você não consiga se tornar o "maioral" em alguma coisa, sempre vai poder melhorar. Não se esqueça disso! Nunca diga: Jamais serei bom. Você pode se tornar melhor. E um dia, você irá acordar e descobrir o quão bom você se tornou".

Neil deGrasse Tyson 
Este trabalho foi realizado com o apoio da Fundação de Amparo à Pesquisa do Estado de São Paulo (FAPESP) e Conselho Nacional de Pesquisa e Desenvolvimento (CNPq) 


\section{RESUMO}

Ramos AD. Imunomodulação da encefalomielite autoimune experimental pelo extrato da glândula salivar de Aedes aegypti [Tese (Doutorado em Imunologia)]. São Paulo: Instituto de Ciências Biomédicas, Universidade de São Paulo, São Paulo; 2014.

A saliva de insetos hematófagos é uma fonte potencial de moléculas biologicamente ativas. Diversos trabalhos já demonstraram que a saliva destes animais possui moléculas capazes de modular o sistema imune do hospedeiro vertebrado com a finalidade de realizar o repasto sanguíneo e, consequentemente, em seu processo reprodutivo o qual é dependente do sangue ingerido. Baseando-nos na literatura científica a respeito das atividades presentes na saliva de diversos artrópodes hematófagos, decidimos investigar no presente trabalho se o extrato da glândula salivar (EGS) do mosquito vetor da dengue, Aedes aegypti, seria capaz de modular a encefalomielite autoimune experimental (EAE), um modelo animal para estudo da esclerose múltipla. Para isso, imunizamos animais C57BL/6 com $\mathrm{MOG}_{35-55}$, um peptídeo imunodominante da mielina de oligodendrócitos, e determinamos o regime de tratamento com EGS de A. aegypti capaz de suprimir a doença. Demonstramos que a adição de EGS na emulsão de $\mathrm{MOG}_{35-55}$ seguido pela administração intraperitoneal pelo período de 10 dias, foi o protocolo mais eficiente para modulação dos sintomas da doença. Neste grupo, a incidência da doença foi menor do que no grupo que recebeu apenas veículo. Além disso, mesmo os animais que ficaram doentes, apresentaram atraso no aparecimento dos sinais clínicos e seus sintomas foram mais brandos. Também observamos que a modulação pelo EGS não se deu na fase efetora da resposta imune, pois quando realizamos o tratamento somente via intraperitoneal não observamos diferença no quadro clínico. Adicionalmente, a análise das células do sistema nervoso central não mostrou efeito do EGS sobre as subpopulações de linfócitos T. Finalmente, nossos dados sugerem que a ação do EGS ocorre durante a indução da resposta imune, uma vez que sua presença somente na emulsão contendo $\mathrm{MOG}_{35-55}$ (sem o tratamento intraperitoneal), é suficiente para reproduzir grande parte dos efeitos observados, sugerindo um papel nos mecanismos de processamento e/ou apresentação de antígeno. De fato, nossos experimentos demonstraram que o EGS consegue suprimir a doença por quatro vias principais: 1) atuando diretamente em células dendríticas e diminuindo a expressão de MHC de classe II, CD80 e CD86, além de diminuir a produção de citocinas responsáveis pela indução das respostas Th1 e Th17;2) indução de células produtoras de IL-10 ex vivo; 3) diminuição das respostas de linfócitos T nä̈ve, talvez como consequência parcial da apoptose induzida pelo EGS ou apresentação deficiente dos antígenos; 4) indução sistêmica de células com perfil Th2 com maior produção de IL-4 e IL-5, sugerindo um desvio do eixo Th1/Th17 durante a resposta imune. Como conclusão, temos que o EGS de A. aegypti é capaz de atuar tanto na supressão dos sintomas durante o curso da EAE, como também atuar preventivamente inibindo o início da resposta imune, sendo assim um candidato para a descoberta de moléculas bioativas que no futuro possam vir a ser usadas na terapêutica da esclerose múltipla e outras doenças autoimunes.

Palavras-chave: Aedes aegypti. Extrato da glândula salivar. Encefalomielite autoimune experimental. Imunomodulação. Doenças autoimunes. 


\begin{abstract}
Ramos AD. Immunomodulation of experimental autoimmune encephalomyelitis by salivary gland extract of Aedes aegypti [Thesis (Ph.D. in Immunology)]. São Paulo: Instituto de Ciências Biomédicas, Universidade de São Paulo, São Paulo; 2014.
\end{abstract}

Saliva of hematophagous insects is a potential source of biologically actives molecules. Previous studies have indicated that the saliva of these animals can modulate the immune system of the vertebrate host, in order to carry out the blood feeding and, consequently in his reproductive process which depends on the ingested blood. Based on the activities described in the saliva of several hematophagous arthropods, we decided to investigate in this work whether the salivary gland extract (SGE) of the mosquito vector of dengue, Aedes aegypti, could modulate experimental autoimmune encephalomyelitis (EAE), an animal model of multiple sclerosis. For this, we have immunized $\mathrm{C} 57 \mathrm{BL} / 6$ mice with $\mathrm{MOG}_{35-55}$, an immunodominant peptide of myelin oligodendrocyte and determine the treatment with $A$. aegypti capable of suppressing the disease. We have demonstrated that, the period of 10 days was the most efficient protocol for the modulation of disease symptoms. In this group, the disease incidence was lower than in the group that received only vehicle. Moreover, even the animals that developed clinical symptoms showed a delayed onset of clinical signs, making them less affected by the disease. We also observed that modulation by SGE did not occur in the effector phase of immune response, because when the treatment is performed intraperitoneally only, no difference was observed in the clinical signs. Additionally, analysis of central nervous system cells showed no effect of the SGE on subpopulations of $T$ lymphocytes. Finally, our data suggest that the action of SGE occurs during the induction phase of immune response, since its presence only in emulsion containing $\mathrm{MOG}_{35-55}$ (without intraperitoneal treatment) is sufficient to reproduce most of the observed effects, suggesting a role in processing mechanism and/or antigen presentation. Indeed, our experiments have shown that SGE can suppress disease through four mainly routes: 1) acting directly on dendritic cells and decreasing the expression of MHC class II, CD80 and CD86, besides decreasing the production of cytokines responsible for Th1 and Th17 response induction; 2) inducing IL-10 producing cells ex vivo; 3 ) decreasing the response of naive T lymphocytes, perhaps as a partial consequence of apoptosis induced by SGE or poor antigen presentation; 4) systemic induction of Th2 cells with increased production of IL-4 and IL-5, suggesting a shift of Th1/Th17 axis during immune response. In conclusion, we have shown that $A$. aegypti SGE is able to relieve the symptoms during the course of EAE and also to act preventively, inhibiting the initiation of immune response, becoming a candidate for the discovery of bioactive molecules that can be used in the future for the treatment of multiple sclerosis and other autoimmune diseases.

Keywords: Aedes aegypti. Salivary gland extract. Experimental autoimmune encephalomyelitis. Immunomodulation. Autoimmune diseases. 


\section{LISTA DE ABREVIATURAS E SIGLAS}

APC - Células apresentadoras de antígenos

CD - Cluster de diferenciação

CEUA - Comissão de Ética em Experimentação Animal

Con A - concanavalina A

EAE - Encefalomielite Autoimune Experimental

EGS - Extrato da glândula salivar

EM - Esclerose Múltipla

GM-CSF - Fator estimulador de colônias de granulócitos e macrófagos

HPLC - Cromatografia líquida de alta performance

IFN - Interferon

IL - Interleucina

MHC II - Complexo principal de histocompatibilidade classe II

$\mathrm{MOG}_{\mathrm{p} 35-55}$ - peptídeo 35-55 da glicoproteína mielina de oligodendrócitos

PAMPs - Padrões moleculares associados a patógenos

PBS - salina tamponada com fosfato

Th - T helper

TNF - Fator de necrose tumoral

upLPS - Lipopolissacarídeo ultra puro 


\section{SUMÁRIO}

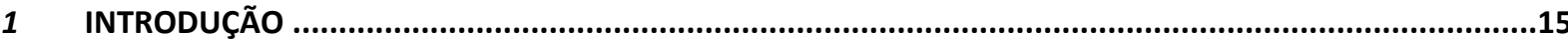

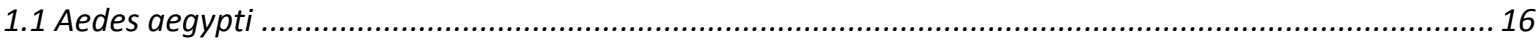

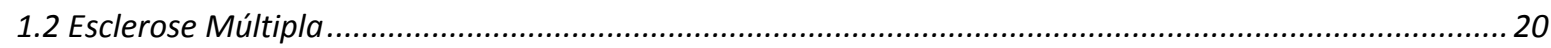

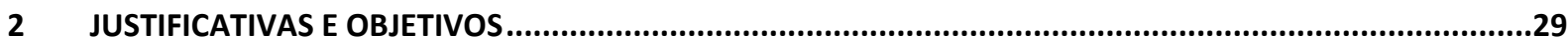

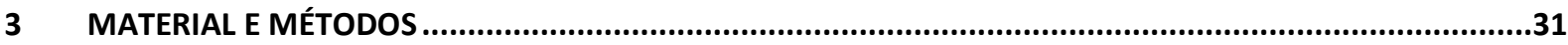

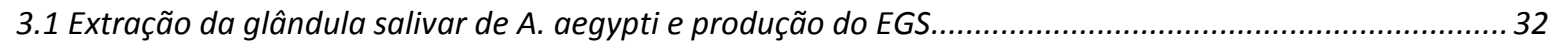

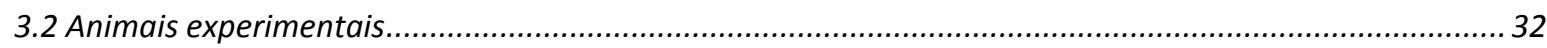

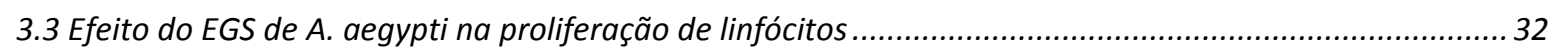

3.4 Fracionamento do EGS por cromatografia líquida de alta performance (HPLC) ……............................... 33

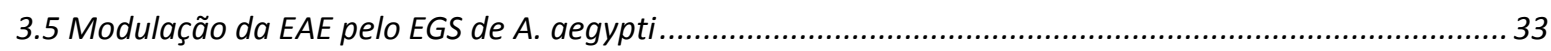

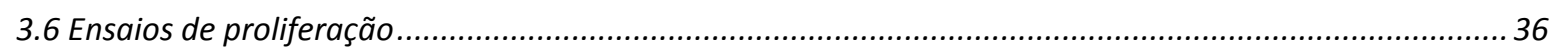

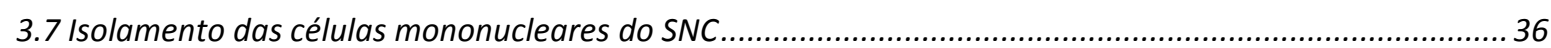

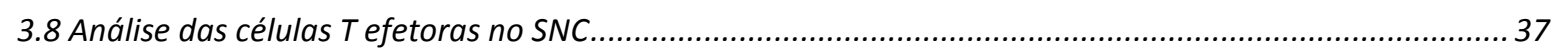

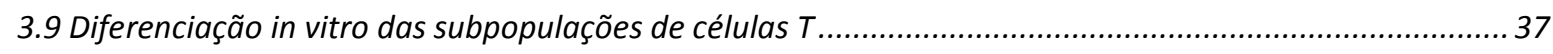

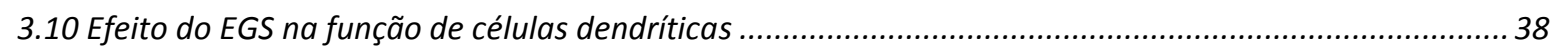

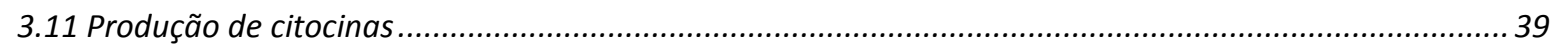

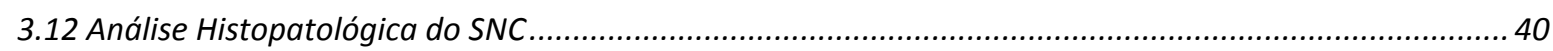

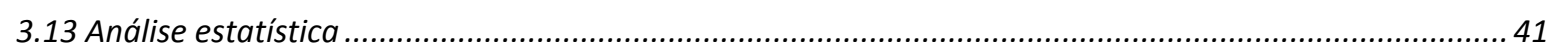

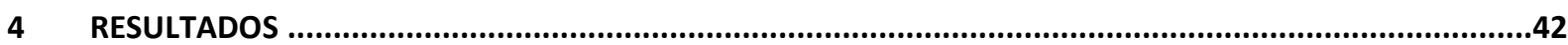

4.1 Determinação do protocolo de tratamento com EGS no modelo de EAE ..................................................... 43

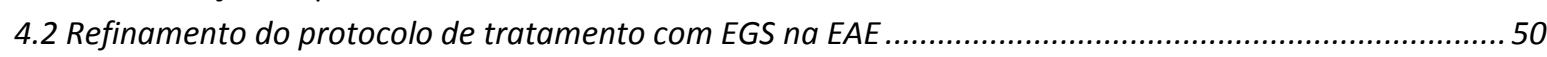

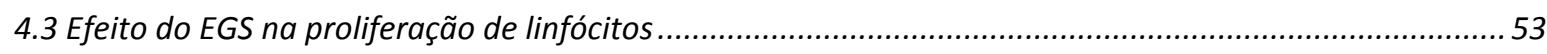

4.4 Efeito do EGS na proliferação de linfócitos e produção de citocinas na EAE: comparação das diferentes

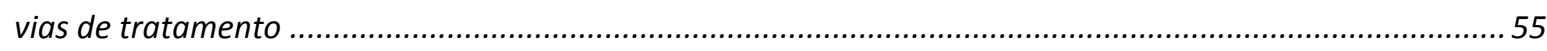

4.5 Frequência de células mononucleares ativadas no SNC dos animais tratados com EGS durante o curso da EAE.

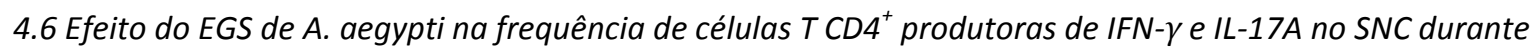

$a$ EAE

4.7 Frequência de células T reguladoras Foxp3+ no SNC dos animais tratados com EGS durante a EAE.......... 63

4.8 Efeito do EGS no infiltrado celular e desmielinização do SNC durante a EAE ........................................... 65

4.9 Proliferação e produção de citocinas após estimulação policlonal e MOG-específica em modelo de

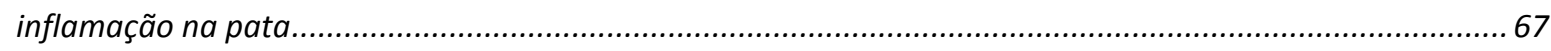

4.10 Efeito do EGS de A. aegypti na diferenciação in vitro de células Th1, Th17 e Treg...................................69

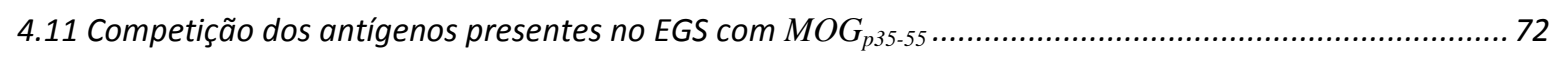

4.12 Efeito do EGS na maturação e diferenciação de células dendríticas ....................................................... 75

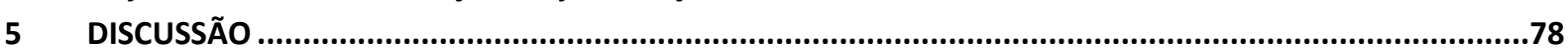

6 CONCLUSÃO

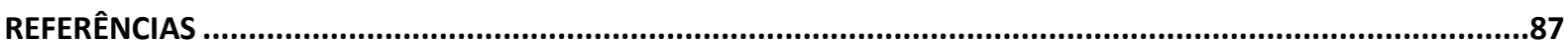


1 INTRODUÇÃO 


\subsection{Aedes aegypti}

O filo Arthropoda possui aproximadamente 1.096.660 espécies descritas, constituindo 85\% de todas as já catalogadas pelo homem (1), embora o número total de espécies estimado fique entre 5 e 10 milhões (2). Dentro do grupo dos artrópodes, diversas espécies desenvolveram de forma independente ao longo da evolução o hábito hematofágico, que consiste na ingestão de sangue de animais vertebrados. Estima-se que existam aproximadamente 14.000 espécies de artrópodes que se alimentam de sangue (3). Dentre os grupos de artrópodes hematófagos, os mosquitos recebem atenção especial, pois, segundo a Organização Mundial da Saúde (OMS), são responsáveis por mais de 1 milhão de mortes/ano, por serem os vetores de diversas doenças emergentes e reemergentes (4).

Os principais gêneros de mosquitos que se alimentam de sangue são Anopheles, Culex, Aedes, Psorophora, Ochlerotatus, Sabethes, Wyeomyia, Culiseta, e Haemagogus (5). No Brasil, uma das espécies de mosquito mais importantes em termos de saúde pública é o Aedes aegypti. Esse inseto possui uma distribuição na região tropical do globo, sendo o vetor primário de doenças como a febre amarela, febre Chikungunya e dengue (6-9). No caso específico da dengue, dados globais de 2010 mostram que foram registrados cerca de 96 milhões de casos graves e aproximadamente 300 milhões de casos moderados ou assintomáticos. Setenta por cento dos casos graves de dengue ocorrem na Ásia, sendo que a Índia responde sozinha por $34 \%$ desse total. Nas Américas, o Brasil e o México apresentam cerca de $14 \%$ dos casos graves, praticamente a mesma porcentagem da África, conforme apresentado na Figura 1 (10). No Brasil, epidemias recorrentes têm ocorrido ao longo das duas últimas décadas embora, segundo o Ministério da Saúde, no primeiro bimestre de 2014 tenha ocorrido uma diminuição de $80 \%$ no número de casos em relação ao mesmo período de 2013 (427 mil em 2013 para 87 mil este ano). No Estado de São Paulo, porém, a situação é um pouco diferente e até junho de 2014 o número de casos registrados em todo o estado já chegava à marca de 98.468 (11), o que significa metade de todos os casos registrados no ano de 2013 (12). Um levantamento recente divulgado pela Secretaria Municipal de Saúde revela que no município de São Paulo ocorreram mais de 6 mil casos da doença esse ano, o que representa mais do que o dobro na comparação com o mesmo período de 2013 (13). 

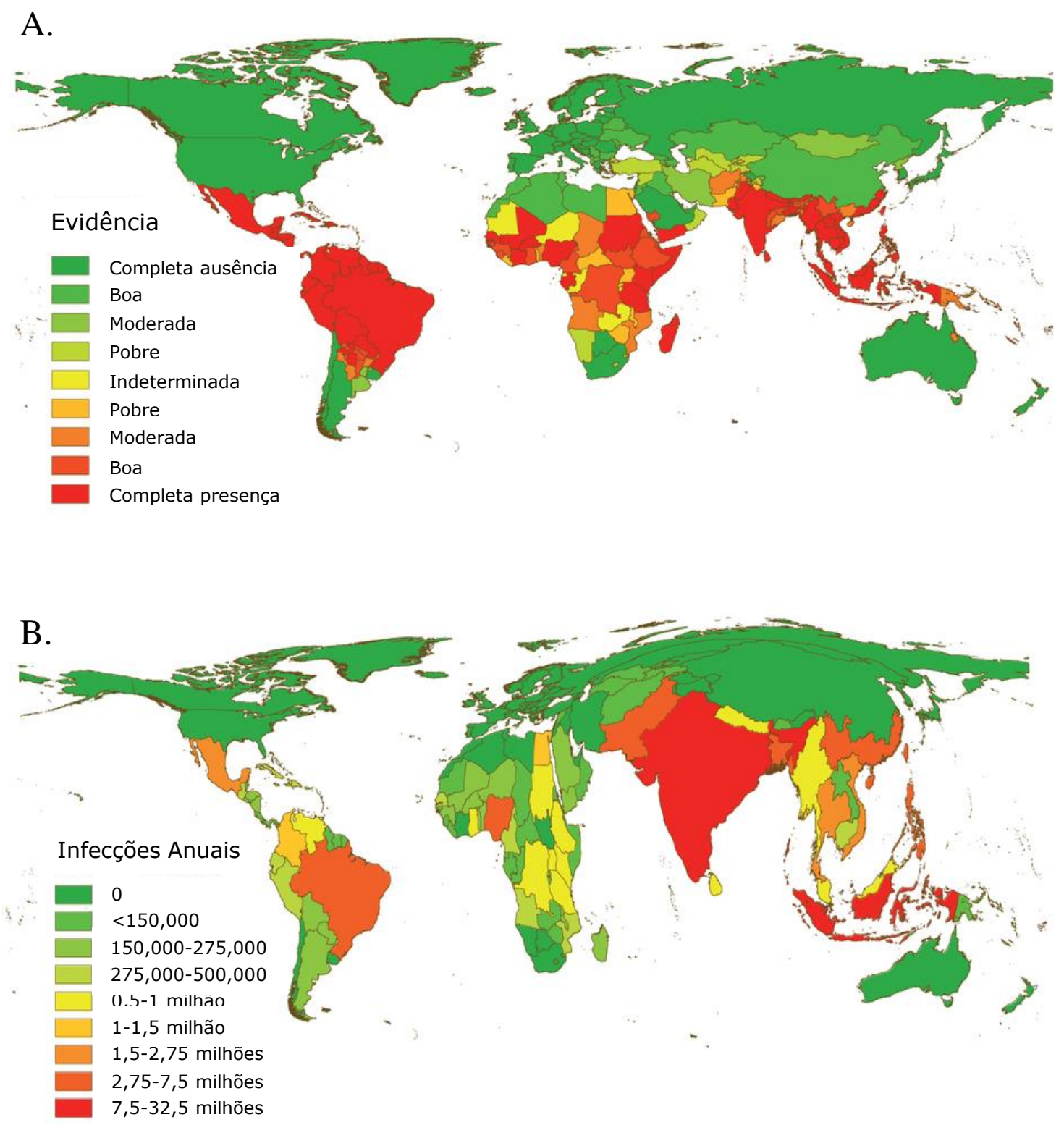

Figura 1 - Evidência global e infecção da dengue em 2010. (a) Evidências nacionais da total presença (verde) ou total ausência (vermelho) da dengue. (b) Cartograma do número anual de infecções para todas as idades como proporção nacional da área geográfica (modificado de Bhatt et al., 2013).

Para obter sucesso no repasto sanguíneo, o mosquito A. aegypti fêmea enfrenta dois grandes obstáculos: a hemostasia e o sistema imune do hospedeiro (14). Com relação à hemostasia, já foram descritas diversas moléculas presentes na saliva de A. aegypti com propriedades capazes de modular o sistema da coagulação. Entre as moléculas presentes na 
saliva temos a apirase, capaz de inibir agregação plaquetária, via hidrólise de ATP e ADP liberados pelas células lesadas ou plaquetas ativadas (15). A aegyptina também exerce ação sobre a agregação de plaquetas, através de sua ligação ao colágeno, bloqueando a interação com os componentes sanguíneos $(16,17)$. Já a vasodilatação verificada durante o repasto do $A$. aegypti é basicamente desencadeada pela ação das sialocininas I e II (18). Adicionalmente, também foi caracterizado um inibidor de serino-proteases (serpina) capaz de atuar sobre o fator Xa da cascata de coagulação (19). Nosso grupo vem trabalhando com outra serpina salivar que também apresenta atividade anticoagulante, embora menos potente, mas cujo mecanismo ainda é desconhecido (20). Deste modo, já foram descritas diversas moléculas presentes na saliva de A. aegypti capazes de modular a hemostasia, com o objetivo de garantir o sucesso do animal no repasto sanguíneo que ocorre no hospedeiro vertebrado.

Outro desafio enfrentado pelo mosquito durante sua alimentação é o sistema imune do hospedeiro. As atividades imunoduladoras da saliva de A. aegypti no hospedeiro vertebrado estão começando a ser entendidas. Por exemplo, já foi visto que o extrato da glândula salivar (EGS) de A. aegypti é capaz de inibir a secreção de TNF- $\alpha$ em mastócitos de ratos, porém a liberação de histamina por estas células não é afetada (21). O EGS também é capaz de suprimir a expressão de transcritos de IL-12, IFN- $\beta$ e a enzima óxido nítrico sintase induzível em células dendríticas e macrófagos de camundongos, inibindo assim o desenvolvimento de uma resposta do padrão Th1 (22). Wanasen e colaboradores (2004) demonstraram que a resposta proliferativa de linfócitos de baço in vitro, tanto antígeno-dependente quanto antígeno-independente, foi suprimida na presença do EGS de A. aegypti. Resultados semelhantes foram apresentados no mesmo ano por Wasserman e colaboradores (2004), que também mostraram uma diminuição significativa na produção de IL-2, IFN- $\gamma$, IL-12, GMCSF, TNF- $\alpha$, IL-4, IL-5 e IL-10 em linfócitos de camundongos DO11.10 estimulados com ovalbumina (OVA). Essa redução maciça da produção de citocinas se correlacionou com um aumento na morte de populações linfocitárias, que foi induzida por uma fração de alto peso molecular, presente na saliva de A. aegypti. Além disso, os linfócitos sobreviventes apresentaram menor capacidade proliferativa (23).

Sabendo que a saliva é capaz de modular os elementos celulares e humorais da resposta imune de seus hospedeiros, é plausível imaginar que essa regulação seja capaz de proporcionar aumento da infectividade dos patógenos transmitidos. Essa hipótese foi corroborada pela inoculação intradérmica do vírus do Nilo Ocidental em sítios onde o mosquito havia se alimentado, o que provocou alta viremia e acelerada neuroinvasão 
comparado aos animais apenas infectados, mas sem prévia exposição às picadas (25). Posteriormente, observou-se que quanto maior a exposição dos camundongos ao A. aegypti, maior a taxa de mortalidade dos animais infectados pelo mesmo vírus. Nestes animais présensibilizados pelas picadas houve uma maior expressão de IL-10 na pele e linfonodos, que possivelmente criou um microambiente favorável para a replicação viral (25). Na tentativa de mimetizar a infecção natural, o mesmo grupo inoculou o vírus Sindbis simultaneamente com a saliva de $A$. aegypti e encontrou uma potencialização na infecção viral, com maior expressão de IL-4 e IL-10, concomitantemente com menor expressão de IFN- $\gamma$, quando comparado aos animais que receberam apenas o vírus (26). Portanto, é possível assumir que a presença da saliva de A. aegypti durante as infecções induz patologia exacerbada de alguns agentes infecciosos por inibir a imunidade celular (Th1), elevar a resposta antiinflamatória/reguladora e, em alguns casos, também da população de linfócitos Th2.

Em nosso laboratório, demonstramos que a sensibilização de camundongos com as picadas do mosquito e posterior desafio intranasal com EGS induz inflamação pulmonar, com aumento no número de eosinófilos, células T CD4 ${ }^{+}, \mathrm{CD}_{1} 9^{+}$e citocinas IL-4, IL-5 e IL-13 no lavado broncoalveolar, anticorpos IgE total e IgG1 e IgG2a específicos no soro. Analisados em conjunto, nossos dados demonstraram o desenvolvimento de uma resposta alérgica diferente dos modelos clássicos, com a presença de elementos que sugerem uma resposta mista, tanto de perfil Th1 quanto Th2 (27). Também observamos que o EGS de A. aegypti afeta a ativação de macrófagos por LPS e IFN- $\gamma$, diminuindo a produção de óxido nítrico e das citocinas inflamatórias IL-6 e IL-12 (Barros, tese de Doutorado em andamento). Adicionalmente, avaliando os efeitos dos componentes salivares de A. aegypti na biologia de células dendríticas, vimos que o EGS não interfere na diferenciação, maturação e função de células dendríticas murinas nas condições estudadas. Entretanto, componentes salivares desse mosquito possuem um efeito direto sobre linfócitos, induzindo a morte tanto de linfócitos $\mathrm{T}$ quando de linfócitos B. O mecanismo de ação do EGS envolveu a apoptose de células T nä̈ve, dependente de caspase-3 e caspase-8, enquanto células de memória foram resistentes a essa atividade (28). Resumindo, nossos resultados demonstram que a saliva de A. aegypti possui componentes que são capazes de induzir uma resposta celular mista Th1/Th2 in vivo, além de atuar diretamente em macrófagos, diminuindo sua ativação, e de linfócitos, induzindo apoptose.

Devido ao efeito modulador observado principalmente em macrófagos e linfócitos, células que possuem um papel importante em doenças autoimunes, nossa hipótese é a de que 
os componentes presentes na saliva de A. aegypti sejam capazes de modular o curso clínico de modelos animais de doenças autoimunes. Nesse sentido, alguns trabalhos com a saliva de outros artrópodes hematófagos já indicaram que essa hipótese é plausível. Em alguns casos, uma ou mais moléculas responsáveis por essas atividades já foram identificadas, incluindo seus prováveis mecanismos de ação. Por exemplo, nucleosídeos provenientes da saliva Phlebotomus papatasi, uma espécie de flebótomo vetor da leishmaniose, tiveram um efeito terapêutico na artrite murina induzida por colágeno. A administração diária de EGS (equivalente a 1 glândula), iniciada no dia dos primeiros sintomas da doença, atenuou a severidade da artrite, reduzindo a lesão na articulação, o infiltrado inflamatório e a liberação de citocinas pró-inflamatórias (29). Outra molécula proveniente da saliva de flebótomos, a proteína LJM 111 de Lutzomyia longipalpis, apresentou um efeito inibidor em parâmetros inflamatórios na artrite experimental, onde foi observada uma redução na migração de neutrófilos, da nocicepção e da liberação de citocinas IL-17, TNF- $\alpha$ e IFN- $\gamma$. Em culturas de células dendríticas, essa proteína foi capaz de reduzir a expressão de MHC de classe II e CD86, além da citocina TNF- $\alpha$. Estes dados sugerem que a LJM 111 é capaz de diminuir a função e maturação de células dendríticas, o que pode estar relacionado com a melhora no curso clínico da doença (30). Além da artrite, já foi demonstrado um efeito modulador de algumas moléculas salivares na encefalomielite autoimune experimental (EAE), um modelo animal de esclerose múltipla. Por exemplo, a sialostatina L1 (SialoL1), um inibidor de cisteíno-proteases identificado na saliva do carrapato vetor da doença de Lime Ixodes scapularis, preveniu os sinais clínicos da doença, que foram associados à redução dos níveis de IFN- $\gamma$ e IL-17, além de uma menor proliferação específica de células T (31). Outra molécula proveniente de I. scapularis capaz de modular o curso da EAE é a Salp15. Porém, ao contrário da SialoL1, esta molécula modulou a doença de forma negativa, induzindo uma EAE mais severa nos animais tratados. Isto ocorre devido ao fato de esta molécula induzir um aumento na diferenciação de células Th17 in vivo (32).

\subsection{Esclerose Múltipla}

A Esclerose Múltipla (EM) é uma doença autoimune inflamatória, desmielinizante, crônica, do sistema nervoso central (SNC). Ocasionada por uma desordem primária do sistema imunológico que agride os componentes da bainha de mielina, resultando em um efeito secundário sobre os neurônios. Em linhas gerais, a destruição da bainha de mielina dos neurônios leva a um bloqueio do impulso elétrico até a célula alvo, resultando em diversos 
sintomas, que podem variar de distúrbios da fala até paralisia total (33). No mundo, há uma estimativa de que aproximadamente 2,3 milhões de pessoas sejam portadoras de EM, segundo a Federação Internacional de Esclerose Múltipla (MSIF). No Brasil, segundo dados da Associação Brasileira de Esclerose Múltipla (ABEM), existem cerca de 35.000 indivíduos portadores de EM, sendo que aproximadamente 10.376 desses portadores estão em tratamento, segundo dados do Sistema Único de Saúde (34).

A EM é uma doença imunomediada que apresenta uma grande variação de incidência e prevalência no mundo. Ela afeta mais mulheres do que homens, sendo a razão de casos de mulheres para homens de 3:1, de acordo com a MSIF. Sua incidência varia geograficamente, sendo a América do Sul considerada região de baixa prevalência (até 20 casos por 100.000 habitantes). Segundo o relatório de 2013 da MSIF para a OMS, a maior incidência da doença ocorre em países da Europa e América do Norte (Figura 2). Estes dados estão de acordo com os primeiros estudos sobre a epidemiologia da EM que relacionaram prevalência e latitude, ocorrendo menor prevalência em países próximos à linha do Equador. De fato, no Brasil observa-se maior incidência da doença no Sul e Sudeste, sugerindo a existência do fator latitudinal. Mas é interessante salientar que embora haja uma prevalência menor em países tropicais, vemos no mapa que a Austrália apresenta uma incidência grande de EM, enquanto países africanos próximos à linha do Equador quase não apresentam casos, o que nos leva a pensar que, de fato, há uma subnotificação nos casos de EM, colocando em dúvida as evidências desse fator latitudinal. Não existem dados estatísticos nacionais no Brasil; apenas dados epidemiológicos regionais, em que essa prevalência varia conforme a região geográfica. No geral, o Brasil tem uma taxa de prevalência de aproximadamente 10 casos para cada 100.000 habitantes, de acordo com o Ministério da Saúde (35).

A etiologia da EM ainda não é bem compreendida, mas muitas evidências sugerem que esteja relacionada tanto a fatores genéticos como ambientais (36,37). Entre os fatores de risco já descritos, muitos estudos sugerem que vacinação, infecções, geografia, genética, nutrição, exposição à luz solar, exercício, estresse, tabagismo e condições de higiene podem precipitar a doença e modular a taxa de progressão (38-49). Grande parte dos estudos abordando os fatores de risco são artigos de revisão e portanto não referem-se a pesquisas recentes, o que leva à incerteza quanto à real influência de cada um desses fatores. Além disso, as pesquisas desenvolvidas com portadores da doença, não mostram dados estatisticamente significativos, fato que dificulta a comprovação da influência real de cada fator de risco. 


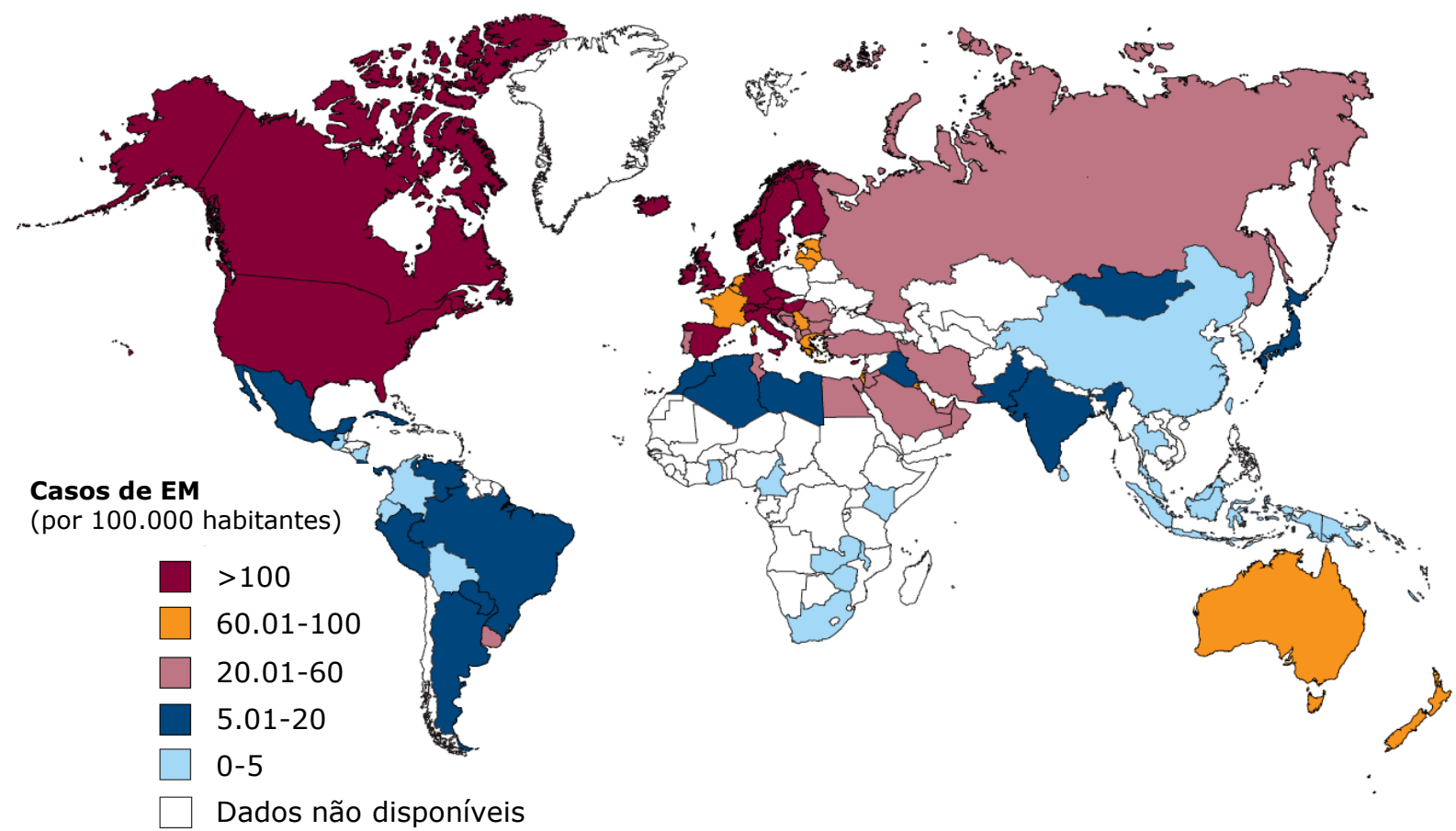

Figura 2 - Prevalência da Esclerose Múltipla por país (2013). Dados da Federação Internacional da Esclerose Múltipla mostrando a prevalência da EM por país.(Modificado do Atlas da Esclerose Múltipla 2013, da Federação Internacional da Esclerose Múltipla).

Há quatro formas clínicas da doença: remitente-recorrente (EM-RR), primariamente progressiva (EM-PP), primariamente progressiva com surto (EM-PP com surto) e secundariamente progressiva (EM-SP). A forma mais comum é a EM-RR, representando 85\% de todos os casos no início de sua apresentação. A forma EM-SP é uma evolução natural da forma EM-RR em 50\% dos casos após 10 anos do diagnóstico (em casos sem tratamento história natural). As formas EM-PP e EM-PP com surto perfazem 10\%-15\% de todos os casos $(50,51)$. De acordo com o Ministério da Saúde, o diagnóstico feito no Brasil é baseado nos critérios de McDonald revisados (52). Estes critérios são os adotados pela comunidade científica mundial para o diagnóstico de esclerose múltipla (Tabela 1).

Tabela 1 - Critérios de McDonald revisados e adaptados:

\section{APRESENTAÇÃO CLÍNICA \\ DADOS ADICIONAIS NECESSÁRIOS PARA O DIAGNÓSTICO}

A. 2 ou mais surtos mais evidência Apenas 1 ou 2 lesões sugestivas de EM à Ressonância 


\begin{tabular}{ll}
\hline clínica de 2 ou mais lesões. & Magnética (RM). \\
\hline B. 2 ou mais surtos mais evidência & Disseminação no espaço, demonstrada por RM com critérios \\
clínica de 1 lesão. & de Barkhoff (presença de pelo menos 3 das 4 características \\
& a seguir): \\
& a. pelo menos 1 lesão impregnada pelo gadolínio ou pelo \\
& menos 9 lesões supratentoriais em T2; \\
& b. pelo menos 3 lesões periventriculares); \\
& c. pelo menos 1 lesão justacortical; \\
& d. pelo menos 1 lesão infratentorial; ou \\
& RM com 2 lesões típicas e presença de bandas oligoclonais \\
& ao exame do líquor; ou aguardar novo surto. \\
\hline C. 1 surto mais evidência clínica de & $\begin{array}{l}\text { Disseminação no tempo, demonstrada por RM, após } 3 \\
\text { meses, com novas lesões ou pelo menos } 1 \text { das antigas } \\
\text { impregnada pelo gadolínio; ou aguardar novo surto. }\end{array}$ \\
\hline D. 1 lesão. & Disseminação no espaço, demonstrada por RM com \\
& Critérios de Barkhoff ou RM com 2 lesões típicas e \\
presença de bandas oligoclonais no exame do líquor e \\
disseminação no tempo, demonstrada por RM, após 3 \\
meses com novas lesões ou pelo menos 1 das antigas \\
impregnada pelo gadolínio ou aguardar novo surto.
\end{tabular}

As características clínicas e patológicas da EM são variáveis, refletindo em diferentes vias para o dano tecidual (53). Os principais mecanismos que causam os danos e levam às manifestações clinicas são: inflamação, desmielinização e degeneração dos axônios (54). A doença se inicia na periferia, onde as células apresentadoras de antígenos (APCs) apresentam os antígenos para os linfócitos $\mathrm{T} \mathrm{CD}^{+}$, o que leva a sua ativação e subsequente geração de subpopulações auto-reativas pró-inflamatórias Th1 e Th17 (55). Ligantes presentes na membrana desses linfócitos auto-reativos interagem com moléculas de adesão presentes na superfície do endotélio do SNC e, juntamente com anticorpos e outras células mononucleares, rompem a barreira hematoencefálica com a ajuda de proteases e quimiocinas. Já no SNC, os antígenos-alvo são reconhecidos (geralmente proteínas presentes na mielina) pelas células $\mathrm{T}$ auto-reativas, o que acaba amplificando a resposta. Os subtipos celulares pró-inflamatórios Th1 e Th17 então proliferam, os linfócitos B começam sua maturação para a secreção de anticorpos e os monócitos se ativam tornando-se macrófagos ativados $(56,57)$. Essas células 
imunes começam então a secretar diversas citocinas inflamatórias (IL-12, IL-23, IFN- $\gamma$ ), proteases, anticorpos, óxido nítrico e glutamato, que acabam levando ao dano da mielina e dos oligodendrócitos. Após isso, com diversas citocinas sendo secretadas, células $\mathrm{T} \mathrm{CD}^{+}$do subtipo Th2 proliferam e começam a secretar citocinas como IL-4, IL5, IL-13 e TGF- $\beta$ que suprimem a resposta imune. Com o dano causado, a desmielinização pode bloquear ou dificultar a condução dos impulsos nervosos, o que acaba resultando nos sintomas neurológicos apresentados pelos pacientes (58-61). Observações feitas em pacientes corroboram os seguintes aspectos:

i) a presença de células inflamatórias como linfócitos T, B e macrófagos em exames histopatológicos feitos em lesões de pacientes com EM (62);

ii) aumento dos níveis de $\operatorname{IgG}$ específico para proteínas presentes em oligodendrócitos e astrócitos presentes no SNC (63);

iii) presença de células $\mathrm{T}$ auto-reativas para mielina em lesões, fluído cérebro- espinhal e circulação periférica de pacientes com $\operatorname{EM}(64,65)$;

iv) ativação de células Th17 mediada por IL-23 associada com lesões de pacientes com EM (66-68).

O tratamento para EM é realizado apenas em pacientes que possuem as formas EMRR e EM-SP, pois não há evidência de benefício para as demais (69). Atualmente existem diversas drogas utilizadas para modificar a doença. Interferon- $\beta$ e acetato de glatirâmer são usados como primeira linha no tratamento da EM-RR. O efeito terapêutico do interferon se dá pela sua ação antiproliferativa, regulação de moléculas coestimuladoras, diminuição de citocinas pró-inflamatórias ou atuando em proteases e moléculas de adesão da barreira hematoencefálica, reduzindo sua permeabilidade e limitando a passagem de linfócitos $\mathrm{T}$ para o SNC. O efeito terapêutico do acetato de glatirâmer pode ser devido à indução de células Th2 reativas, que atravessam a barreira hematoencefálica e aumentam a secreção de citocinas antiinflamatórias, que irão suprimir a resposta no SNC (70-72). A mitoxantrona possui efeitos imunossupressores e imunomoduladores, que são efetivos em paciente com EM agressiva, porém, devido aos seus efeitos colaterais (cardiotoxicidade e leucemia), e ao surgimento de novas drogas, não é mais amplamente utilizada (52,73). O natalizumab é um anticorpo monoclonal utilizado por pacientes com formas reincidentes de EM. Seu efeito é devido ao bloqueio da ligação da subunidade $\alpha 4$ da integrina $\alpha 4 \beta 1$ (VLA-4), expressa na superfície de células T ativadas, com a molécula de adesão (VCAM-1) presente na superfície vascular da 
barreira hematoencefálica. Essa interação entre $\alpha 4$ e a VCAM-1é essencial para as células T chegarem até o SNC (74). O fingolimode é um agonista da esfingosina-1-fosfato (S1P), se ligando a 4 dos 5 subtipos de receptores da S1P, atuando funcionalmente como um antagonista. Interfere com o mecanismo que os linfócitos usam para saírem dos linfonodos (75). O aprisionamento dos linfócitos nos linfonodos faz com que eles não entrem no SNC para causarem as lesões da EM, além disso, causa linfopenia nos pacientes (76). A teriflunomida é usada para formas reincidentes de EM. Ela inibe a enzima diidroorotato desidrogenase, que está envolvida na síntese de pirimidina, e diminui a ativação e proliferação de células T e B (73). Atualmente novas drogas estão em testes e já vêm sendo utilizadas em alguns países. Entre as terapias emergentes podemos citar o dimetil fumarato, alemtuzumab, laquinimode, daclizumab e ocrelizumab. $\mathrm{O}$ dimetil fumarato atua ativando a via transcricional do fator nuclear erotroide 2, o que acaba reduzindo o stress oxidativo celular, e também atua modulando o fator nuclear $\kappa \mathrm{B}$, induzindo, assim, efeitos anti-inflamatórios $(77,78)$. $\mathrm{O}$ alemtuzumab é um anticorpo monoclonal anti-CD52, um marcador de superfície presente em monócitos e linfócitos. Seu mecanismo é decorrente a depleção de células T, B e natural killer (79). O laquinimode é derivado da droga imunomoduladora linomida, que atua reduzindo o infiltrado de linfócitos nos sítios inflamatórios e fazendo uma mudança na diferenciação de células Th1 para Th2 $(73,80)$. O daclizumab é um anticorpo monoclonal, que se liga com alta afinidade à subunidade $\alpha$ (CD25) do receptor da IL-2, que é expresso em células T (81). O ocrelizumab é um anticorpo monoclonal anti-CD20, que atua depletando as células B (menos as células progenitoras e plasmocitóides), resultando numa diminuição de células B, porém com efeitos menores na diminuição da produção de anticorpos $(82,83)$.

Os modelos animais para estudo de doenças humanas fornecem uma nova visão para entender os mecanismos patológicos das doenças, como também fornecem maneiras de estudar o mecanismo e desenvolvimento de novos fármacos. O modelo animal mais usado para o estudo da EM é a encefalomielite autoimune experimental (EAE) (84), um modelo animal de doença do sistema nervoso central, sendo usada em laboratório para a investigação da EM por se assemelhar a essa condiçãoem muitos aspectos.(85). Esse modelo surgiu na realidade à partir esforços para entender a patogênese da encefalomielite decorrente da vacinação anti-rábica. A vacina anti-rábica de Pasteur consistia em uma suspensão de cordões espinhais dissecados de coelhos infectados com raiva. Após uma série de injeções, alguns pacientes desenvolviam uma encefalomielite que era diferente da raiva. Antes disso, alguns pesquisadores foram capazes de induzir uma encefalomielite similar em coelhos e macacos 
administrando tecido neural em repetidas injeções, assim, demonstrando que a encefalomielite após vacinação anti-rábica era provavelmente resultado da indução não intencional de uma resposta autoimune contra antígenos neurais (86-88). Nesses primeiros experimentos, a incidência da doença foi baixa e a indução da doença necessitava de múltiplas injeções através de um período de várias semanas. A introdução do adjuvante completo de Freund (CFA) tornou a indução da EAE mais simples e confiável. O CFA consiste em uma mistura de óleo mineral e Mycobacterium tuberculosis formando uma emulsão com o antígeno, e a injeção do antígeno em CFA induz uma resposta imune vigorosa e prolongada contra o antígeno. Vários pesquisadores começaram a utilizar esta técnica para induzir EAE em diversas espécies como coelhos, macacos e cobaias e a partir disso, na maioria dos casos os animais começaram a desenvolver o déficit neurológico após uma ou poucas injeções de tecido neural em CFA, e o início dos sintomas clínicos ocorreram entre 3 a 4 semanas após a primeira injeção (89-93). Tentativas iniciais de induzir EAE em camundongos com o antígeno em CFA não obtiveram êxito. Olitsky e Yager (1949) publicaram o primeiro trabalho com EAE em camundongos. A grande maioria dos animais desenvolveu sintomas neurológicos após 3 a 5 semanas após injeções do tecido cerebral em CFA. Os sintomas tiveram início cerca de 3 semanas após a primeira injeção. Após isso, Lee e Olitsky (1955) mostraram que a vacina de pertussis dada como uma injeção separada em adição ao antígeno em CFA, aumentava a incidência da doença. Munoz e colaboradores (1984) descobriram que a molécula ativa na vacina de pertussis era uma toxina, que atualmente é usada na rotina como um adjuvante adicional para induzir EAE em camundongos. Todos esses experimentos iniciais com EAE foram realizados com homogenato ou extrato do tecido do CNS como antígeno.

Um dos desafios iniciais na pesquisa da EAE foi a identificação de componentes encefalitogênicos nesses homogenatos. $\mathrm{O}$ encefalitógeno estava presente na matéria branca ou mielina e acreditava-se ser proteína e não lipídio. Nessa época, havia controvérsia se o homogenato do cérebro continha um ou mais encefalitógenos e em quais das misturas purificadas, através dos métodos limitados disponíveis na época, estaria o encefalitógeno relevante. No começo, ambas proteínas principais da estrutura da mielina, a proteína básica da mielina (MBP) e a proteína proteolipídica (PLP) demonstraram ser encefalitogênicas (97-99). Estudos posteriores com MBP mostraram que não era necessário a proteína intacta para a indução da EAE. Fragmentos específicos da MBP gerados pela digestão com pepsina ou tripsina da molécula inteira eram encefalitogênicos e em 1970, Eylar e colaboradores, 
conseguiram induzir a EAE com um peptídeo sintético correspondente a uma parte de 9 aminoácidos da MBP (100). Recentemente muitas outras proteínas da mielina ou peptídeos baseados em proteínas da mielina já foram mostradas como encefalitogênicos. Outra proteína da mielina encefalitogênica muito usada atualmente é a glicoproteína da mielina de oligodendrócitos (MOG) (101-104). O MOG é um antígeno interessante pois é capaz de induzir uma EAE remitente com extensiva desmielinização. Proteínas que não fazem parte da mielina também são capazes de induzir EAE porém a distribuição das lesões é diferente $(105,106)$ e nem todas proteínas do CNS são capazes de induzir EAE $(107,108)$. O modelo animal de EAE auxiliou na demonstração de que tanto elementos do sistema imune inato quanto adquirido estão envolvidos na patogênese da doença. Embora, por muitas décadas grande parte dos estudos tenha investigado o papel de linfócitos T e B (50, 86-93), hoje se sabe que as células apresentadoras de antígeno, tanto da periferia (como os macrófagos e as células dendríticas), quanto as do SNC (células microgliais), estão associadas ao processo de indução da doença (117), uma vez que apresentam antígenos aos linfócitos T, geram coestimulação e produzem citocinas requeridas para ativação e diferenciação dos linfócitos $\mathrm{T}$ em células efetoras.

Até poucos anos, acreditava-se que a polarização da resposta imune para o perfil Th1 fosse o principal fator responsável pela destruição neuronal, sendo os linfócitos $\mathrm{T} \mathrm{CD}^{+}$e as citocinas TNF- $\alpha$, IFN- $\gamma$ e IL-12 os principais componentes envolvidos na patogenia da doença (118). De fato, o tratamento de macacos com anticorpos anti-CD4 prolongou a sobrevida destes animais, após indução da EAE (119) e o tratamento profilático em ratos impediu completamente o desenvolvimento da doença, ao passo que o tratamento terapêutico, após o aparecimento dos sintomas, conseguiu reduzir os sinais da doença para uma forma mais branda (120). Também foi visto que a neutralização de TNF- $\alpha$ reduziu a severidade da EAE (121), enquanto o tratamento de ratos Lewis com TNF- $\alpha$ prolongou seus sinais clínicos e intensificou as áreas de infiltrado inflamatório (122). Porém, de forma surpreendente, a administração endovenosa de IFN- $\gamma$ induziu proteção contra a doença (123-125), enquanto a administração de anticorpos anti-IFN- $\gamma$ exacerbou seus sintomas (124,126,127). Susceptibilidade semelhante foi observada em animais nocautes para o gene do IFN- $\gamma$ ou de seu receptor $(128,129)$. Paradoxalmente, a administração de anticorpos monoclonais contra IL-12, citocina capaz de induzir a diferenciação de células Th1, preveniu a indução da EAE $(118,130)$, assim como camundongos nocautes para o gene da IL-12 foram menos suscetíveis à doença (131). Essa contradição só foi solucionada pela descoberta de que a IL-12 
biologicamente ativa (p70) é formada por uma subunidade maior (p40) e uma menor (p35), mas que a subunidade maior também pode se associar com a p19, formando a citocina IL-23 (132). Assim, foi demonstrado que camundongos nocautes para IL-12p35 são susceptíveis enquanto os camundongos nocautes para IL-12p40 são completamente resistentes à EAE (133). Somente alguns anos depois foi evidenciado o papel regulador do IFN- $\gamma$ na produção da citocina IL-17, produzida pela subpopulação Th17 $(66,134)$ e cujo potencial próencefalopatogênico foi considerado superior à linhagem Th1 (135). Esse achado foi comprovado em estudos de EAE em animais deficientes em IL-23, que apresentaram menor potencial de desenvolver a doença $(136,137)$. Hoje se sabe que esta citocina é crucial para o desenvolvimento de células Th17 patogênicas, as quais são capazes de aumentar o processo inflamatório através da produção de GM-CSF, IL-6 e algumas quimiocinas, que, em conjunto, contribuem na inflamação severa do SNC (138).

Por outro lado, a polarização da resposta imune para os perfis Th2 e regulador (Treg) leva a uma inibição da EAE e melhora clínica da doença, pois interferem na proliferação e diferenciação de células pertencentes às populações Th1 e Th17, e inibem uma série de funções efetoras causadas pela resposta inflamatória excessiva (139). Além disso, foi demonstrado que a transferência passiva de clones linfocitários produtores de IL-4, IL-10 e TGF- $\beta$, específicos ao antígeno MOG, protegeram animais saudáveis da EAE (140-142). Em humanos também têm sido demonstrado o potencial protetor de populações produtoras de IL4 , IL-10 e TGF- $\beta$ durante a doença ativa $(143,144)$. Por esta razão, alternativas terapêuticas que possam aumentar tais respostas representariam medidas extremamente interessantes para amenizar ou suprimir os efeitos patogênicos ocasionados pelas populações Th1 e Th17 na EAE. 
2 JUSTIFICATIVAS E OBJETIVOS 
O repertório salivar de artrópodes hematófagos representa valiosa fonte para descoberta de novas moléculas farmacologicamente ativas. Evidências recentes sugerem que componentes salivares de artrópodes hematófagos apresentam grande potencialidade de prevenir e/ou tratar uma série de doenças associadas à resposta imune. Em especial, a modulação exercida sobre o sistema imune evidencia o grande potencial de moléculas salivares que possam ser empregadas no tratamento de doenças em que o sistema imunológico do indivíduo é o causador do quadro patológico, como no caso das hipersensibilidades e das doenças autoimunes. Nesse contexto, escolhemos a EAE, um modelo animal da esclerose múltipla, para investigar o potencial preventivo/terapêutico dos componentes presentes na saliva de A. aegypti.

Baseado no fato de que a grande parte dos tratamentos usados atualmente para a EM são calcados na diminuição da resposta de linfócitos e no desvio da resposta para um padrão regulador e/ou Th2, e que na saliva de $A$. aegypti existe uma série de moléculas bioativas e que tais moléculas isoladas ou em conjunto são capazes de alterar a resposta imunológica de hospedeiros vertebrados, nossa hipótese é a de que os componentes salivares desse mosquito sejam capazes de inibir o processo inflamatório na EM. Assim, o objetivo central deste trabalho foi o de avaliar o potencial imunomodulador da saliva de A. aegypti na patologia da EAE e seus mecanismos de ação. Para isso, tivemos como objetivos específicos:

1. Determinar um protocolo de administração do EGS capaz de alterar o curso clínico da doença;

2. Analisar a frequência de monócitos e linfócitos $\mathrm{T} \mathrm{CD} 4^{+}, \mathrm{CD}^{+}$, de células Th1, Th17 e T reguladoras em gânglios linfáticos e no SNC de camundongos durante o curso da EAE;

3. Avaliar os parâmetros associados à imunidade na EAE, como a produção de citocinas do tipo Th1, Th2 e Th17;

4. Analisar parâmetros histopatológicos do SNC de animais após indução da EAE e submetidos ou não a modulação com o EGS;

5. Avaliar o efeito do EGS na maturação, diferenciação e produção de citocinas pelas células dendríticas. 
3 MATERIAL E MÉTODOS 


\subsection{Extração da glândula salivar de A. aegypti e produção do EGS}

Fêmeas de A. aegypti com 5 a 7 dias após emergirem, tiveram seu metabolismo reduzido sob baixas temperaturas. Em seguida, estes insetos foram dissecados em salina tamponada com fosfato (PBS) e suas glândulas salivares foram transferidas para um tubo, contendo $50 \mu \mathrm{l}$ de PBS gelado. Posteriormente, este material foi sonicado e então centrifugado a $14.000 \mathrm{~g}$, para remoção do material insolúvel. O sobrenadante resultante, referido como EGS, foi esterilizado em membrana de nitrocelulose (poro 0,22 $\mu \mathrm{m}$ ) e a concentração proteica determinada em espectrofotômetro NanoDrop 2000 (Thermo Fisher Scientific, Estados Unidos). Alíquotas foram armazenadas a $-80{ }^{\circ} \mathrm{C}$, até o momento do uso.

\subsection{Animais experimentais}

Foram utilizados camundongos isogênicos BALB/c e C57BL/6 fêmeas com 8-10 semanas de idade, adquiridos do Biotério Central do Instituto de Ciências Biomédicas da USP e do Centro de Desenvolvimento de Modelos Experimentais para Medicina e Biologia da Universidade Federal de São Paulo (CEDEME - UNIFESP). O delineamento experimental deste projeto se pautou nas recomendações dos Princípios Éticos de Experimentação Animal, adotado pela Sociedade Brasileira de Ciência de Animais de Laboratório (SBCAL) e foi aprovado pela Comissão de Ética no Uso de Animais do Instituto de Ciências Biomédicas da Universidade de São Paulo (CEUA-ICB/USP), certificado 91/09 e pela Comissão de Ética em Pesquisa da Universidade Federal de São Paulo (CEP-UNIFESP), certificado 7623150114.

\subsection{Efeito do EGS de A. aegypti na proliferação de linfócitos}

Após eutanásia, camundongos BALB/c fêmeas tiveram o baço retirado em condições assépticas e colocado em $5 \mathrm{~mL}$ de RPMI 1640. O órgão foi macerado em peneiras com poros de $40 \mu \mathrm{m}$, com a ajuda de um êmbolo de seringa estéril. As células foram centrifugadas a $300 \mathrm{~g}\left(5 \mathrm{~min} / 4^{\circ} \mathrm{C}\right)$ e, após o descarte do meio, os eritrócitos foram lisados. As células foram lavadas novamente e ressuspendidas em meio completo para contagem em câmara de Neubauer. Suspensões celulares contendo $10^{6}$ células $/ \mathrm{mL}$ foram preparadas e distribuídas em alíquotas de $100 \mu \mathrm{L}$ por poço, e placas de 96 poços. A seguir, foram adicionadas nos poços da cultura diversas concentrações de EGS $(0,1 ; 1 ; 5 ; 10$ e $20 \mu \mathrm{g} / \mathrm{mL}$ - concentração final no poço). Após 30 minutos de pré-incubação, concanavalina A (Con A) diluída em meio completo foi adicionada em cada poço na concentração final de $0,5 \mu \mathrm{g} / \mathrm{mL}$, e as culturas 
foram incubadas a $37{ }^{\circ} \mathrm{C}$ e $5 \% \mathrm{CO}_{2}$. Após $48 \mathrm{~h}$ de incubação, $25 \mu \mathrm{L}$ de resazurina $0,01 \%$ (preparada em meio completo) foram adicionados em todos os poços. Após 24 horas após da adição de resazurina, a densidade óptica (D.O.) de cada poço foi medida a 570 e $600 \mathrm{~nm}$ e a proliferação avaliada pela subtração dos valores obtidos entre a D.O. das duas leituras.

\subsection{Fracionamento do EGS por cromatografia líquida de alta performance (HPLC)}

Para o fracionamento do EGS de A. aegypti, o extrato foi aplicado em um sistema de cromatografia líquida de alta pressão (GE Healthcare, Uppsala, Suécia) acoplado a uma coluna de gel filtração Biosep SEC S 4000 (Phenomenex, Torrance, CA, Estados Unidos). As frações foram eluídas a $0,5 \mathrm{~mL} / \mathrm{min}$ com PBS ( $\mathrm{pH} 7,4)$ monitorando-se a absorbância dos picos a $280 \mathrm{~nm}$. Após o fracionamento, $5 \mu \mathrm{L}$ de cada fração foram utilizados para testar sua atividade em um ensaio de triagem de larga escala, usando cultura de esplenócitos totais de camundongos $\mathrm{BALB} / \mathrm{c}$ estimulados com Con A. A proliferação das células dos poços contendo as frações e a Con A, e a avaliação dos resultados foi feita da mesma maneira descrita no item 3.3. Uma vez determinada as frações ativas nos ensaios funcionais, alíquotas das mesmas foram agrupadas, e o conteúdo protéico dosado para uso em posteriores atividades.

\subsection{Modulação da EAE pelo EGS de A. aegypti}

EAE foi induzida de acordo com o método descrito por Sá-Nunes et al.(2009) com pequenas alterações. Fêmeas de camundongos C57BL/6 foram imunizadas com $150 \mu \mathrm{g}$ do peptídeo imunogênico p35-55 (MEVGWYRSPFSRVVHLYRNGK) correspondente à glicoproteína mielina de oligodendrócitos $\left(\mathrm{MOG}_{\mathrm{p} 35-55}\right.$ - myelin oligodendrocyte glycoprotein $)$ (Proteimax - Cotia, São Paulo, SP, Brasil). Tal imunógeno foi emulsificado com adjuvante incompleto de Freund (Sigma-Aldrich, St. Louis, MO, Estados Unidos), com a adição de 4 $\mathrm{mg} / \mathrm{mL}$ de Mycobacterium tuberculosis cepa H37Ra, mortos por calor. Cerca de $100 \mu \mathrm{L}$ do imunógeno foram inoculados subcutaneamente em 2 pontos na região peritoneal, próximos às patas posteriores. Nos dias 0 e 2 estes animais receberam $200 \mathrm{ng}$ de toxina de Bordetella pertussis (Sigma-Aldrich). O curso clínico da doença foi acompanhado por 25 e 30 dias e avaliado diariamente, com base na seguinte escala:

0 - normal; 
1 - cauda flácida;

2 - cauda flácida e fraqueza dos membros posteriores;

3 - cauda flácida e paralisia dos membros posteriores;

4 - cauda flácida, paralisia dos membros posteriores e paralisia parcial dos membros anteriores;

5 - paralisia total (animais que porventura alcançaram esse valor na escala foram eutanasiados).

Para avaliar o efeito modulador do EGS e de suas frações no curso da EAE, os camundongos foram imunizados com peptídeo $\mathrm{MOG}_{\mathrm{p} 35-55}$ e receberam EGS ou suas frações junto com o antígeno, ou por via intravenosa ou por via intraperitoneal. Como o período de tratamento e a dose utilizada variaram em cada caso, apresentamos as seguir os protocolos empregados nesse trabalho, esquematizados na Figura 3:

Protocolo 1: efeitos da anestesia - Com o objetivo de verificar se a anestesia dos animais, necessária em alguns experimentos, poderia alterar os parâmetros de indução e desenvolvimento da doença, imunizamos os animais conforme descrito acima e realizamos anestesia diária com halotano durante 10 dias.

Protocolo 2: tratamento intravenoso - Para verificarmos o efeito do tratamento com EGS na EAE, realizamos um tratamento intravenoso (20 $\mu \mathrm{g}$ /animal), durante os 5 primeiros dias após a imunização.

Protocolo 3: presença do EGS na emulsão e tratamento intraperitoneal - Além disso, resolvemos testar outros protocolos de tratamento com EGS, onde o grupo experimental recebeu um tratamento intraperitoneal de EGS (10 $\mu \mathrm{g}$ /animal) e/ou fração ( $2 \mu \mathrm{g} / \mathrm{animal}), 10$ dias após a imunização e, além disso, $10 \mu \mathrm{g}$ EGS ou $2 \mu \mathrm{g}$ fração por animal foi adicionada à emulsão contendo o peptídeo $\mathrm{MOG}_{\mathrm{p} 35-55}$. Posteriormente, os animais foram tratados, recebendo EGS (10 $\mu \mathrm{g} /$ animal), intraperitonealmente, durante 10 dias após a imunização ou $10 \mu \mathrm{g}$ EGS, por animal, foi adicionado à emulsão contendo o peptídeo $\mathrm{MOG}_{\mathrm{p} 35-55}$.

Protocolo 4: adição de uma proteína a emulsão (OVA) - Para testar se a adição de uma outra proteína a emulsão interferiria na doença, fizemos um experimento onde o adicionamos $10 \mu \mathrm{g} / \mathrm{mL}$ de OVA a emulsão de $M_{\mathrm{p} 35-55}$. 


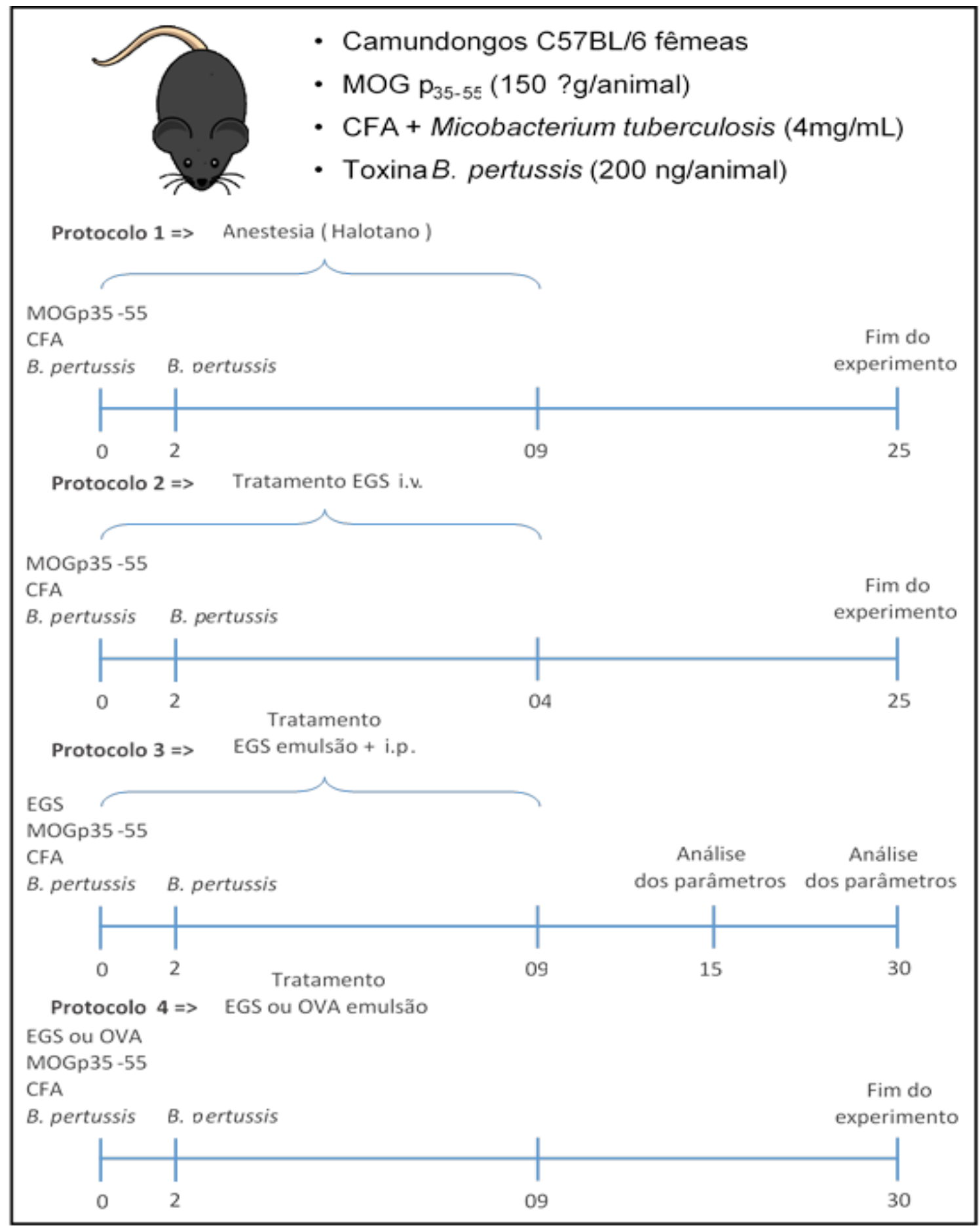

Figura 3 - Protocolos de imunização e tratamento da EAE utilizados nesse trabalho. Camundongos C57BL/6 fêmeas foram imunizados com $\mathrm{MOG}_{\mathrm{p} 35-55}$, e a escala clínica monitorada diariamente. Animais foram imunizados s.c. com $\mathrm{MOG}_{\mathrm{p} 35-55}$ $(150 \mu \mathrm{g})$ emulsificado em CFA (contendo $4 \mathrm{mg} / \mathrm{mL}$ de $M$. tuberculosis) em duas regiões do peritôneo. Toxina de $B$. pertussis (200 ng) foi administrada i.p. nos dias 0 e 2 após a imunização. Os tratamentos foram realizados conforme esquema acima e descritos em Material e Métodos. 


\subsection{Ensaios de proliferação}

Sete e/ou trinta dias após a indução da EAE, os animais tiveram o baço e/ou linfonodos drenantes retirados em condições assépticas e colocados em 5 mL de RPMI 1640. O órgão foi macerado em peneiras com poros de $40 \mu \mathrm{m}$ com a ajuda de um êmbolo de seringa estéril. As células foram centrifugadas a $300 \mathrm{~g}\left(5 \mathrm{~min} / 4{ }^{\circ} \mathrm{C}\right)$ e, após descarte do meio, os eritrócitos foram lisados. As células foram lavadas novamente e ressuspendidas em meio completo (RPMI-1640, suplementado com 10\% de soro bovino fetal, $2 \mathrm{mM}$ de L-glutamina, 100 unidade/mL penicilina, $100 \mu \mathrm{g} / \mathrm{mL}$ de estreptomicina, $25 \mathrm{mM}$ Hepes, $2,5 \times 10^{-5} \mathrm{M} 2$ mercaptoetanol) (Gibco Invitrogen, Carlsbad, CA, Estados Unidos) para contagem em câmara de Neubauer. Suspensões celulares contendo $10^{6}$ células $/ \mathrm{mL}$ foram preparadas e distribuídas em alíquotas de $100 \mu \mathrm{L}$ por poço, em placas de 96 poços. A seguir, as células foram incubadas com $100 \mu \mathrm{L}$ de meio (grupo controle) ou estimuladas com o mesmo volume de Con A $(0,5 \mu \mathrm{g} / \mathrm{mL}$ - concentração final $)$ ou $\mathrm{MOG}_{\mathrm{p} 35-55}(10$ e $50 \mu \mathrm{g} / \mathrm{mL}$ - concentração final $)$, diluídos em meio completo. Após $48 \mathrm{~h}$ de incubação a $37^{\circ} \mathrm{C}$ e $5 \% \mathrm{CO}_{2}, 25 \mu \mathrm{L}$ de resazurina $0,01 \%$ foram adicionadas em todos os poços. Vinte e quatro horas após a adição da resazurina, a D.O. de cada poço foi medida a 570 e $600 \mathrm{~nm}$, e a proliferação avaliada pela subtração dos valores obtidos entre a D.O. das duas leituras $(28,31)$. Após a leitura, as placas foram centrifugadas e o sobrenadante de cultura removido para a dosagem das citocinas IL17 , IFN- $\gamma$, IL-4, IL-5 e IL-10.

\subsection{Isolamento das células mononucleares do SNC}

Para a análise das células mononucleares presentes no SNC durante o curso da EAE, quinze dias após a imunização, três animais representativos de cada grupo foram submetidos à eutanásia por aprofundamento de plano anestésico com ketamina (250 mg/Kg) e xilazina (500 $\mathrm{mg} / \mathrm{Kg}$ ) e perfundidos com PBS gelado. Encéfalo e medula espinhal foram coletados, cortados e mantidos em HBSS suplementado com $2 \mathrm{mg} / \mathrm{mL}$ de colagenase D (Roche®, Basileia, Suiça) em estufa a $37^{\circ} \mathrm{C}$ com $5 \%$ de $\mathrm{CO}_{2}$. Após $45 \mathrm{~min}$, as suspensões foram dissociadas mecanicamente em peneiras com poros de70 $\mu \mathrm{m}$, lavadas com HBSS e centrifugadas a $300 \mathrm{~g}$, por 5 minutos. Em seguida, as células foram suspendidas em Percoll® (Sigma-Aldrich) a 37\% e gentilmente colocadas sobre Percoll ${ }^{\circledR}$ a $70 \%$, em tubos de $15 \mathrm{~mL}$. Os tubos foram centrifugados a $900 \mathrm{~g}$, por 20 minutos, a $4^{\circ} \mathrm{C}$, sem freio do rotor, e os anéis contendo as células mononucleares foram coletados, as células lavadas e submetidas à 
marcação de citometria de fluxo ou plaqueadas em cultura para ativação e marcação intracelular. Para a marcação das células infiltrantes do sistema nervoso central foi realizado o bloqueio do receptor Fc, utilizando o anticorpo anti-CD16/CD32 (eBioscience, San Diego, CA, Estados Unidos), por 20 minutos. Em seguida, as células foram lavadas e a superfície marcada com anti-mouse CD45 conjugado com PerCPCy5.5, anti-mouse CD11b conjugado com FITC, anti-mouse CD4 conjugado com PE e anti-mouse CD8 conjugado com APC, por 20 minutos. As células foram lavadas em PBS, centrifugadas e ressuspendidas em PBS para a análise em citometro de fluxo FACSCanto II (BD Biosciences, San Jose, CA, Estados Unidos). Os resultados da citometria foram analisados no software FlowJo (Tree Star Inc., Ashland, OR, Estados Unidos).

\subsection{Análise das células T efetoras no SNC}

As células mononucleares isoladas do SNC foram ressuspendidas em meio RPMI 1640, suplementado com $10 \%$ de soro bovino fetal, $2 \mathrm{mM}$ de GlutaMaxTM-I, $1 \mathrm{mM}$ de piruvato de sódio, $1 \mathrm{mM}$ de solução de aminoácidos não essenciais MEM, solução de vitaminas MEM, $100 \mathrm{U} / \mathrm{mL}$ de penicilina, $100 \mu \mathrm{g} / \mathrm{mL}$ de estreptomicina (Gibco, Life Technology) e 62,5 $\mu \mathrm{M}$ de $\beta$-mercaptoetanol (Sigma-Aldrich), contadas, plaqueadas ( $5 \times 10^{5}$ células/poço) e ativadas com PMA $(50 \mathrm{ng} / \mathrm{mL})$ e ionomicina $(1 \mu \mathrm{M})$ na presença de brefeldina A. Após 4 h, a superfície das células foi marcada com anti-mouse CD3 conjugado com PE-Cy7 e anti-mouse CD4 conjugado com PE, por 20 minutos. Após isso, as células foram fixadas e permeabilizadas para a marcação intracelular com anti-IL-17A e anti-IFN- $\gamma$ conjugados, respectivamente, com PercPCy5.5 e APC. A presença de células T reguladoras foi avaliada pela expressão de Foxp3 avaliada por anticorpos conjugados com PE. Em seguida, as células foram lavadas e ressuspendidas em PBS para análise em citometria de fluxo. As células foram lavadas com tampão de permeabilização e ressuspendidas em PBS para a análise em citometro de fluxo FACSCanto II (BD Biosciences). Os resultados da citometria foram analisados no software FlowJo (Tree Star Inc.).

\subsection{Diferenciação in vitro das subpopulações de células $T$}

Células $\mathrm{T} \mathrm{CD}^{+}$naïve $\left(\mathrm{CD} 4^{+} \mathrm{CD} 25^{-} \mathrm{CD} 62 \mathrm{~L}^{+}\right)$do baço foram isoladas por cell sorting em citometro de fluxo FACSAria II (BD Biosciences) e cultivadas em meio de cultura Dulbecco, modificado por Iscove (IMDM, Sigma-Aldrich), suplementado com soro bovino fetal a 10\%, $2 \mathrm{mM}$ de GlutaMaxTM, $100 \mathrm{U} / \mathrm{mL}$ de penicilina, $100 \mu \mathrm{g} / \mathrm{mL}$ de estreptomicina e 
$50 \mu \mathrm{M}$ de $\beta$-mercaptoetanol (Gibco, Life Technologies). As células Th1 foram diferenciadas com anti-CD3 $(1 \mu \mathrm{g} / \mathrm{mL})$, imobilizado em placas, na presença das citocinas IL-12 $(10 \mu \mathrm{g} / \mathrm{mL})$ e de $10 \mu \mathrm{g} / \mathrm{mL}$ do anticorpo neutralizante anti-IL-4 (eBioscience), por 5 dias. As células Th17 foram diferenciadas com anti-CD3 $(1 \mu \mathrm{g} / \mathrm{mL})$, imobilizado em placas, na presença das citocinas IL-6 (40 ng/mL), TGF- $\beta 1$ (1 ng/mL), IL-1 $\beta$ (10 ng/mL), TNF- $\alpha$ (10 ng/mL), IL-23 (10 ng/mL) (R\&D Systems, Minneapolis, MN, Estados Unidos) e de $2 \mu \mathrm{g} / \mathrm{mL}$ dos anticorpos neutralizantes anti-IFN- $\gamma$ e anti-IL-4 (eBioscience), por 5 dias. As células $\mathrm{T}$ reguladoras foram diferenciadas com anti-CD3 $(1 \mu \mathrm{g} / \mathrm{mL})$ imobilizado e anti-CD28 $(2 \mu \mathrm{g} / \mathrm{mL})$ solúvel em placas na presença de TGF- $\beta 1(2,5 \mathrm{ng} / \mathrm{mL})$ (R\&D Systems) por 5 dias. As células foram marcadas com anti-mouse CD4 conjugado com APC, por 20 minutos, e as células Th1, Th17 e T reguladoras foram avaliadas pela expressão de IFN- $\gamma$, IL-17A e Foxp3 no canal PE em citometro de fluxo FACScanto II (BD Biosciences). Para a quantificação da IL-17A, IFN- $\gamma$, Foxp3 intracelular, as células foram estimuladas com $50 \mathrm{ng} / \mathrm{mL}$ de PMA, $1 \mu \mathrm{M}$ de ionomicina na presença de brefeldina A, por 4 horas, no quinto dia após o início da cultura. As células foram marcadas com anti-mouse CD4 conjugado com APC, por 20 minutos. Após isso, as células foram fixadas e permeabilizadas (usando kit da eBioscience) para a marcação intracelular com anti-IFN- $\gamma$, anti-IL-17A e anti-Foxp3, conjugado com PE. Em seguida, as células foram lavadas e ressuspendidas em PBS para análise em citometro de fluxo FACSCanto II (BD Biosciences). Os resultados da citometria foram analisados no software FlowJo (Tree Star Inc.).

\subsection{Efeito do EGS na função de células dendríticas}

Células dendríticas derivadas da medula óssea ("Bone marrow derived dendritic cells" - BMDC) foram diferenciadas à partir de células totais da medula óssea de camundongos C57BL/6, em meio contendo $10 \%$ de soro bovino fetal, suplementado com $20 \mathrm{ng} / \mathrm{mL}$ de GMCSF. No $3^{\circ}$ dia de cultura, foi adicionado meio fresco contendo $20 \mathrm{ng} / \mathrm{mL}$ de GM-CSF. No sexto dia, novamente, foi adicionado meio fresco contendo $20 \mathrm{ng} / \mathrm{mL}$ de GM-CSF. No oitavo dia, as células não aderentes foram coletadas e recultivadas em meio suplementado com $10 \%$ de soro bovino fetal. No nono dia, as células foram pré-incubadas por 24 horas com EGS de A. aegypti $(1,5,10,20$ e $40 \mu \mathrm{g} / \mathrm{mL}$ - concentração final), seguidas por incubação com meio (controle) ou estimulação com LPS (200 ng/mL) por mais 24 horas. Os sobrenadantes de cultura livre de células foram coletados e as concentrações das citocinas IL-6, IL-10, IL12p40, IL-12p70e IL-23 foram determinadas por ELISA, conforme descrito no item 3.11. As 
células aderentes foram coletadas e marcadas com anti-CD11c conjugado com PE, anti-MHC de classe II conjugado com APC, anti-CD80 conjugado com FITC e anti-CD86 conjugado com FITC e analisadas por citometria de fluxo.

\subsection{Produção de citocinas}

Para a dosagem das citocinas IL-4, IL-5, IL-6, IL-10, IL-12p40, IL-12p70, IL-17A, IL-23 e IFN- $\gamma$, foram utilizados os kits segundo as recomendações dos fabricantes como descrito a seguir. Para a dosagem das citocinas IL-4e IL-17 foi utilizado o kit "Mouse ELISA Max”(BioLegend, Estados Unidos), seguindo as instruções do fabricante. Para isso, placas de 96 poços foram incubadas com anticorpos de captura de camundongo, diluídos em tampão próprio (100 $\mu \mathrm{L}$ poço). Após incubação overnight a $4{ }^{\circ} \mathrm{C}$, foram feitas 3 lavagens com PBS/Tween 0,05\%. (300 $\mu \mathrm{L} /$ poço) e, em seguida, os poços foram bloqueados com 200 $\mu \mathrm{L} /$ poço de PBS/SFB $10 \%$ por $1 \mathrm{~h}$ à temperatura ambiente, sob agitação. Após nova lavagem, as amostras previamente diluídas do sobrenadante, e a curva padrão foram adicionadas (100 $\mu \mathrm{L} /$ poço) e incubadas por 2 horas à temperatura ambiente, sob agitação. Após ciclo de 3 lavagens, foi adicionado $100 \mu \mathrm{L}$ /poço de solução de detecção (anticorpo secundário biotinilado) diluído em PBS/SFB $10 \%$ e incubado à temperatura ambiente por $1 \mathrm{~h}$, sob agitação. Após 3 lavagens, foram adicionados $100 \mu \mathrm{L} /$ poço de estreptoavidina, conjugada com peroxidase, e incubados por 30 minutos à temperatura ambiente, sob agitação. Após 5 lavagens, foram adicionados $100 \mu \mathrm{L}$ /poço da solução substrato 3,3', 5,5' tetramethylbenzidine (TMB) e incubado por no máximo 30 minutos, à temperatura ambiente, no escuro. Para parar a reação foram adicionados $100 \mu \mathrm{L}$ /poço de ácido fosfórico $\left(\mathrm{H}_{3} \mathrm{PO}_{4}\right) 1 \mathrm{M}$ e a leitura da placa foi feita em um espectrofotômetro a $450 \mathrm{~nm}$. A concentração das citocinas presente nas amostras foi calculada com base na curva padrão de cada citocina.

Para a dosagem das citocinas IL-5, IL-6, IL-12p40, IL-12p70, IL-10 e IFN- $\gamma$ foram utilizados kits BD OptEIA ELISA Sets (BD Biosciences), seguindo as instruções do fabricante. Resumidamente, placas de 96 poços foram incubadas com anticorpo de captura diluído em tampão carbonato de sódio $0,1 \mathrm{M}, \mathrm{pH}$ 9,5 (100 $\mu \mathrm{L} /$ poço). Após incubação overnight a $4{ }^{\circ} \mathrm{C}$, as placas foram lavadas 3 vezes com PBS/Tween $0,05 \%$ (300 $\mu \mathrm{L} /$ poço) e, em seguida, bloqueadas com $200 \mu \mathrm{L} /$ poço de PBS/SFB $10 \%$ por $1 \mathrm{~h}$ à temperatura ambiente. Após nova lavagem, as amostras do sobrenadante, devidamente diluídas, e a curva padrão de cada citocina foram adicionadas $(100 \mu \mathrm{L} /$ poço $)$ e incubadas por 2 horas à temperatura ambiente. Após ciclo de 5 lavagens, foi adicionado $100 \mu \mathrm{L} /$ poço de solução de detecção 
(anticorpo secundário biotinilado e estreptoavidina conjugada com peroxidase) diluída em PBS/SFB 10\%, e a placa foi incubada à temperatura ambiente, por $1 \mathrm{~h}$. Após 7 lavagens, foram adicionados $100 \mu \mathrm{L}$ /poço da solução substrato 3,3', 5,5' tetramethylbenzidine (TMB), seguida por incubação por, no máximo, 30 minutos à temperatura ambiente, no escuro. Para parar a reação foram adicionados $50 \mu \mathrm{L}$ /poço de ácido fosfórico $\left(\mathrm{H}_{3} \mathrm{PO}_{4}\right) 1 \mathrm{M}$, e a leitura da placa foi feita em um espectrofotômetro a $450 \mathrm{~nm}$. A concentração das citocinas presente nas amostras foi calculada com base na curva padrão de cada citocina.

Para a dosagem da citocina IL-23 foi utilizado o kit Mouse IL-23 Quantikine ELISA Kit (R\&D Systems), seguindo as instruções do fabricante. Para isso, Para isso, placas de 96 poços foram incubadas com anticorpos de captura de camundongo, diluídos em PBS (100 $\mu \mathrm{L}$ /poço). Após incubação overnight a temperatura ambiente, foram feitas 3 lavagens com PBS/Tween 0,05\%. (300 $\mu \mathrm{L} /$ poço) e, em seguida, os poços foram bloqueados com 200 $\mu \mathrm{L} /$ poço de PBS/SFB $10 \%$ por $1 \mathrm{~h}$ à temperatura ambiente, sob agitação. Após nova lavagem, as amostras previamente diluídas do sobrenadante, e a curva padrão foram adicionadas (100 $\mu \mathrm{L} /$ poço) e incubadas por 2 horas à temperatura ambiente, sob agitação. Após ciclo de 3 lavagens, foi adicionado $100 \mu \mathrm{L}$ /poço de solução de detecção (anticorpo secundário biotinilado) diluído em PBS/SFB $10 \%$ e incubado à temperatura ambiente por $1 \mathrm{~h}$, sob agitação. Após 3 lavagens, foram adicionados $100 \mu \mathrm{L} /$ poço de estreptoavidina, conjugada com peroxidase, e incubados por 30 minutos à temperatura ambiente, sob agitação. Após 5 lavagens, foram adicionados $100 \mu \mathrm{L}$ /poço da solução substrato 3,3', 5,5' tetramethylbenzidine (TMB) e incubado por no máximo 30 minutos, à temperatura ambiente, no escuro. Para parar a reação foram adicionados $100 \mu \mathrm{L}$ /poço de ácido fosfórico $\left(\mathrm{H}_{3} \mathrm{PO}_{4}\right) 1 \mathrm{M}$ e a leitura da placa foi feita em um espectrofotômetro a $450 \mathrm{~nm}$. A concentração da citocina presente nas amostras foi calculada com base na curva padrão.

\subsection{Análise Histopatológica do SNC}

Quinze dias após a imunização, animais representativos de cada grupo (PBS e EGS) foram submetidos à eutanásia, por aprofundamento de plano anestésico com ketamina (250 $\mathrm{mg} / \mathrm{Kg}$ ) e xilazina $(500 \mathrm{mg} / \mathrm{Kg}$ ) e perfundidos com PBS gelado. Encéfalo e medula espinhal foram coletados e fixados em paraformaldeído 10\%, por 24 h. Após esse período, os órgãos foram mantidos em etanol $70 \%$ até serem incluídos em parafina. Cortes de $5 \mu \mathrm{m}$ foram produzidos e as lâminas foram coradas com: 1) Hematoxilina/Eosina (H\&E), para 
visualização do infiltrado celular; 2) Luxol Fast Blue (LFB), para evidenciar mielina. As imagens foram analisadas com aumento de $4 \times$ ou $20 \times$.

\subsection{Análise estatística}

Os dados foram apresentados como média \pm erro padrão da média (SEM). Para análise da escala clínica da EAE, as diferenças estatísticas foram avaliadas pelo teste não paramétrico de Mann-Whitney. As diferenças nos demais parâmetros que apresentaram mais de 2 grupos experimentais foram avaliadas por análise de variância (ANOVA), seguidas pelo pós-teste de Tukey. Os valores de $p$ menores que 0,05 foram considerados significativos. 
4 RESULTADOS 


\subsection{Determinação do protocolo de tratamento com EGS no modelo de EAE}

O primeiro protocolo de tratamento com as moléculas salivares de A. aegypti que decidimos avaliar nesse trabalho consistiu na administração intravenosa do EGS por 5 dias consecutivos. Pela dificuldade técnica de se fazer essa administração diária pelas veias da cauda, escolhemos o plexo retro-orbital como local de administração do EGS, o que requer sedação leve dos animais com halotano. Como algumas fontes afirmam que qualquer tipo de anestesia/sedação poderia afetar o curso clínico da EAE (145), decidimos primeiramente realizar um experimento piloto para avaliar se a anestesia diária por halotano, que necessitamos fazer para o tratamento com o EGS de fato afetaria o desenvolvimento da doença. Assim, imunizamos 2 grupos de animais conforme explicado na seção de "Material e Métodos", sendo que um grupo foi diariamente anestesiado com halotano por 2 minutos, seguido pela inoculação i.v. de PBS por 10 dias consecutivos, e o outro grupo não foi anestesiado nem inoculado. Pode-se perceber na Figura 4 que a anestesia usada para o tratamento dos animais não interfere no desenvolvimento dos sintomas da EAE e, com essa informação em mãos, nosso próximo passo foi realizar experimentos onde um dos grupos foi tratado com EGS de A. aegypti por via intravenosa.

Novamente, a EAE foi induzida em 2 grupos de animais, conforme descrito em "Material e Métodos". Um dos grupos recebeu EGS (20 $\mu \mathrm{g} / \mathrm{animal})$ enquanto outro grupo recebeu apenas o veículo usado na inoculação (PBS), ambos pela via intravenosa, nos primeiros 5 dias após a imunização com $\mathrm{MOG}_{\mathrm{p} 35-55}$. Para nossa surpresa, nessas condições experimentais, ambos os grupos desenvolveram os sintomas clínicos semelhantes, não sendo observadas diferenças significativas nas curvas indicativas da escala clínica ou no início dos primeiros sintomas. Também é importante ressaltar que a incidência da doença foi de $100 \%$, o pico da doença ocorreu aos 16 dias e a escala clínica máxima $(3,25 \pm 0,133$ para grupo EGS versus 3,11 \pm 0.200 para grupo PBS) foi semelhante em ambos os grupos (Figura 5).

Em vista desse resultado negativo, alteramos o protocolo experimental de maneira a realizar um tratamento mais agressivo com o EGS de A. aegypti. Como não conhecemos a farmacocinética, biodisponibilidade e degradação dos componentes salivares após inoculação in vivo, optamos por alterar a rota, assim como a frequência do tratamento. Além disso, como publicamos recentemente que o EGS é capaz de induzir a morte de linfócitos T (28), testamos também nesse ensaio se a fração responsável por essa atividade poderia modular os sinais 
clínicos da EAE. Utilizando uma coluna de gel filtração, fracionamos o extrato em 40 frações que foram testadas individualmente no ensaio de proliferação de linfócitos induzida por Con A. A Figura 6 apresenta o cromatograma desse fracionamento (linha azul) e mostra que algumas frações do EGS são capazes de inibir a proliferação de linfócitos derivados do baço em cultura (linha preta).

Assim, induzimos a EAE em 3 grupos de animais. Um dos grupos recebeu EGS (10 $\mu \mathrm{g} /$ animal) emulsificado na preparação de $\mathrm{CFA}$ e $\mathrm{MOG}_{\mathrm{p} 35-55}$, seguido por um tratamento peritoneal diário também com EGS $(10 \mu \mathrm{g} / \mathrm{animal})$ por 10 dias. Um segundo grupo recebeu a fração ativa ( $2 \mu \mathrm{g} / \mathrm{animal})$ na emulsão e um tratamento peritoneal diário com a mesma dose da fração por 10 dias. Um terceiro grupo recebeu PBS na imunização e como tratamento, nos mesmos volumes e vias durante o período (Controle). Com essas alterações no protocolo experimental, o tratamento com EGS de A. aegypti foi capaz de inibir consistentemente os sinais clínicos da EAE (Figura 7A). O tratamento com a fração ativa do EGS proveniente do ensaio de inibição da proliferação de linfócitos também foi capaz de modular os sinais clínicos, mas em menor intensidade do que o extrato bruto (Figura 7B). Os dados mostrados nessa figura referem-se ao mesmo experimento, mas foram apresentados separadamente para facilitar a visualização. A Tabela 2 apresenta um resumo dos parâmetros clínicos avaliados nesses animais. Enquanto no grupo controle todos os animais desenvolveram a doença (100\% de incidência), a incidência no grupo tratado com EGS foi de $60 \%$ e no grupo tratado com a fração do EGS selecionada, a incidência foi de $90 \%$. O pico da doença também foi alterado pelos tratamentos, tendo ocorrido aos 15 dias no grupo controle e somente aos 21 dias nos grupos tratados com EGS ou com a fração. Além disso, enquanto o pico da escala clínica máxima foi de 3,5 \pm 0,22 no grupo controle, no grupo tratado com EGS esse valor foi de 1,5 \pm 1,27 e no grupo tratado esse valor foi de $2,5 \pm 0,6$. Analisados em conjunto, concluímos que os componentes salivares de A. aegypti são capazes de alterar a incidência, o desenvolvimento e a gravidade da EAE (Tabela 2), porém os efeitos da fração ativa no ensaio de proliferação linfocitária foram menores que o EGS total. Isso sugere que o EGS possui outras frações potencialmente eficazes em modular o desenvolvimento da doença e por isso, todos os demais experimentos foram realizados utilizando o EGS total e não suas frações. 


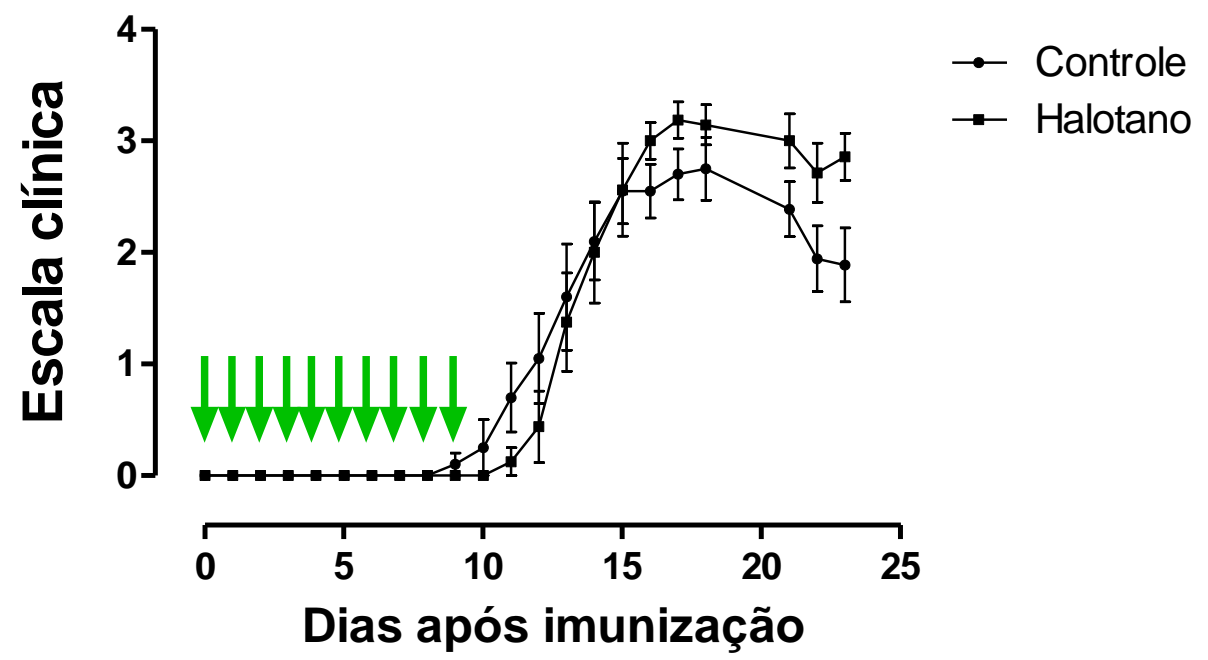

Figura 4 - Efeito da anestesia diária com halotano no desenvolvimento da EAE. Camundongos C57BL/6 foram imunizados s.c. com $\mathrm{MOG}_{\mathrm{p} 35-55}(150 \mu \mathrm{g})$ emulsificado em CFA (contendo $4 \mathrm{mg} / \mathrm{mL}$ de $M$. tuberculosis) em duas regiões do peritôneo. Toxina pertussis (200 ng) foi administrada i.p. nos dias 0 e 2 após a imunização. Em um dos grupos, os animais foram anestesiados com halotano durante 10 dias após a imunização. As setas em verde representam os dias anestesia com halotano. Os animais foram monitorados por 25 dias e os resultados estão apresentados como média \pm SEM da escala clínica da doença, conforme descrito em Material e Métodos. $n=10$ por grupo. 


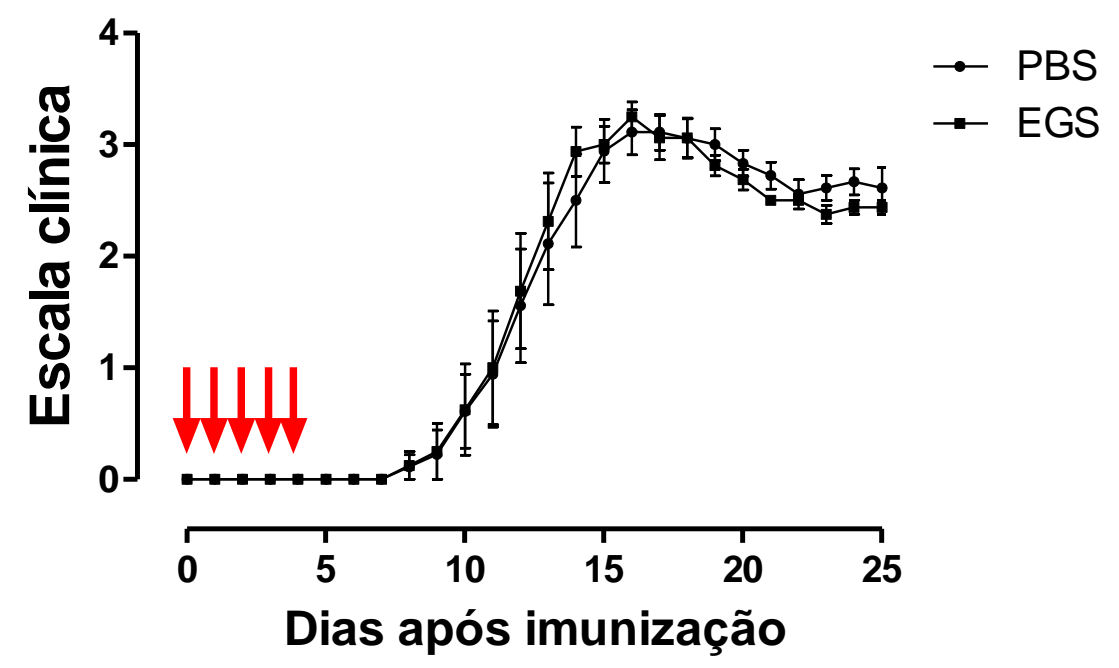

Figura 5 - Efeito do tratamento intravenoso com EGS de $A$. aegypti no desenvolvimento da EAE. Camundongos C57BL/6 foram imunizados s.c. com $\mathrm{MOG}_{\mathrm{p} 35-55}(150 \mu \mathrm{g})$ emulsificado em CFA (contendo $4 \mathrm{mg} / \mathrm{mL}$ de $M$. tuberculosis) em duas regiões do peritôneo. Toxina pertussis ( $200 \mathrm{ng}$ ) foi administrada i.p. nos dias 0 e 2 após a imunização. Os animais foram tratados nos 5 primeiros dias após a inoculação de $\mathrm{MOG}_{\mathrm{p} 35-55}$ com EGS $(20 \mu \mathrm{g} / \mathrm{animal})$ ou receberam apenas PBS (veículo) nesses dias, por via intravenosa. As setas em vermelho representam os dias de tratamento i.v. Os animais foram monitorados por 25 dias e os resultados estão apresentados como média \pm SEM da escala clínica da doença, conforme descrito em Material e Métodos.

$n=$ 10 por grupo. 


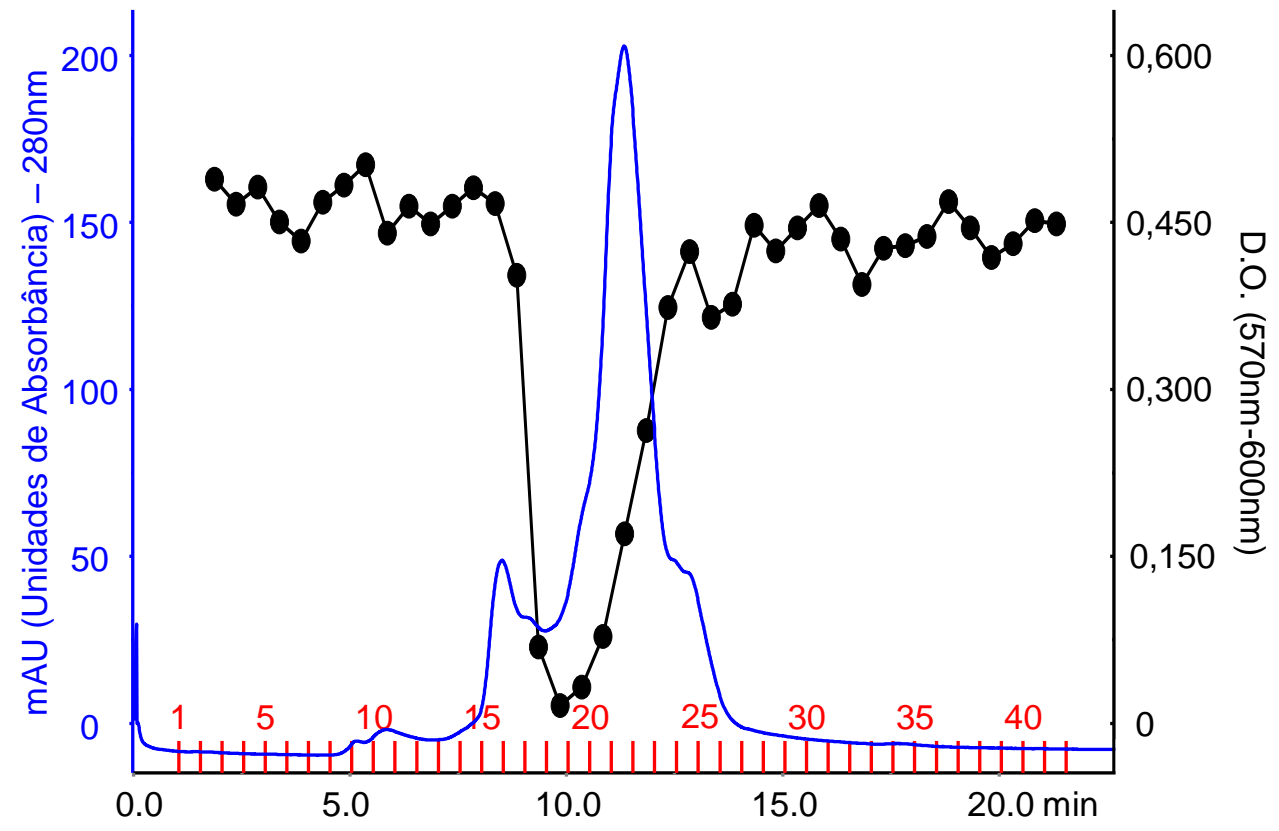

Figura 6 - Fracionamento do EGS de $A$. aegypti por HPLC e avaliação da atividade antiproliferativa de suas frações. A linha azul representa o perfil cromatográfico do EGS fracionado em coluna de gel filtração. A linha preta apresenta a proliferação de células totais de baço induzida por Con A na presença de cada fração. A numeração em vermelho no eixo $X$ representa o número da fração testada. A numeração em preto no eixo X representa o tempo de eluição de cada fração. 

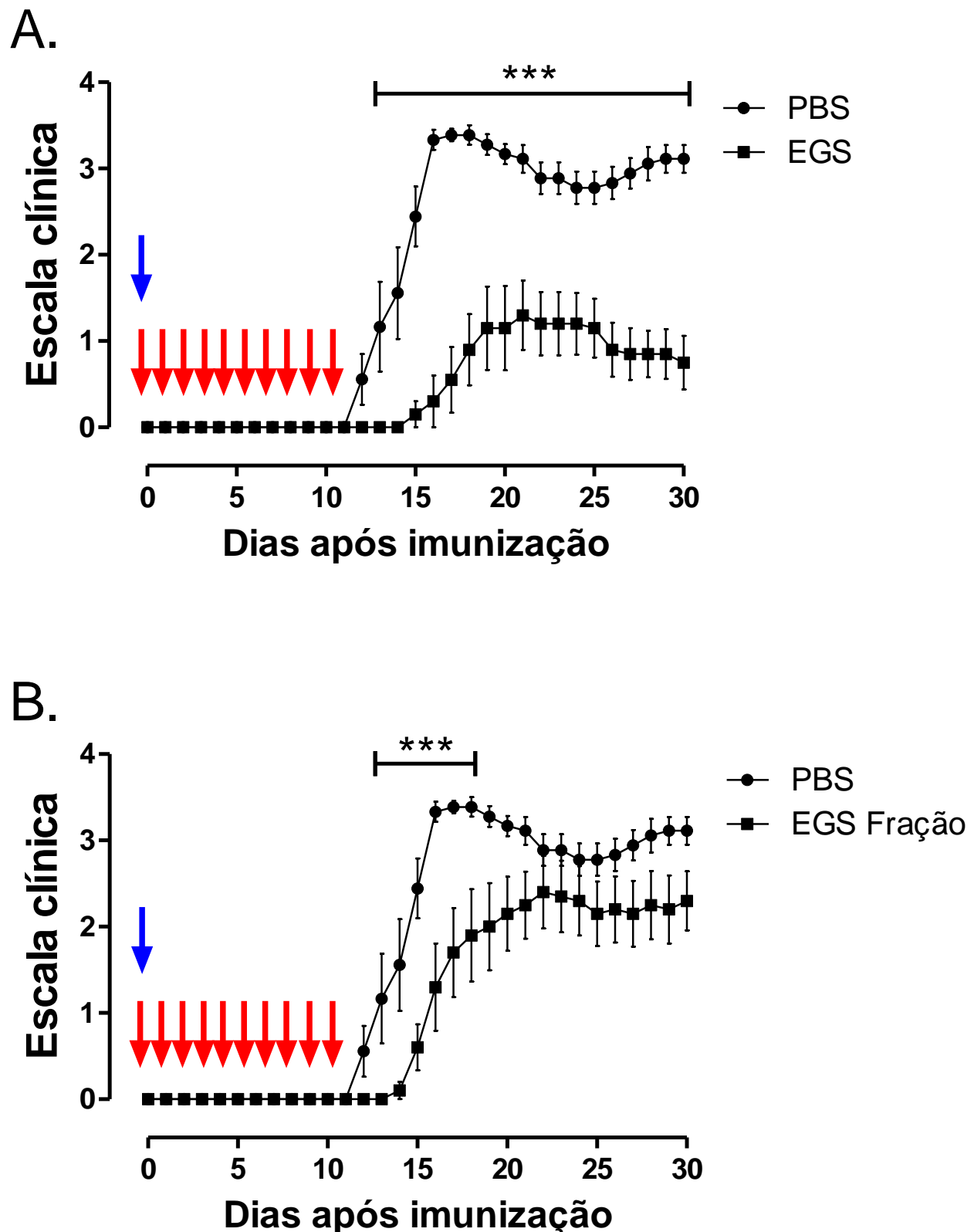

Figura 7 - Efeito do tratamento com EGS de A. aegypti e com sua fração ativa do ensaio de proliferação de linfócitos, na emulsão e administrados intraperitonealmente, no desenvolvimento da EAE. Camundongos C57BL/6 foram imunizados s.c. com MOG $_{\mathrm{p} 35-55}(150 \mu \mathrm{g}$ ) emulsificado em CFA (contendo $4 \mathrm{mg} / \mathrm{mL}$ de M. tuberculosis) em duas regiões do peritôneo. Em um dos grupos, o EGS foi adicionado à emulsão (equivalente a $10 \mu \mathrm{g} /$ animal) e em outro grupo uma fração purificada ( $2 \mu \mathrm{g} /$ animal). Toxina pertussis (200 ng) foi administrada i.p. nos dias 0 e 2 após a imunização. Os animais foram tratados nos 10 primeiros dias após a inoculação de MOG $_{\mathrm{p} 35-55}$ com PBS (veículo), EGS (10 $\mu \mathrm{g} /$ animal) e Fração EGS $(2 \mu \mathrm{g} / \mathrm{animal})$. (A) PBS versus EGS. (B) PBS versus Fração. As setas em vermelho representam os dias de tratamento intraperitoneal e a seta em azul o tratamento na emulsão. Os animais foram monitorados por 30 dias e os resultados estão apresentados como média \pm SEM da escala clínica da doença, conforme descrito em Material e Métodos. $* p<0,05$ versus grupo PBS. $n=10$ por grupo. 
Tabela 2 - Parâmetros clínicos da EAE nos animais controle (PBS) e tratados com EGS e com sua fração ativa proveniente do ensaio de proliferação de linfócitos.

\section{Tratamentos}

\begin{tabular}{cccc}
\hline & PBS & EGS & Fração \\
\hline Incidência* $^{*}$ & $100 \%$ & $60 \%$ & $90 \%$ \\
Início dos sinais clínicos $^{\#}$ & $12^{\circ}$ dia & $15^{\circ}$ dia & $14^{\circ}$ dia \\
Escala máxima alcançada $^{\$}$ & $3,5 \pm 0,22$ & $1,5 \pm 1,27$ & $2,5 \pm 0,60$ \\
Pico da doença & $15^{\circ}$ dia & $21^{\circ}$ dia & $21^{\circ}$ dia \\
\hline
\end{tabular}

* Número de animais que apresentaram sinais clínicos da doença.

\# Dia em que o primeiro animal do grupo apresentou sinais clínicos.

\$Escala máxima obtida pelos animais do grupo, segundo painel de sintomas apresentado em material e métodos.

${ }^{\&}$ Dia em que a maioria dos animais do grupo apresentou os piores sintomas da doença. 


\subsection{Refinamento do protocolo de tratamento com EGS na EAE}

Como o tratamento com o EGS foi eficiente quando este esteve presente tanto na emulsão de CFA com $\mathrm{MOG}_{\mathrm{p} 35-55}$ quanto inoculado intraperitonealmente, decidimos avaliar se uma dessas duas vias isoladamente teria melhor eficácia na modulação da EAE. No intuito de dissociar as atividades de cada via de tratamento, comparamos o desenvolvimento da EAE em animais que receberam o EGS por ambas as vias com aqueles que receberam EGS somente na emulsão de CFA e $M_{\mathrm{pOG}}$ es5 e com aqueles que receberam EGS somente intraperitonealmente. A presença de EGS tanto na emulsão quanto administrado intraperitonealmente é capaz de modular os sinais clínicos da EAE (Figura 8A), reproduzindo os dados apresentados na Figura 7. Quando esses tratamentos foram dissociados, somente a presença do EGS na emulsão já foi capaz de modular os sinais clínicos da doença (Figura 8B), enquanto o tratamento intraperitoneal não apresentou nenhum efeito nesses sinais clínicos (Figura 8C). A Tabela 3 apresenta um resumo dos parâmetros clínicos avaliados nesses animais. Tanto no grupo controle quanto no grupo tratado apenas intraperitonealmente, houve 90\% de incidência da doença, enquanto no grupo que recebeu EGS somente na emulsão, a incidência foi de 70\%. No grupo que recebeu os dois tratamentos (emulsão + i.p.) apenas houve apenas $20 \%$ de incidência, confirmando novamente a eficácia desse tratamento. O pico da doença também foi alterado, ocorrendo aos 18 dias no grupo controle, assim como no grupo que recebeu EGS apenas intraperitonealmente, e somente aos 21 dias nos demais grupos tratados com EGS, tanto o que recebeu apenas na emulsão quanto o que recebeu EGS na emulsão e via i.p.. Além disso, enquanto a média da escala clínica máxima desse pico foi de 3,5 no grupo controle, assim como no grupo tratado com EGS apenas intraperitonealmente, o grupo que recebeu EGS na emulsão apresentou escala clínica máxima foi de 1,5 no pico da doença, e o grupo tratado em ambas as vias apresentou escala de 0,5 no pico da doença (Tabela 3). Esses dados sugerem que a modulação da EAE pelo EGS de A. aegypti é decorrente da modulação na fase de indução da resposta autoimune e não na fase efetora dessa resposta, visto que os principais efeitos foram observados nos grupos que receberam o tratamento com EGS na emulsão, momento no qual a apresentação do antígeno está acontecendo. 

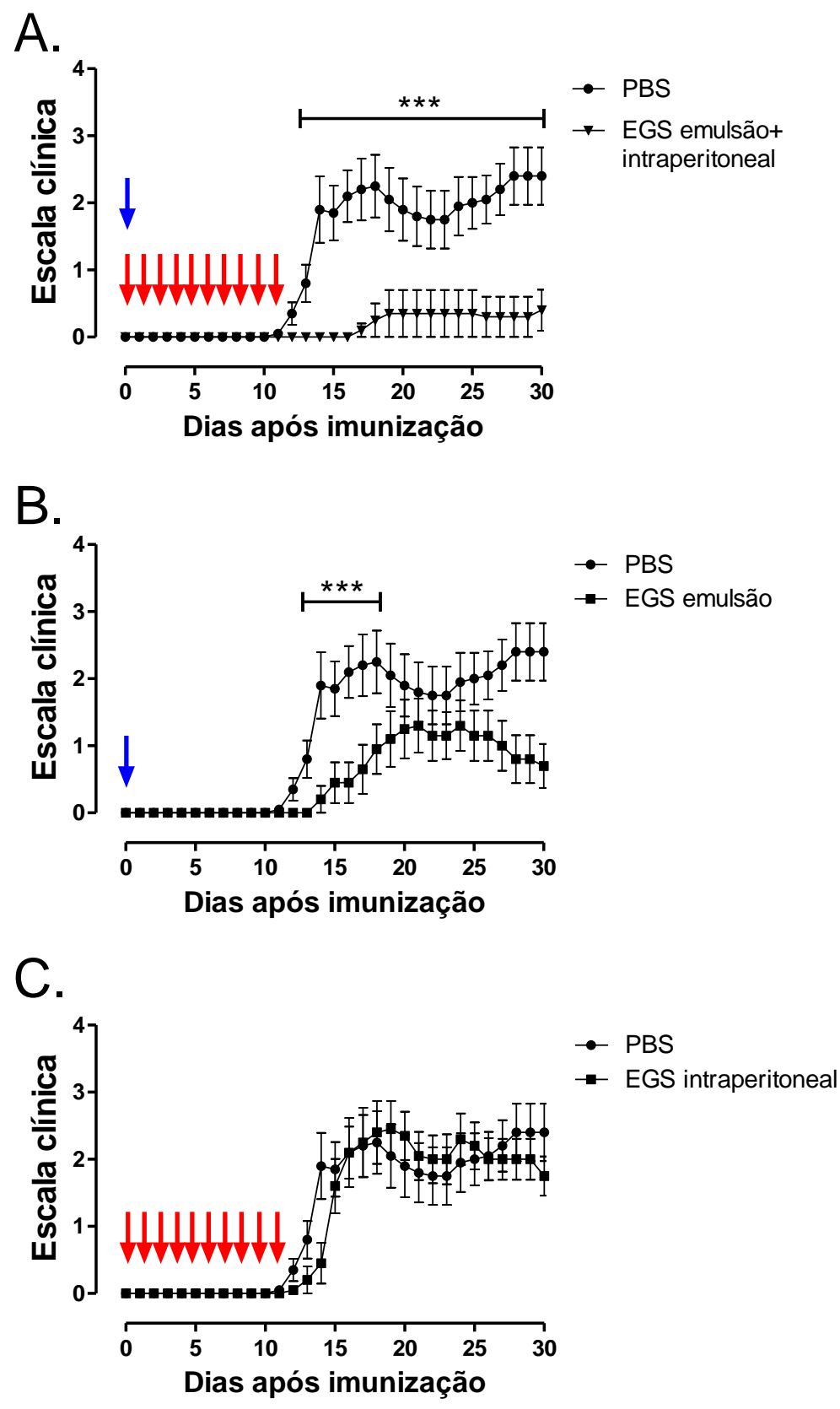

Figura 8 - Modulação da EAE pelo extrato da glândula salivar (EGS) de Aedes aegypti. Camundongos C57BL/6 foram imunizados s.c. com $\mathrm{MOG}_{\mathrm{p} 35-55}(150 \mu \mathrm{g})$ emulsificado em CFA (contendo $4 \mathrm{mg} / \mathrm{mL}$ de M. tuberculosis) em duas regiões do peritôneo. Em um dos grupos, o EGS foi adicionado à emulsão (equivalente a $10 \mu \mathrm{g} / \mathrm{animal})$, em outro, foi feito um tratamento intraperitoneal $(10 \mu \mathrm{g} / \mathrm{animal}$ de EGS), durante 10 dias após a imunização, e num terceiro, esses dois tratamentos foram feitos em conjunto. Toxina pertussis ( $200 \mathrm{ng}$ ) foi administrada i.p. nos dias 0 e 2 após a imunização. Os animais controle receberam PBS. (A) PBS versus EGS emulsão+i.p. (B) PBS versus EGS emulsão. (C) PBS versus EGS i.p. As setas em vermelho representam os dias de tratamento intraperitoneal e a seta em azul, o tratamento na emulsão. Os animais foram monitorados por 30 dias e os resultados estão apresentados como média \pm SEM da escala clínica da doença, conforme descrito em Material e Métodos. ${ }^{*} p<0,05$ versus grupo PBS. $n=10$ por grupo. 
Tabela 3 - Parâmetros clínicos da EAE nos animais tratados com PBS ou EGS.

\section{Tratamentos}

\begin{tabular}{ccccc}
\hline & PBS & EGS i.p. & EGS emulsão & EGS emulsão + \\
& & & & i.p. \\
\hline Incidência* $^{*}$ & $90 \%$ & $90 \%$ & $70 \%$ & $20 \%$ \\
Início dos sinais clínicos $^{\#}$ & $11^{\circ}$ dia & $13^{\circ}$ dia & $14^{\circ}$ dia & $17^{\circ}$ dia \\
Escala máxima alcançada & & & & \\
Pico da doença & $2,05 \pm 0,47$ & $2,40 \pm 0,47$ & $1,3 \pm 0,40$ & $0,35 \pm 0,35$ \\
\hline
\end{tabular}

* Número de animais que apresentaram sinais clínicos da doença.

\# Dia em que o primeiro animal do grupo apresentou sinais clínicos.

\$Escala máxima obtida pelos animais do grupo, segundo painel de sintomas apresentado em material e métodos.

${ }^{\&}$ Dia em que a maioria dos animais do grupo apresentou os piores sintomas da doença. 


\subsection{Efeito do EGS na proliferação de linfócitos}

Um trabalho anterior do nosso grupo demonstrou que o EGS de A. aegypti é capaz de inibir a proliferação de linfócitos T murinos in vitro (28). Para verificarmos se a inibição da proliferação das células $\mathrm{T}$ específicas para o $\mathrm{MOG}_{\mathrm{p} 35-55}$ seria um dos mecanismos da modulação da EAE pelo EGS, imunizamos animais C57BL/6 com $\mathrm{MOG}_{\mathrm{p} 35-55}$ nas mesmas condições usadas para a indução da doença e após sete dias os linfonodos drenantes foram retirados e uma cultura celular realizada. A Figura 9A mostra que a incubação de células dos linfonodos de animais naïve com EGS inibe a subsequente proliferação desses linfócitos induzidas por Con A, confirmando os resultados prévios do grupo (28). Por outro lado, quando as células de linfonodos dos animais imunizados com $\mathrm{MOG}_{\mathrm{p} 35-55}$ são incubadas com EGS, a proliferação induzida tanto por Con A quanto por $\mathrm{MOG}_{\mathrm{p} 35-55}$ ocorre normalmente. Com isso podemos concluir que o principal efeito observado na modulação da EAE pelo EGS não foi ocasionado pela inibição da proliferação de linfócitos, via morte celular, visto que a proliferação de células T antígeno-específicas não é afetada. 
Naive

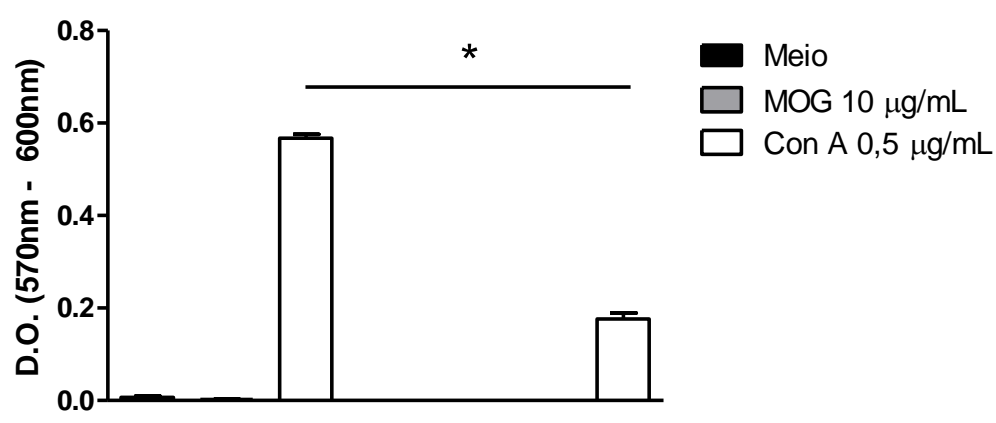

\section{Imunizado}

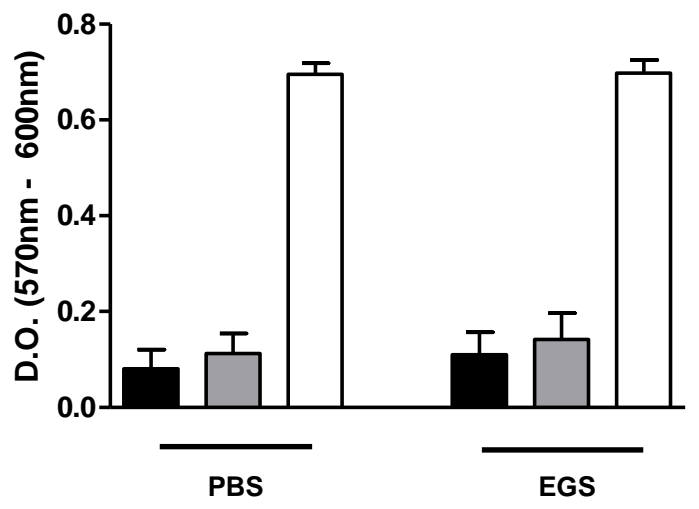

Figura 9 - EGS de A. aegypti afeta proliferação de linfócitos de camundongos naïve mas

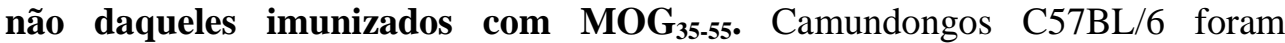
imunizados com $\mathrm{MOG}_{\mathrm{p} 35-55}(150 \mu \mathrm{g}$ ) emulsificado em CFA (contendo $4 \mathrm{mg} / \mathrm{mL}$ de M. tuberculosis) no coxim plantar. (A) Como controle foram utilizados animais que não foram imunizados. (B) Sete dias após a inoculação, os animais foram eutanasiados e os linfonodos drenantes retirados para a cultura celular. Células $\left(2 \times 10^{6}\right.$ células $\left./ \mathrm{mL}\right)$ foram pré incubadas por 30 minutos com PBS ou EGS $(5 \mu \mathrm{g} / \mathrm{mL})$ incubadas com meio, Con A $(0,5 \mu \mathrm{g} / \mathrm{mL})$ ou $\mathrm{MOG}_{\mathrm{p} 35-55}(10 \mathrm{ou}$ $50 \mu \mathrm{g} / \mathrm{mL}$ ) por $48 \mathrm{~h}$ e após esse período foi adicionado resazurina e feita uma nova incubação por mais $24 \mathrm{~h}$. A densidade óptica dos poços foi avaliada a 570 e 600 $\mathrm{nm}$ e o resultado expresso como a média \pm SEM da diferença entre as duas leituras. ${ }^{*} p<0,05$ versus respectivo grupo PBS. $n=3$ por grupo. 


\subsection{Efeito do EGS na proliferação de linfócitos e produção de citocinas na EAE: comparação das diferentes vias de tratamento}

Como observamos diferenças significativas no desenvolvimento da EAE entre os grupos tratados com EGS de A. aegypti nos diferentes protocolos, avaliamos nesses grupos alguns parâmetros imunológicos associados à doença. Para isso, 30 dias após a inoculação do $\mathrm{MOG}_{\mathrm{p} 35-55}$, o baço dos animais foi retirado e um teste de proliferação celular realizado, utilizando estímulo específico $\left(\mathrm{MOG}_{\mathrm{p} 35-55}\right)$ ou policlonal (Con A). Como mostra a Figura 10, os grupos que receberam EGS, não importando a via de administração (emulsão, intraperitoneal ou ambas), apresentaram redução na atividade proliferativa de suas células esplênicas, quando as mesmas foram estimuladas in vitro com $\mathrm{MOG}_{\mathrm{p} 35-55}$. O mesmo não ocorreu quando as células desses animais foram estimuladas com Con A.

A seguir, avaliamos a diferenciação dessas células, determinando a produção de citocinas representativas do padrão Th1 (IFN- $\gamma$ ), Th2 (IL-4 e IL-5) e Th17 (IL-17A) presentes nos sobrenadantes de cultura. Observamos que as células de ambos os grupos que receberam EGS na emulsão (apenas na emulsão ou seguido de tratamento intraperitoneal) apresentaram diminuição da produção de IL-17A e IFN- $\gamma$ MOG-específicos e não alteraram a produção de IL-4 e IL-5, quando comparadas com as células dos animais que receberam apenas PBS (Figura 11). Já as células dos animais que receberam EGS apenas intraperitonealmente, tiveram uma redução apenas de IFN- $\gamma$ e não alteraram a produção de IL-17A nessas mesmas condições. Outro dado interessante, foi que as células de baço de ambos os grupos que receberam EGS intraperitonealmente (precedido por EGS na emulsão ou não), tiveram um grande aumento dos níveis de IL-4 e IL-5 quando estimuladas com Con A somente e, portanto, não específicas para $\mathrm{MOG}_{\mathrm{p} 35-55}$. Esses dados sugerem que o tratamento com EGS durante a fase de indução da resposta imunológica inibe a produção de citocinas IFN- $\gamma$ e IL17A e que o tratamento com EGS sistêmico estimula a produção de citocinas IL-4 e IL-5 durante a EAE de forma MOG-independente. 


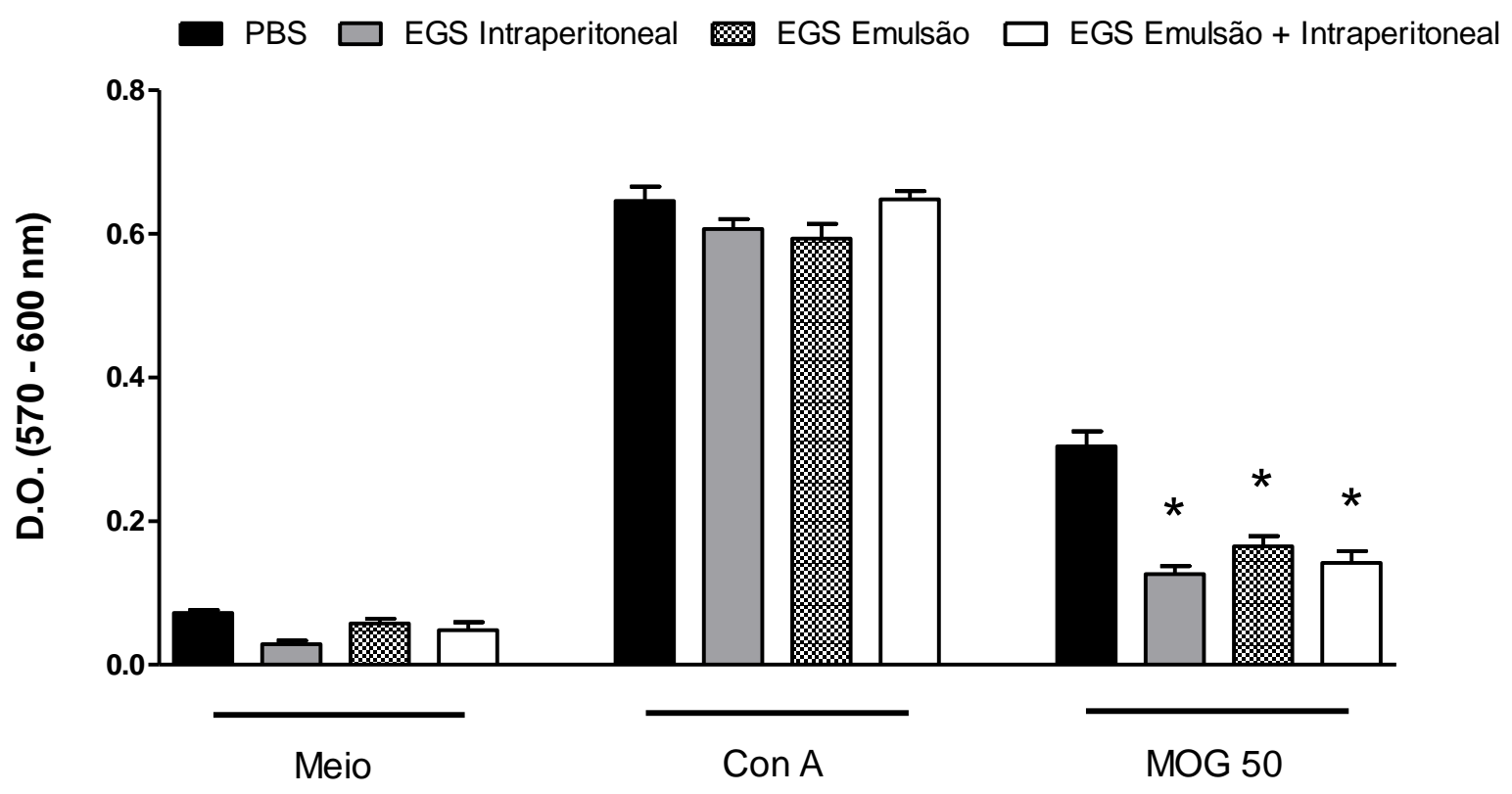

Figura 10 - Proliferação de linfócitos do baço dos animais imunizados com MOG p35-55. $_{\text {. }}$

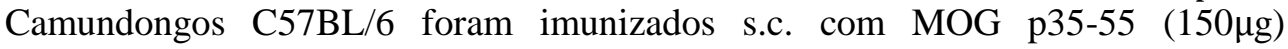
emulsificado em CFA (contendo $4 \mathrm{mg} / \mathrm{mL}$ de $M$. tuberculosis) em duas regiões do peritônio. Em um dos grupos, o EGS foi adicionado à emulsão (equivalente a $10 \mu \mathrm{g} / \mathrm{animal}$ ), em outro grupo foi feito um tratamento intraperitoneal (10 $\mu \mathrm{g} /$ animal de EGS) durante 10 dias após a imunização e num terceiro grupo, ambos tratamentos foram realizados. Toxina pertussis $(200 \mathrm{ng})$ foi administrada i.p. nos dias 0 e 2 após a imunização. Os animais controle foram tratados com PBS. Trinta dias após a inoculação, os animais foram eutanasiados e o baço retirado para a cultura celular. Células $\left(10^{6} / \mathrm{mL}\right)$ foram incubadas com meio, Con $\mathrm{A}(0,5 \mu \mathrm{g} / \mathrm{mL})$ ou $\mathrm{MOG}_{\mathrm{p} 35-55}(10$ ou $50 \mu \mathrm{g} / \mathrm{mL})$ e a proliferação foi avaliada como descrito em Material e Métodos. Os resultados estão expressos como a média \pm SEM. $* p<0,05$ versus respectivo grupo PBS. $n=10$ por grupo. 
A.

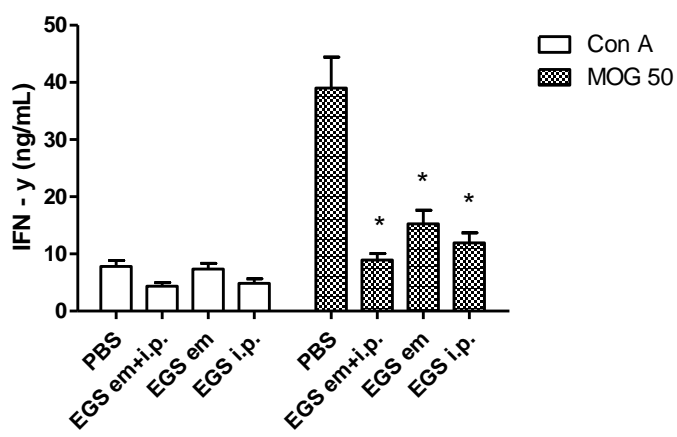

C.

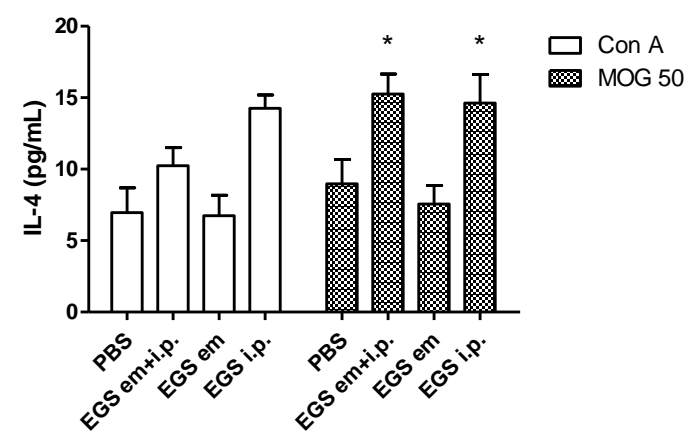

B.

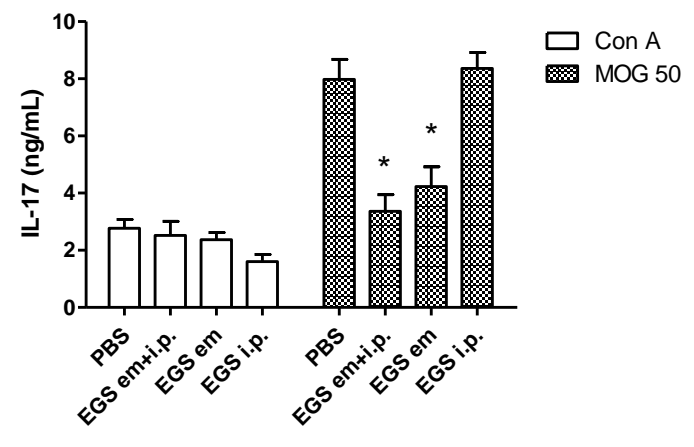

D.

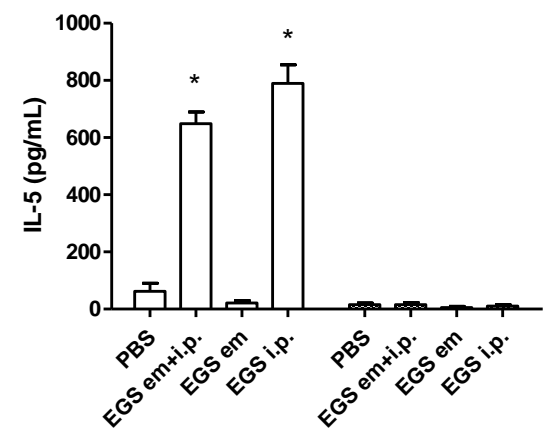

$\square \operatorname{Con} A$

MOG 50

Figura 11 - Perfil de citocinas no baço dos animais imunizados com MOG 35-55. Camundongos C57BL/6 foram imunizados s.c. com $\mathrm{MOG}_{\mathrm{p} 35-55}(150 \mu \mathrm{g})$ emulsificado em CFA (contendo $4 \mathrm{mg} / \mathrm{mL}$ de $M$. tuberculosis) em duas regiões do peritônio. Em um dos grupos, o EGS foi adicionado à emulsão (equivalente a $10 \mu \mathrm{g} / \mathrm{animal}$ ), em outro grupo foi feito um tratamento intraperitoneal (10 $\mu \mathrm{g} / \mathrm{animal}$ de EGS) durante 10 dias após a imunização e num terceiro grupo esses dois tratamentos foram feitos em conjunto. Toxina pertussis $(200 \mathrm{ng})$ foi administrada i.p. nos dias 0 e 2 após a imunização. Os animais controle foram tratados com PBS. Trinta dias após a inoculação, os animais foram sacrificados e o baço retirado para a cultura celular. Células $\left(10^{6}\right.$ células $\left./ \mathrm{mL}\right)$ foram incubadas com meio, Con A $(0,5 \mu \mathrm{g} / \mathrm{mL})$ ou $\mathrm{MOG}_{\mathrm{p} 35-55}(10 \mathrm{ou} 100 \mu \mathrm{g} / \mathrm{mL})$ por $72 \mathrm{~h}$ e as citocinas (A) IFN- $\gamma$, (B) IL-17, (C) IL-4 e (D) IL-5 foram determinadas no sobrenadante de cultura. Os resultados estão expressos como a média \pm SEM. ${ }^{*} p<0,05$ versus respectivo grupo PBS. $n=10$ por grupo. 


\subsection{Frequência de células mononucleares ativadas no SNC dos animais tratados com EGS durante o curso da EAE}

Como nossos resultados mostraram que o EGS está atuando na fase inicial da resposta e que a presença do EGS apenas na emulsão reproduz boa parte da inibição dos sinais da EAE, resolvemos estudar mecanismos adicionais dessa modulação tratando os animais com EGS apenas na emulsão. Nosso próximo passo foi avaliar, por citometria de fluxo, as frequências das populações de células mononucleares presentes no SNC de animais com EAE, tratados ou não com EGS de A. aegypti. Nesse experimento, realizado ao redor do pico dos sinais clínicos da doença (dia 15 - Figura 12A), coletamos o SNC e isolamos as células conforme explicado em Material e Métodos. Observamos uma diminuição do infiltrado inflamatório para o SNC no grupo tratado com EGS, quando comparado com o grupo que recebeu PBS (Figura 12B). A seguir, foram caracterizadas as populações de linfócitos $\left(\mathrm{CD} 11 \mathrm{~b}^{-} \mathrm{CD} 45^{+} \mathrm{CD} 4^{+}\right.$e $\left.\mathrm{CD} 11 \mathrm{~b}^{-} \mathrm{CD} 45^{+} \mathrm{CD} 8^{+}\right)$; micróglias $\left(\mathrm{CD} 11 \mathrm{~b}^{+} \mathrm{CD} 45^{\mathrm{lo}}\right)$; macrófagos infiltrantes e micróglias ativadas $\left(\mathrm{CD} 11 \mathrm{~b}^{+} \mathrm{CD} 45^{\mathrm{hi}}\right)$. Nessa análise, observamos que ocorreu uma diminuição significativa na frequência de macrófagos e microglias ativadas (células $\mathrm{CD} 11 \mathrm{~b}^{+} \mathrm{CD} 45^{\mathrm{hi}}$ ) nos animais tratados com EGS em relação aos animais controle (Figura 12C e 12D). Paralelamente, vimos que os animais tratados com EGS apresentaram uma frequência significativamente maior de micróglias não ativadas (células CD11b+CD45lo) comparada a porcentagem de células nos animais controle (Figura 12E). Além disso, vimos também que apesar da freqüência dos linfócitos $\mathrm{T} \mathrm{CD}^{+}$e $\mathrm{CD}^{+}$não terem sido alteradas nos grupos experimentais (Figura 13A e 13B), houve uma diminuição no número desses linfócitos no grupo tratado com EGS (Figura 13C). Esses dados coincidem com a nossa observação de que os animais tratados com EGS apresentam menor quantidade de macrófagos, micróglias ativadas e linfócitos efetores e isso provavelmente está associado à diminuição da gravidade da EAE quando comparado ao grupo que recebeu PBS. Assim, os nossos dados indicam que o tratamento com o EGS diminuiu a inflamação do sistema nervoso durante a EAE. 
A.

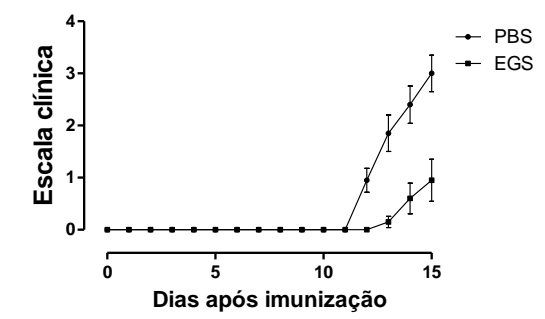

B.

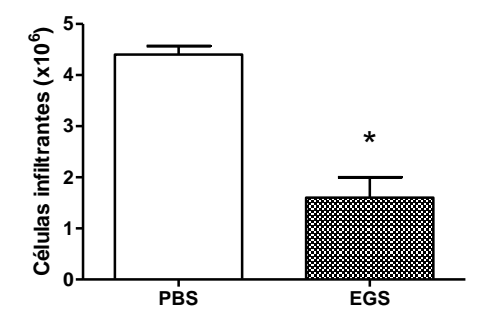

C.

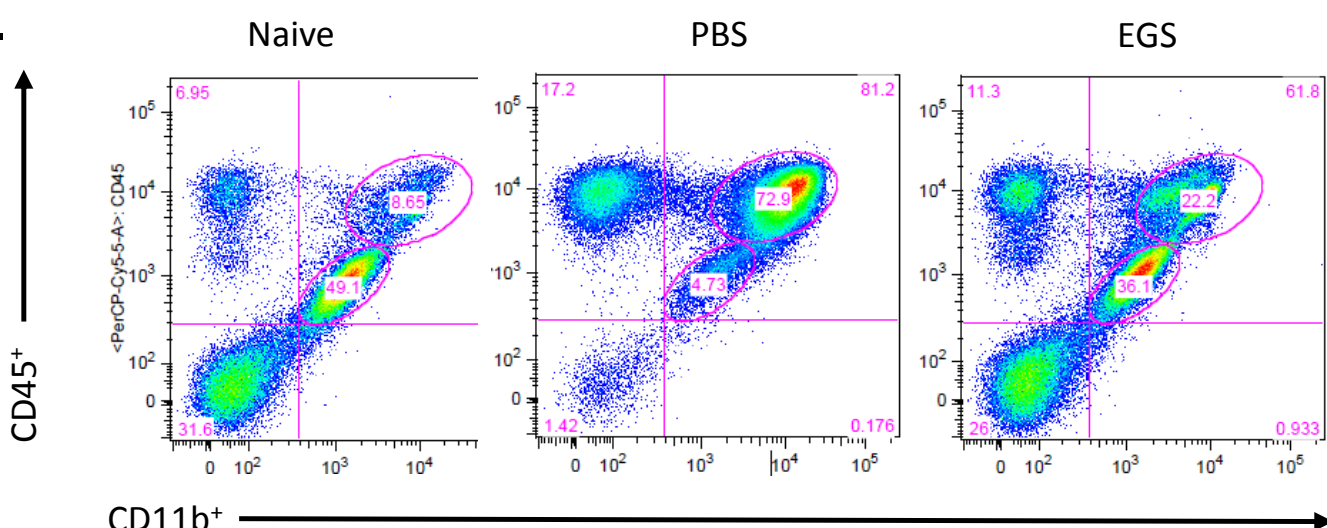

D.
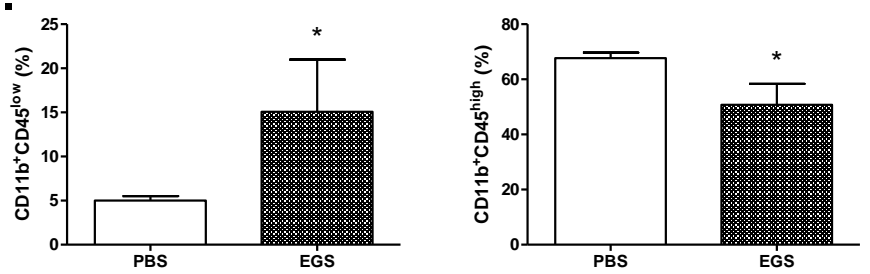

E.
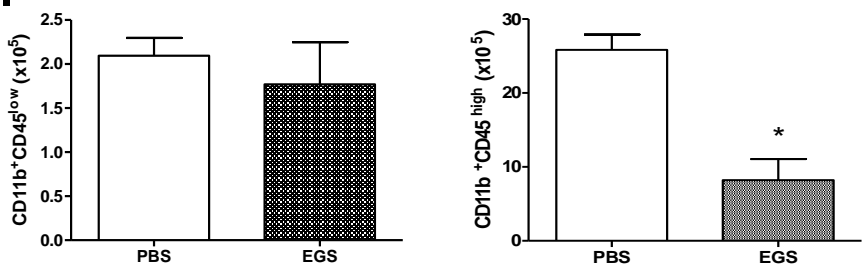

Figura 12 - Caracterização e frequência das populações de células mononucleares no SNC no pico da EAE. As células mononucleares do encéfalo e medula espinhal dos animais controle e tratados com EGS foram isoladas e marcadas com anti-CD45 e anti-CD11b e analisadas por citometria de fluxo. (A) Escala clínica da doença. (B) Número de celulares infiltrantes no SNC. (C) Dot plots representativos mostrando as frequências das populações de linfócitos $\left(\mathrm{CD}^{\left.-11 \mathrm{~b}^{-} \mathrm{CD} 45^{+}\right)}\right.$microglia $\left(\mathrm{CD} 11 \mathrm{~b}^{+} \mathrm{CD} 45^{\mathrm{lo}}\right)$ e macrófagos/microglia ativada $\left(\mathrm{CD} 11 \mathrm{~b}^{+} \mathrm{CD} 45^{\mathrm{hi}}\right)$ no pico da EAE. (D) Análise da frequência de macrófagos e microglia ativada na EAE dos animais controle e tratados com EGS. (E) Número absoluto de macrófagos e micróglia ativada na EAE dos animais controle e tratados com EGS. Os resultados estão expressos como a média \pm SEM. ${ }^{*} p<0,05$ versus grupo PBS. $n=5$ por grupo. 
A.

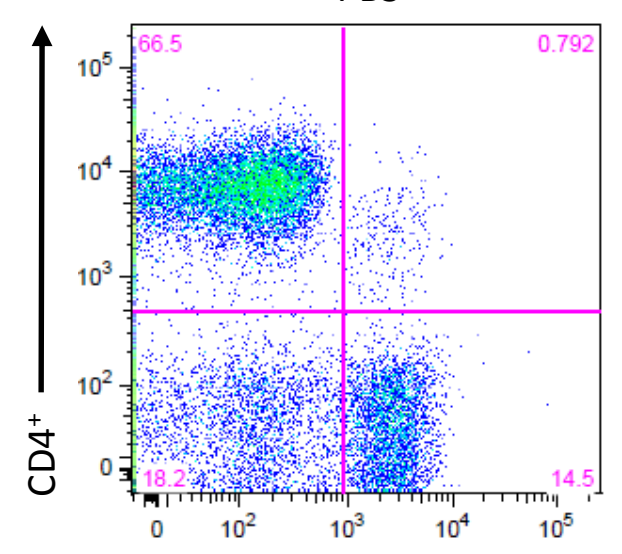

$\mathrm{CD}^{+}$

B.
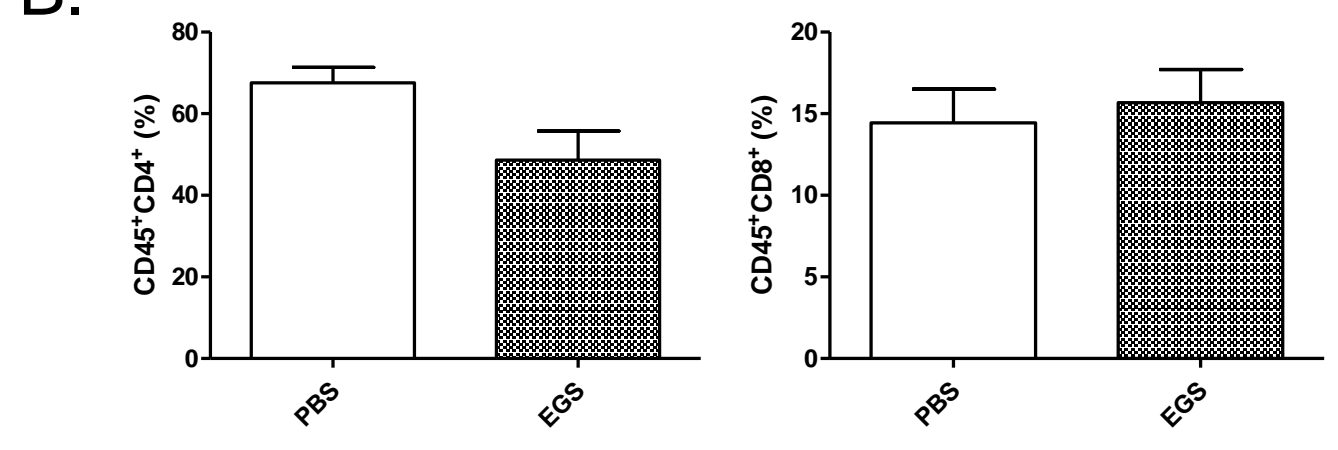

C.

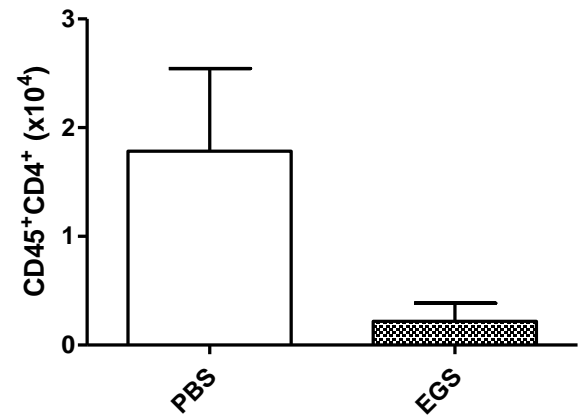

EGS

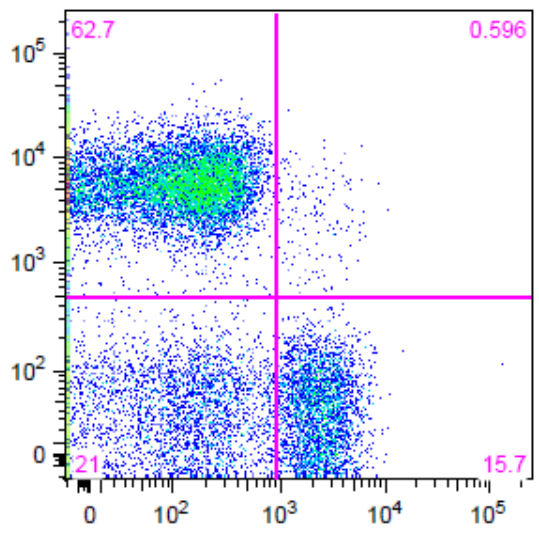

$10^{5}$

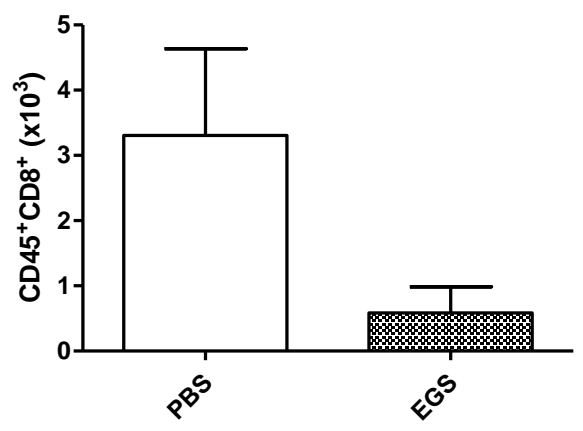

Figura 13 - Frequência das células T $\mathrm{CD4}^{+}$e $\mathrm{CD8}^{+}$no SNC no pico da EAE. Camundongos C57BL/6 foram imunizados com $150 \mu \mathrm{g}$ do peptídeo $\mathrm{MOG}_{35-55}$ em adjuvante completo de Freund (CFA) contendo $4 \mathrm{mg} / \mathrm{mL}$ de M. tuberculosis. Os animais foram tratados com EGS $(10 \mu \mathrm{g} / \mathrm{animal})$ junto na emulsão. Os animais foram sacrificados no pico da EAE e as células infiltrantes marcadas para identificação das células T CD4 ${ }^{+}$e $\mathrm{T} \mathrm{CD} 8^{+}$. (A) Dot plots representativos da análise no gate de células $\mathrm{CD} 45^{+} \mathrm{CD} 4{ }^{+}$e $\mathrm{CD} 45+\mathrm{CD} 8+$. (B) Frequência de células T $\mathrm{CD} 4^{+} \mathrm{CD} 8^{+}$no sistema nervoso central (SNC). (C) Número absoluto de células $\mathrm{T} \mathrm{CD}^{+} \mathrm{CD} 8^{+}$no sistema nervoso central (SNC). Os resultados estão expressos como a média \pm SEM.

$=$

5

por

grupo. 


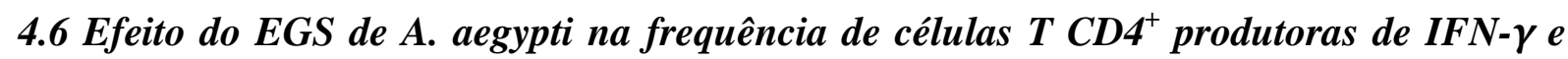
IL-17A no SNC durante a EAE

Também avaliamos a presença de células $\mathrm{T} \mathrm{CD}^{+}$produtoras de IFN- $\gamma$ e IL-17 no SNC utilizando a marcação intracelular para essas citocinas. As células isoladas do SNC no pico da EAE foram ativadas em cultura com PMA e ionomicina na presença de brefeldina A. Em seguida, as células foram marcadas na superfície com anti-CD3 e anti-CD4, fixadas e permeabilizadas para marcação intracelular de IFN- $\gamma$ e IL-17A. Na estratégia de análise da citometria foi feito um gate nas células consideradas vivas e em seguida um gate nas células $\mathrm{CD}^{+} \mathrm{CD}^{+}$expressando IFN- $\gamma$ e IL-17A nos animais controle e tratados (Figura 14A). A análise das células $\mathrm{T} \mathrm{CD}^{+}$produtoras de IFN- $\gamma$ e IL-17A mostrou que não houve diferenças na frequência dessas células nos animais tratados com EGS (Figura 14B). No entanto, o número absoluto de células $\mathrm{T} \mathrm{CD}^{+}$produtoras de IFN- $\gamma$ e IL-17A foi menor nos animais que receberam tratamento com EGS (Figura 14C). Dessa forma, o nosso resultado de mesma frequência de células $\mathrm{T} \mathrm{CD} 4^{+}$produzindo IFN- $\gamma$ e IL-17, porém um menor número absoluto de células nos animais tratados com EGS pode representar uma diminuição das células $\mathrm{T}$ efetoras patogênicas e consequentemente a redução dos sinais clínicos da EAE nos animais. 
A.

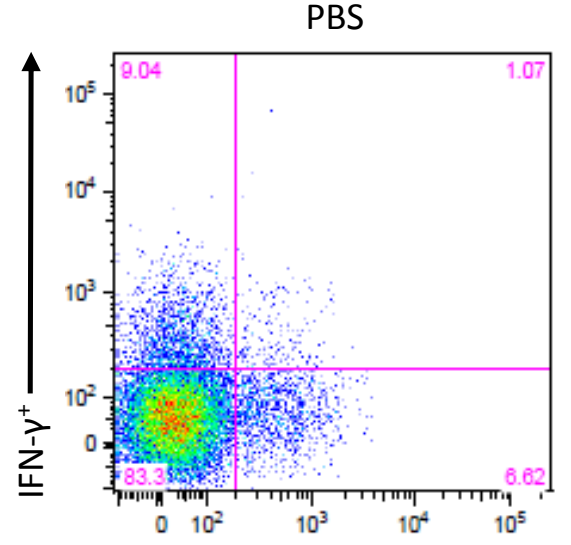

IL-17A

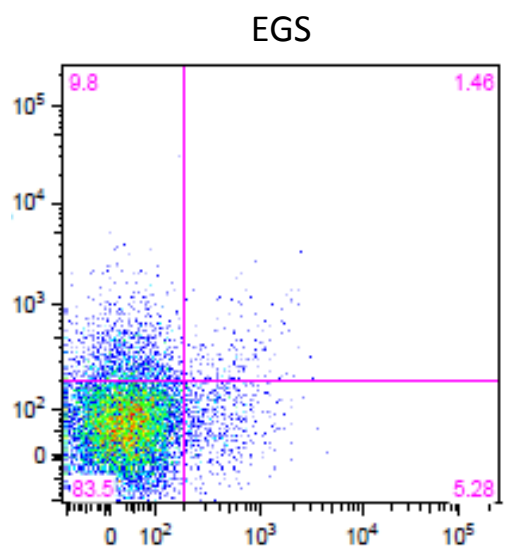

B.
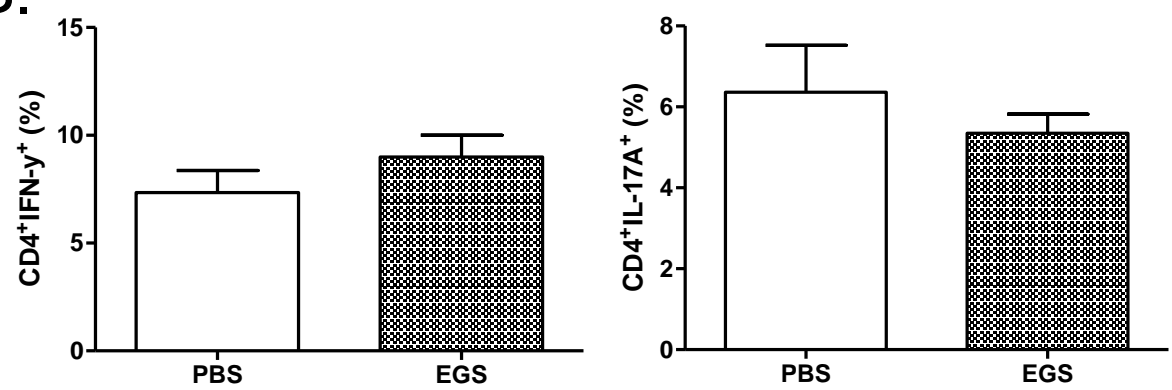

C.
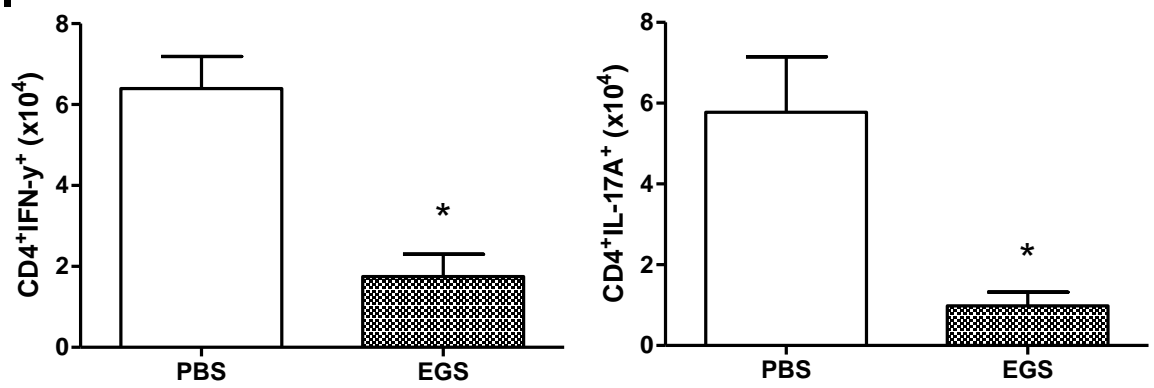

Figura 14 - Frequência de células T CD4 ${ }^{+}$efetoras e expressão de IFN- $\gamma$ e IL-17 no SNC no pico da EAE. As células mononucleares foram separadas do SNC e estimuladas com PMA $(50 \mathrm{ng} / \mathrm{mL})$ e ionomicina $(1 \mu \mathrm{M})$ na presença de Brefeldina A por 4 horas para marcação intracelular de IFN- $\gamma$ e IL-17A. (A) Dot Plot representativo a partir do gate de células $\mathrm{T} \mathrm{CD} 3^{+} \mathrm{CD} 4{ }^{+}$para análise da produção de IFN- $\gamma$ e IL-17A nos animais no pico da EAE. (B) Porcentagem de células T CD4 ${ }^{+}$ IFN- $\gamma^{+}$e IL-17A ${ }^{+}$. (C) Número absoluto de células T CD4 ${ }^{+}$IFN- $^{+} \gamma^{+}$e IL-17A ${ }^{+}$. Os dados representam a média da porcentagem $(\%)$ ou do número total de células \pm SEM. $* p<0,05$ versus grupo PBS. $n=5$ por grupo. 
4.7 Frequência de células $T$ reguladoras Foxp3+ no SNC dos animais tratados com EGS durante a EAE

Como os animais tratados com EGS apresentaram uma diminuição da gravidade da EAE e consequente diminuição das células $\mathrm{T}$ efetoras no pico da doença, decidimos investigar a frequência de células $T$ reguladoras nessa fase da doença. Para esse experimento, coletamos o SNC e caracterizamos as populações de linfócitos $\mathrm{T} \mathrm{CD}^{+} / \mathrm{CD}^{+} / \mathrm{Foxp}^{+}$. Assim, observamos que não houve diferença na frequência dessas células nos animais tratados em relação ao controle (Figura 15A e 15B). Entretanto, notamos uma diminuição no número absoluto dessas células nos animais tratados com EGS (Figura 15C). 
A.

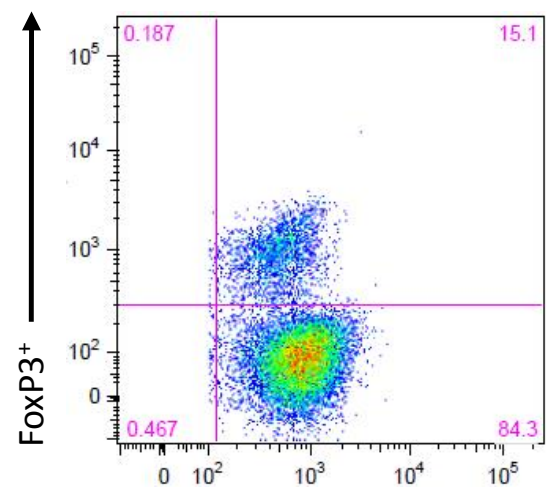

EGS

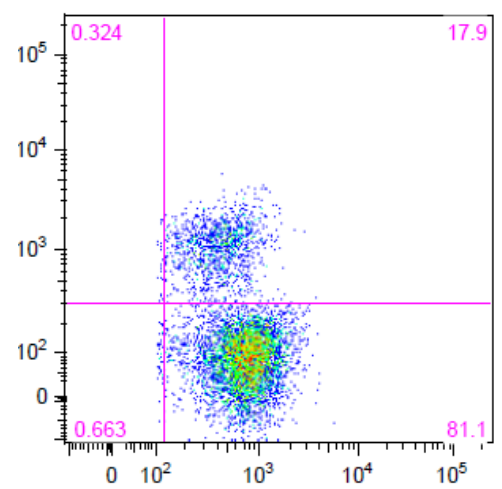

$\mathrm{CD}^{+}$

B.

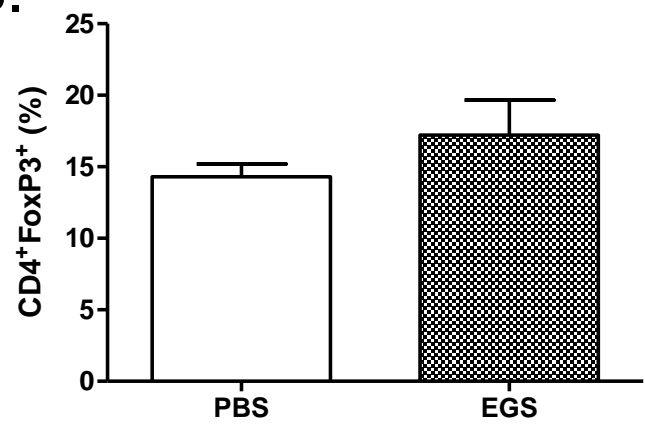

C.

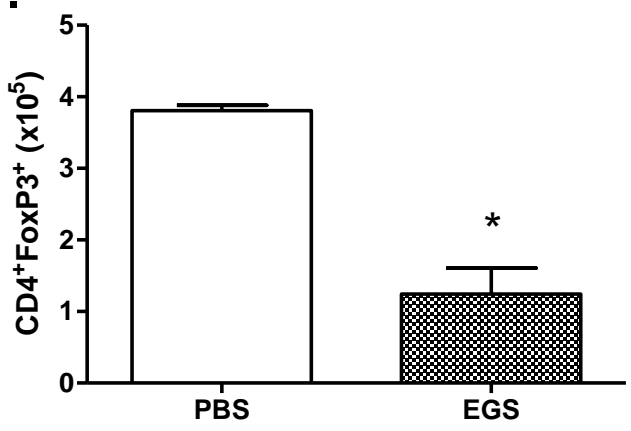

Figura 15 - Frequência das células T reguladoras no SNC no pico da EAE. Camundongos C57BL/6 foram imunizados com $150 \mu \mathrm{g}$ do peptídeo $\mathrm{MOG}_{35-55}$ em adjuvante completo de Freund (CFA) contendo $4 \mathrm{mg} / \mathrm{mL}$ de M. tuberculosis. Os animais foram tratados com EGS $(10 \mu \mathrm{g} / \mathrm{animal})$ junto na emulsão. Os animais foram sacrificados no pico da EAE e as células infiltrantes marcadas para identificação das células T reguladoras Foxp $3^{+}$. (A) Dot plots representativos da análise no gate de células $\mathrm{CD} 3^{+} \mathrm{CD} 4^{+}$. (B) Frequência de células $\mathrm{T}$ CD $4^{+}$Foxp $3^{+}$no SNC. (C) Número absoluto de células $\mathrm{T} \mathrm{CD}^{+}{ }^{+} \mathrm{Foxp}^{+}$no SNC. Os dados representam a média da frequência de células T reguladoras \pm SEM. $* p<0,05$ versus grupo PBS. $n$ $=$ 


\subsection{Efeito do EGS no infiltrado celular e desmielinização do SNC durante a EAE}

Para verificar se o infiltrado celular e a desmilienização do SNC são afetados pelo tratamento com EGS, os cérebros e cordões espinhais dos animais induzidos a EAE e tratados com PBS ou EGS foram coletados no $15^{\circ}$ dia (pico da doença) para a contagem total de células no homogenato dos órgãos e para a análise histológica.

Os cortes histopatológicos apresentados na Figura 16 mostram que, em relação ao grupo que recebeu PBS, os animais tratados com EGS apresentaram menor infiltrado celular na medula espinhal (setas vermelhas - Figuras 16A), como também pode ser visto no menor número absoluto de células infiltrantes para o SNC (Figura 16B). Em consequência disso, os animais que receberam o tratamento com EGS não apresentam uma grande desmielinização do SNC comparada com a dos animais do grupo controle (Figura 16C) onde observamos uma perda de $60 \%$ na taxa de mielinização contra apenas $35 \%$ no grupo tratado com EGS (Figura 16D). Estes dados sugerem que o tratamento com EGS foi capaz de inibir a inflamação do SNC, com um menor número de células patogênicas infiltrantes e em consequência disso, uma menor desmielinização. 

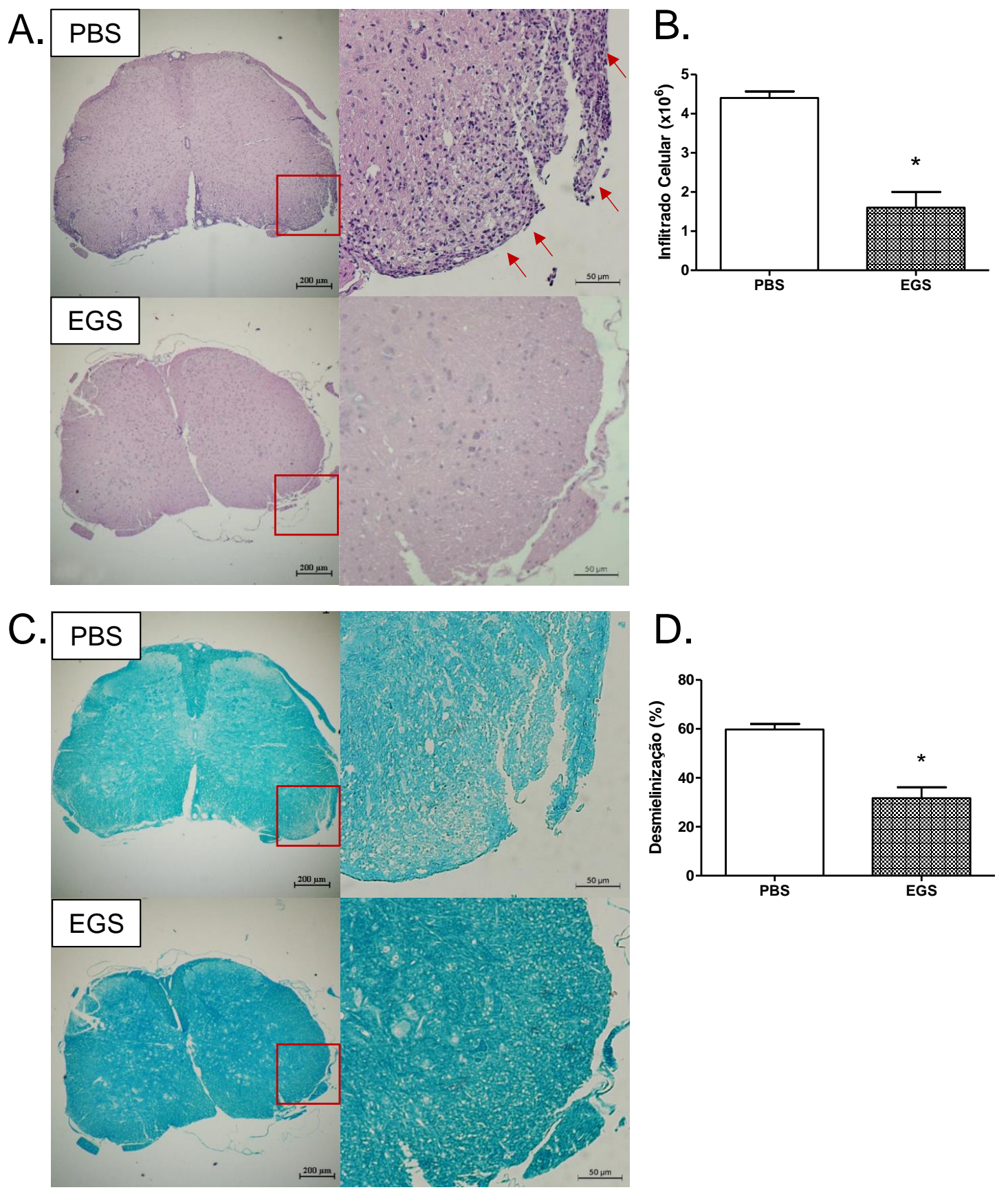

Figura 16 - EGS diminuiu o infiltrado inflamatório e a desmielinização do SNC de animais com EAE. No pico da doença, as medulas espinhais foram perfundidas e coletadas para análise histológica conforme descrito em Material e Métodos. Para análise do infiltrado celular as lâminas foram coradas com Hematoxilina/Eosina (A e B) e Luxol Fast Blue para a análise do conteúdo de mielina. A taxa de desmielinização foi avaliada como a porcentagem de mielina pela área total do tecido medular $(\mathbf{C}$ e D). Fotomicrografias representativas do tecido medular (aumento de $4 \times$ e $20 \times$ ) dos grupos PBS e EGS são mostradas. ${ }^{*} p<0,05$ versus grupo

PBS.

$n=$

5

por

grupo. 


\subsection{Proliferação e produção de citocinas após estimulação policlonal e MOG-específica em modelo de inflamação na pata}

Os nossos resultados claramente demonstram que os animais tratados com EGS apresentam uma menor inflamação do SNC. Um ponto importante da indução da EAE é ativação da resposta imune adaptativa. Para avaliar o papel do SNC durante a fase efetora da resposta imune, os animais controle e tratados com EGS foram imunizados e, após sete dias, as células dos linfonodos drenantes foram coletadas e reestimuladas in vitro com o peptídeo de $\mathrm{MOG}_{35-55}$ para avaliar a proliferação e a produção das citocinas IFN- $\gamma$, IL-17A, IL-4, IL-5 e IL-10 ex vivo. Observamos que as células primadas provenientes dos animais tratados com EGS proliferaram menos do que as células do grupo que recebeu apenas PBS, quando reestimuladas com o peptídeo de $\mathrm{MOG}_{35-55}$ (Figura 17A). A avaliação das citocinas presentes nos sobrenadantes de cultura revelou uma diminuição da produção das citocinas IFN- $\gamma$ e IL17A no grupo EGS quando comparado ao grupo PBS (Figura 17B e 17C). No entanto, não observamos diferença significativa na produção de IL-4 e IL-5 nos sobrenadantes das células dos animais de ambos os grupos (dados não mostrados). Por outro lado, foi observado um aumento significativo de IL-10 nos sobrenadantes provenientes das culturas de células dos animais tratados com EGS, quando comparado com aqueles de animais que receberam apenas PBS em todas as condições testadas (Figura 17D). 
A.

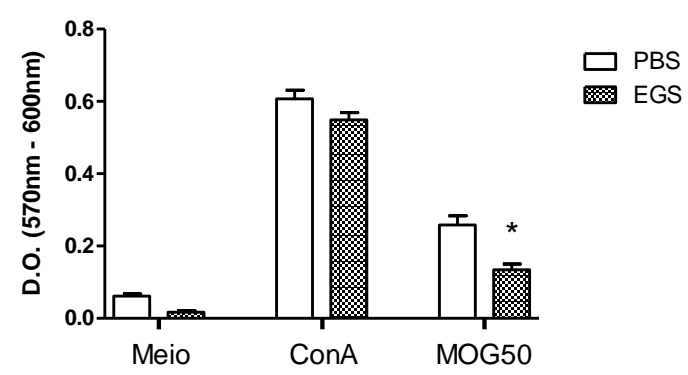

C.

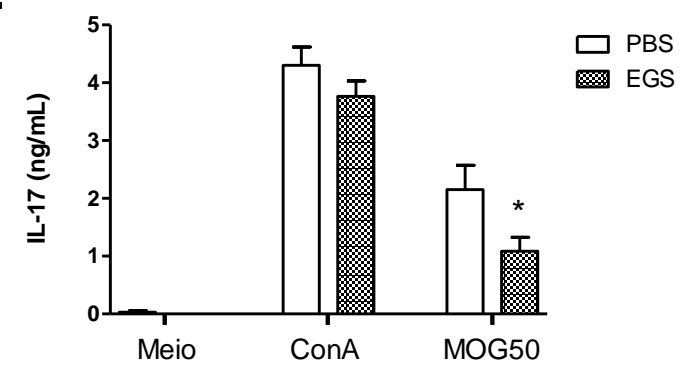

B.

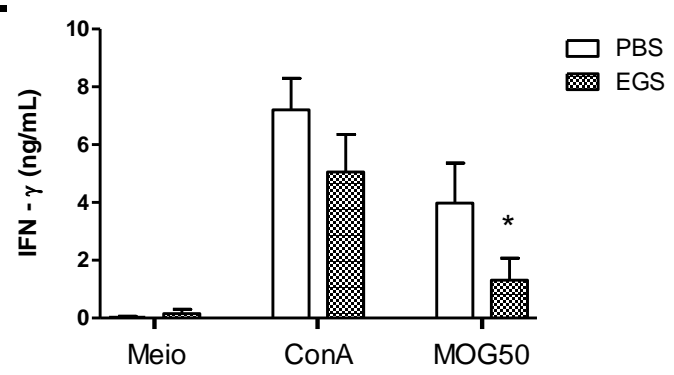

D.

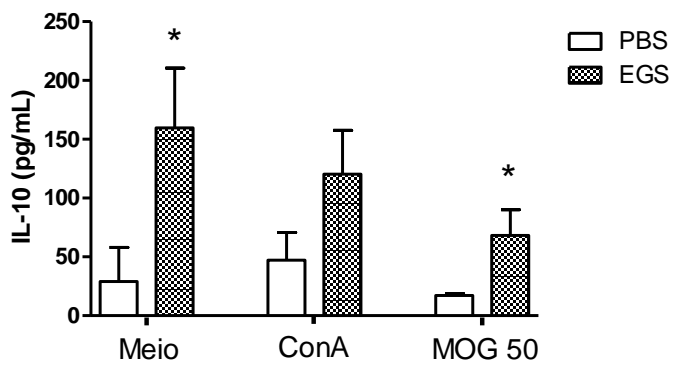

Figura 17 - Proliferação e perfil de citocinas nos linfonodos drenantes de animais imunizados com $\mathbf{M O G}_{\mathbf{p 3 5 - 5 5}}$. Camundongos C57BL/6 foram imunizados na pata com $\mathrm{MOG}_{\mathrm{p} 35-55}(150 \mu \mathrm{g}$ ) emulsificado em CFA (contendo $4 \mathrm{mg} / \mathrm{mL}$ de $M$. tuberculosis). Em um dos grupos, o EGS foi adicionado à emulsão (equivalente a $10 \mu \mathrm{g} / \mathrm{animal})$. Toxina pertussis ( $200 \mathrm{ng}$ ) foi administrada i.p. nos dias 0 e 2 após a imunização. Sete dias após a inoculação, os animais foram sacrificados e os linfonodos drenantes retirados para a cultura celular. Células $\left(2 \times 10^{6}\right.$ células $\left./ \mathrm{mL}\right)$ foram incubadas com meio, Con A $(0,5 \mu \mathrm{g} / \mathrm{mL})$ ou $\mathrm{MOG}_{\mathrm{p} 35-55}(10$ ou $50 \mu \mathrm{g} / \mathrm{mL})$ conforme descrito em Material e Métodos. (A) Proliferação dos linfócitos. (B) Produção de IFN- $\gamma$. (C) Produção de IL-17A. (D) Produção de IL-10. Os resultados estão expressos como a média \pm SEM. ${ }^{*} p<0,05$ versus respectivo grupo PBS. $n \quad=$ 5 por grupo. 


\subsection{Efeito do EGS de A. aegypti na diferenciação in vitro de células Th1, Th17 e Treg}

Como observamos um menor número de células produtoras de IFN- $\gamma$ (Th1) e IL-17A (Th17) e que expressam menos Foxp3 (T reguladoras) no infiltrado celular do SNC, investigamos a capacidade do EGS em diminuir a diferenciação de células T $\mathrm{CD}^{+}$naïve em células Th1, Th17 e T reguladoras in vitro. Para isso, células $\mathrm{T} \mathrm{CD}^{+} \mathrm{CD} 25^{-} \mathrm{CD} 62 \mathrm{~L}^{+}$do baço de animais naïve foram isoladas e cultivadas em meio de cultura com as respectivas citocinas para cada subtipo celular (Th1, Th17 e T reguladoras) e incubadas com EGS. Como sabemos que o EGS de A. aegypti é capaz de matar linfócitos em altas concentrações in vitro (28), primeiramente determinamos concentrações adequadas desse extrato bruto através de um teste de linfoproliferação (Figura 18). Como pode ser observado, o EGS foi capaz de inibir a proliferação dos linfócitos estimulados com Con A de maneira concentração-dependente e já detectável na concentração de $0,5 \mu \mathrm{g} / \mathrm{mL}$. Por esse motivo, decidimos utilizar para este experimento uma concentração que não é capaz de inibir a proliferação $(0,1 \mu \mathrm{g} / \mathrm{mL})$ e uma outra capaz de matar apenas cerca de $50 \%$ das células estimuladas com Con A ( $1 \mu \mathrm{g} / \mathrm{mL})$.

Assim, avaliamos a capacidade de diferenciação das células T CD4+ naïve em células Th1, Th17 e T reguladoras ao longo de cinco dias após o início da cultura na presença e na ausência de EGS $(0,1$ e $1 \mu \mathrm{g} / \mathrm{mL}$ ). Nossos resultados demonstram que o EGS (em ambas as concentrações) não alterou de maneira significativa a quantidade de células produtoras de IFN- $\gamma$ (Th1) e IL-17A (Th17) e a expressão do fator de transcrição Foxp3 (T reguladoras) nas culturas de células $\mathrm{T} \mathrm{CD}^{+}$naïve quando comparado às células controle (Figura 19). Estes resultados mostram que o EGS não é capaz de alterar a capacidade de diferenciação das células naïve em células Th1, Th17 e T reguladoras in vitro. 


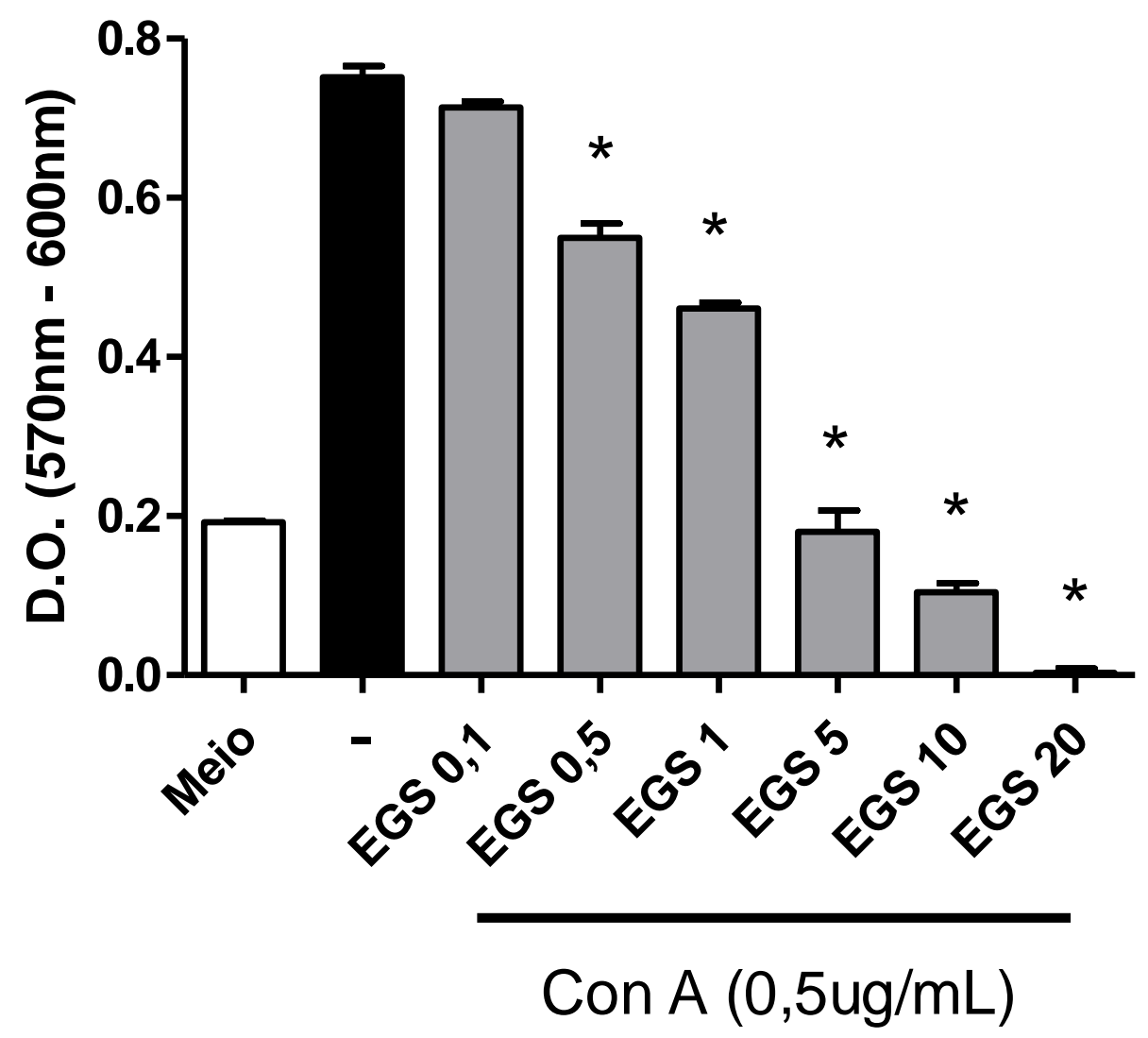

Figura 18 - Linfoproliferação induzida por Con A na presença de EGS de A. aegypti. Os animais foram eutanasiados e o baço retirado para a cultura celular. Células $\left(10^{6} / \mathrm{mL}\right)$ foram pré-incubadas com EGS $(0,1 ; 0,5 ; 1 ; 5 ; 10$ e $20 \mu \mathrm{g} / \mathrm{mL})$ por trinta minutos e incubadas com meio somente ou estimuladas com Con $\mathrm{A}(0,5 \mu \mathrm{g} / \mathrm{mL})$. Após 48 horas, foi adicionado resazurina e feita uma nova incubação por mais 24 h. A densidade óptica dos poços foi avaliada a 570 e $600 \mathrm{~nm}$ e o resultado expresso como a média \pm SEM da diferença entre as duas leituras. Os resultados estão expressos como a média \pm SEM. ${ }^{*} p<0,05$ versus grupo Con A. $n=3$ por grupo. 
A.
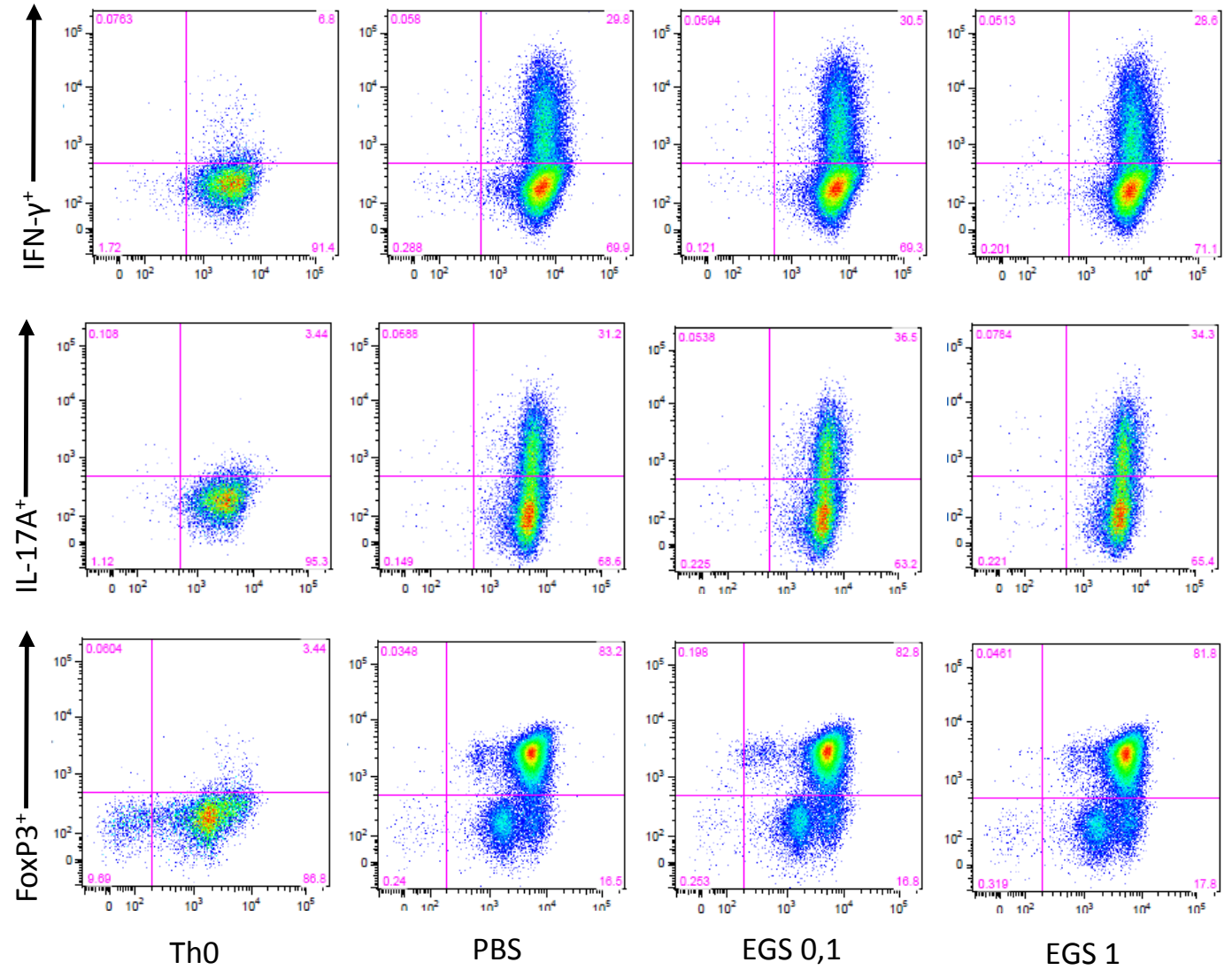

CD4 ${ }^{+}$

B.
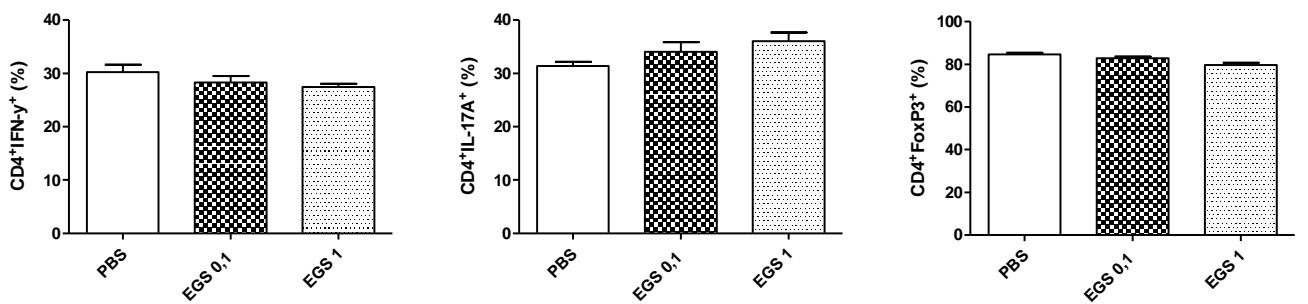

Figura 19 - Diferenciação de células Th1, Th17 e Treg a partir de células $\mathbf{T} \mathrm{CD4}^{+}$na presença de EGS de $\boldsymbol{A}$. aegypti. Marcação intracelular para IFN- $\gamma$, IL-17A e Foxp3 nas células $\mathrm{T} \mathrm{CD}^{+}$polarizadas nas condições de diferenciação para Th1, Th17 e Treg durante 5 dias e incubadas com PBS, EGS $0,1 \mu \mathrm{g} / \mathrm{mL}$ e $1 \mu \mathrm{g} / \mathrm{mL}$. (A) Dot Plots representativos para as marcações intracelulares. (B) Frequência de células $\mathrm{T} \mathrm{CD}^{+}$produtoras de IFN- $\gamma$, IL-17A e Foxp3. Os resultados estão expressos como a média das porcentagens \pm SEM. $n=3$ por grupo. 


\subsection{Competição dos antígenos presentes no EGS com MOG ${ }_{p 35-55}$}

Como o tratamento mais eficiente com EGS foi aquele onde o adicionamos à emulsão de $\mathrm{MOG}_{35-55}$, nos perguntamos se os antígenos salivares presentes no extrato poderiam estar competindo com o peptídeo pela fenda do MHC de classe II durante seu processamento e apresentação pelas células apresentadoras de antígeno. Para responder a essa pergunta, induzimos a EAE em 3 grupos de animais, sendo que o primeiro grupo recebeu apenas emulsão com $\mathrm{MOG}_{\mathrm{p} 35-55}$, um segundo recebeu emulsão com $\mathrm{MOG}_{\mathrm{p} 35-55}$ e EGS e um terceiro grupo recebeu emulsão com $M_{\text {p35-55 }}$ e OVA, na mesma dose do EGS (10 $\mu \mathrm{g} /$ animal). Como pode ser visto na Figura 20, a presença de OVA na emulsão não é capaz de competir com $M_{35-55}$ uma vez que em ambos os grupos, a indução da EAE não foi significativamente diferente. Ao contrário, e confirmando nossos resultados anteriores, a presença de EGS na emulsão foi capaz de modular negativamente os sintomas da EAE e todos os parâmetros associados, como incidência, início dos sinais clínicos, escala máxima alcançada e pico da doença.

Além disso avaliamos se as células dos linfonodos drenantes também estariam reconhecendo o EGS e apresentando-o para as células efetoras, induzindo assim células EGS específicas. Para isso, imunizamos camundongos C57BL/6 com $\mathrm{MOG}_{35-55}$ com ou sem EGS (10 $\mu \mathrm{g} /$ animal) e após 7 dias, os animais foram eutanasiados e os linfonodos drenantes retirados para cultura celular. Na cultura celular estas células foram pré-incubadas com EGS $(10 \mu \mathrm{g} / \mathrm{mL})$ e estimuladas de maneira antígeno-específica $\left(\mathrm{MOG}_{\mathrm{p} 35-55}\right)$ ou policlonalmente (Con A). Como mostra a Figura 21, de fato ocorreu a indução tanto de células MOGespecíficas quanto EGS-específicas nos grupos que receberam o extrato salivar. Porém podemos observar que a contribuição de células específicas para o EGS no ensaio de proliferação é muito pequeno quando comparado às células específicas para $\mathrm{o} \mathrm{MOG}_{\mathrm{p} 35-55}$. Esses resultados confirmam que o EGS não está competindo de maneira significativa com o $\mathrm{MOG}_{\mathrm{p} 35-55}$ uma vez que a taxa de proliferação das células MOG-específicas é muito maior que as células EGS-específicas. 


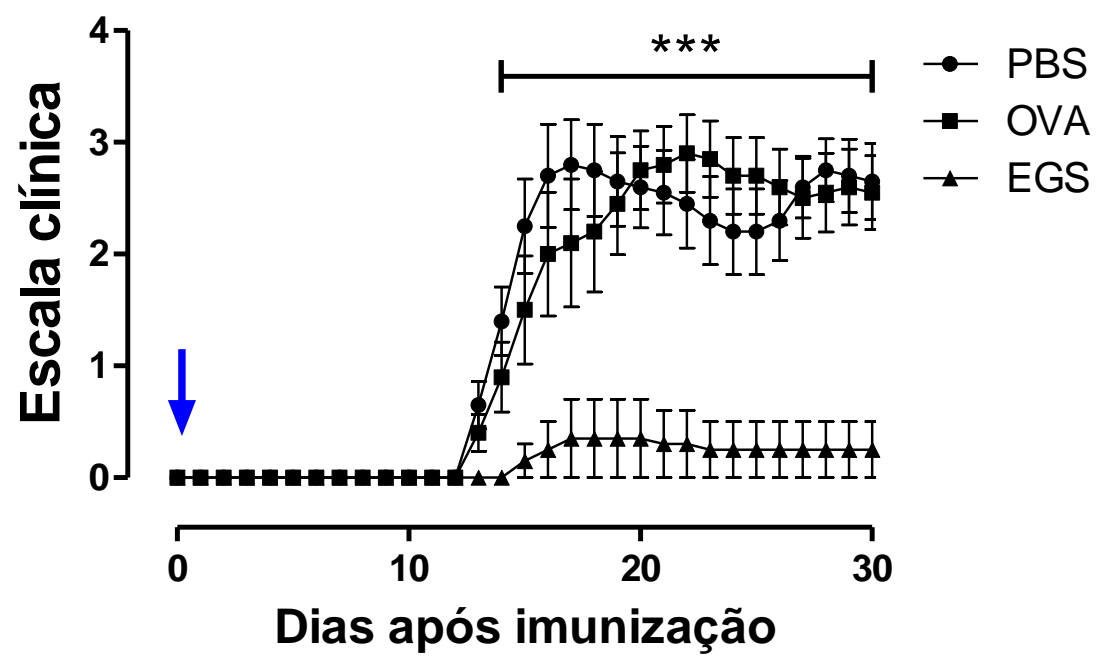

Figura 20 - Efeitos do EGS na EAE não são decorrentes da competição com $\mathrm{MOG}_{\mathrm{p} 35-55}$ na apresentação de antígenos pelas APCs. Camundongos C57BL/6 foram

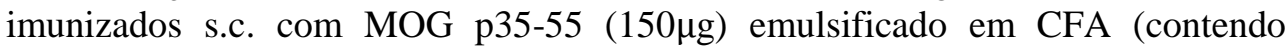
$4 \mathrm{mg} / \mathrm{mL}$ de $M$. tuberculosis) em duas regiões do peritônio. Em um dos grupos, o EGS foi adicionado à emulsão (equivalente a $10 \mu \mathrm{g} / \mathrm{animal}$ ) e em outro grupo foi adicionado OVA (10 $\mu \mathrm{g} /$ animal). Toxina pertussis $(200 \mathrm{ng})$ foi administrada i.p. nos dias 0 e 2 após a imunização. Os animais controle receberam PBS. A seta em azul representa o tratamento na emulsão. Os animais foram monitorados por 30 dias e os resultados estão apresentados como média \pm SEM da escala clínica da doença, conforme descrito em Material e Métodos. ${ }^{*} p<0,05$ versus grupo PBS. $n=$ 10 


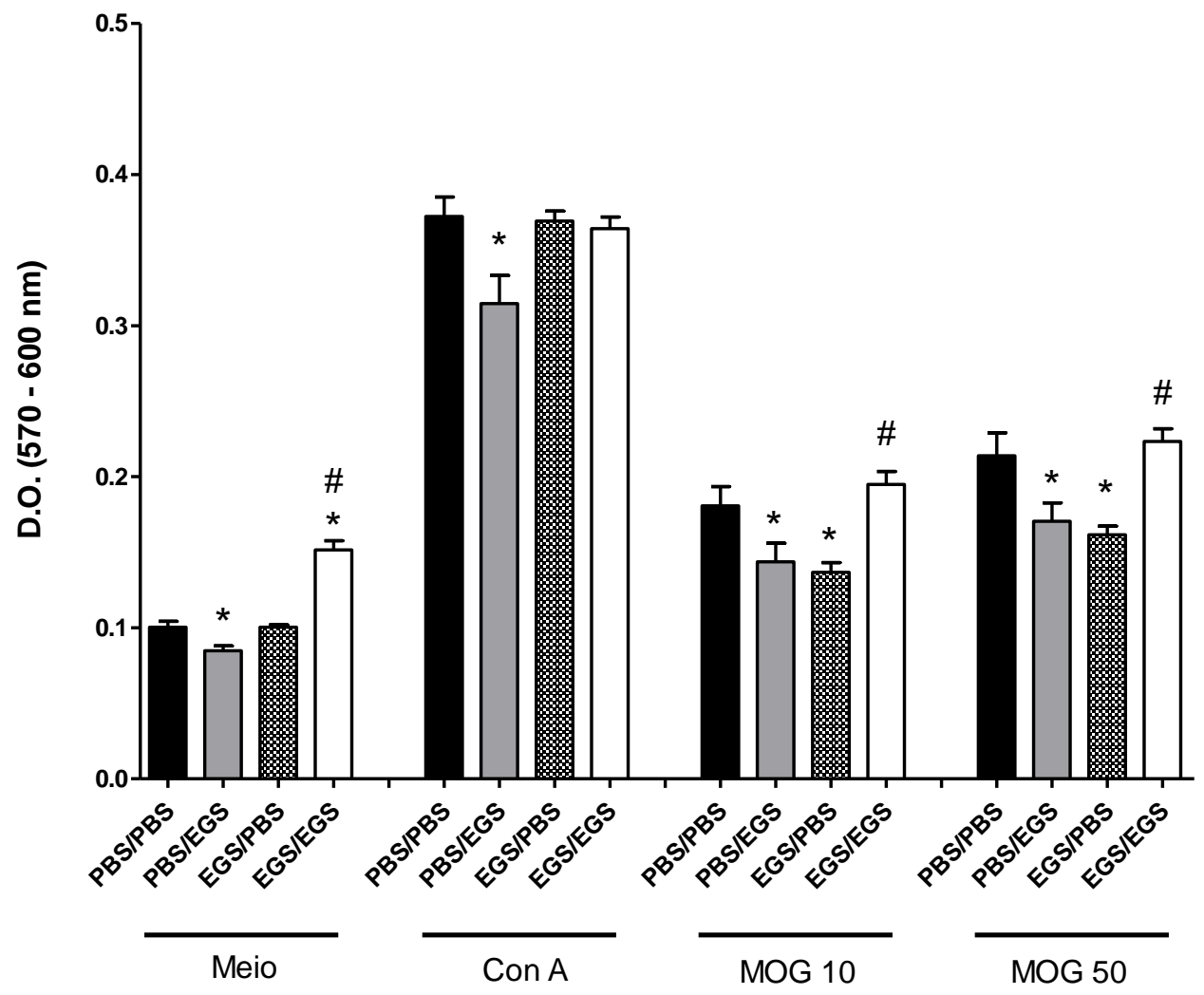

Figura 21 - Proliferação de linfócitos T nos linfonodos drenantes de animais imunizados com MOG $_{35-55}$. Camundongos C57BL/6 foram imunizados na pata com $\mathrm{MOG}_{\mathrm{p} 35-}$ $55(150 \mu \mathrm{g}$ ) emulsificado em CFA (contendo $4 \mathrm{mg} / \mathrm{mL}$ de $M$. tuberculosis). Em um dos grupos, o EGS foi adicionado à emulsão (equivalente a $10 \mu \mathrm{g} / \mathrm{animal})$. Toxina pertussis (200 ng) foi administrada i.p. nos dias 0 e 2 após a imunização. Sete dias após a inoculação, os animais foram eutanasiados e os linfonodos drenantes retirados para a cultura celular. Células $\left(2 \times 10^{6}\right.$ células $\left./ \mathrm{mL}\right)$ foram pré incubadas com EGS $(5 \mu \mathrm{g} / \mathrm{mL})$ por 30 minutos e após este tempo incubadas com meio, Con A $(0,5 \mu \mathrm{g} / \mathrm{mL})$ ou $\mathrm{MOG}_{\mathrm{p} 35-55}(10$ ou $50 \mu \mathrm{g} / \mathrm{mL})$ e a proliferação foi avaliada como descrito em Material e Métodos. Os resultados estão expressos como a média \pm SEM. ${ }^{*} p<0,05$ versus grupo PBS/PBS; ${ }^{*} p<0,05$ versus grupo EGS/PBS. $n=5$ por

grupo. 


\subsection{Efeito do EGS na maturação e diferenciação de células dendríticas}

Nosso próximo passo foi avaliar se o EGS estaria afetando a maturação de células dendríticas, uma vez que elas estão sabidamente envolvidas no processo de indução da resposta adaptativa que causa os sintomas da EAE. Como podemos observar na Figura 22, o EGS foi capaz de inibir a maturação das células dendríticas induzida por LPS, uma vez que observa-se uma menor frequência de células MHCII ${ }^{\text {high }}$ que expressam os coestimuladores $\mathrm{CD}^{+} 0^{+}$e $\mathrm{CD} 6^{+}$. As frequências de $\mathrm{CD} 11 \mathrm{c}^{+}$não foram alteradas pelo tratamento com EGS (dados não mostrados). Como efeito dessa inibição da maturação, também tivemos uma menor produção de citocinas pelas células que foram tratadas com EGS, onde vemos que o tratamento com EGS, tanto 20 como $40 \mu \mathrm{g} / \mathrm{mL}$ foi capaz de inibir a produção das citocinas IL-6, IL-12p40, IL-12p70 e IL-23. Não foram detectadas diferenças na produção de IL-10 (Figura 23). 


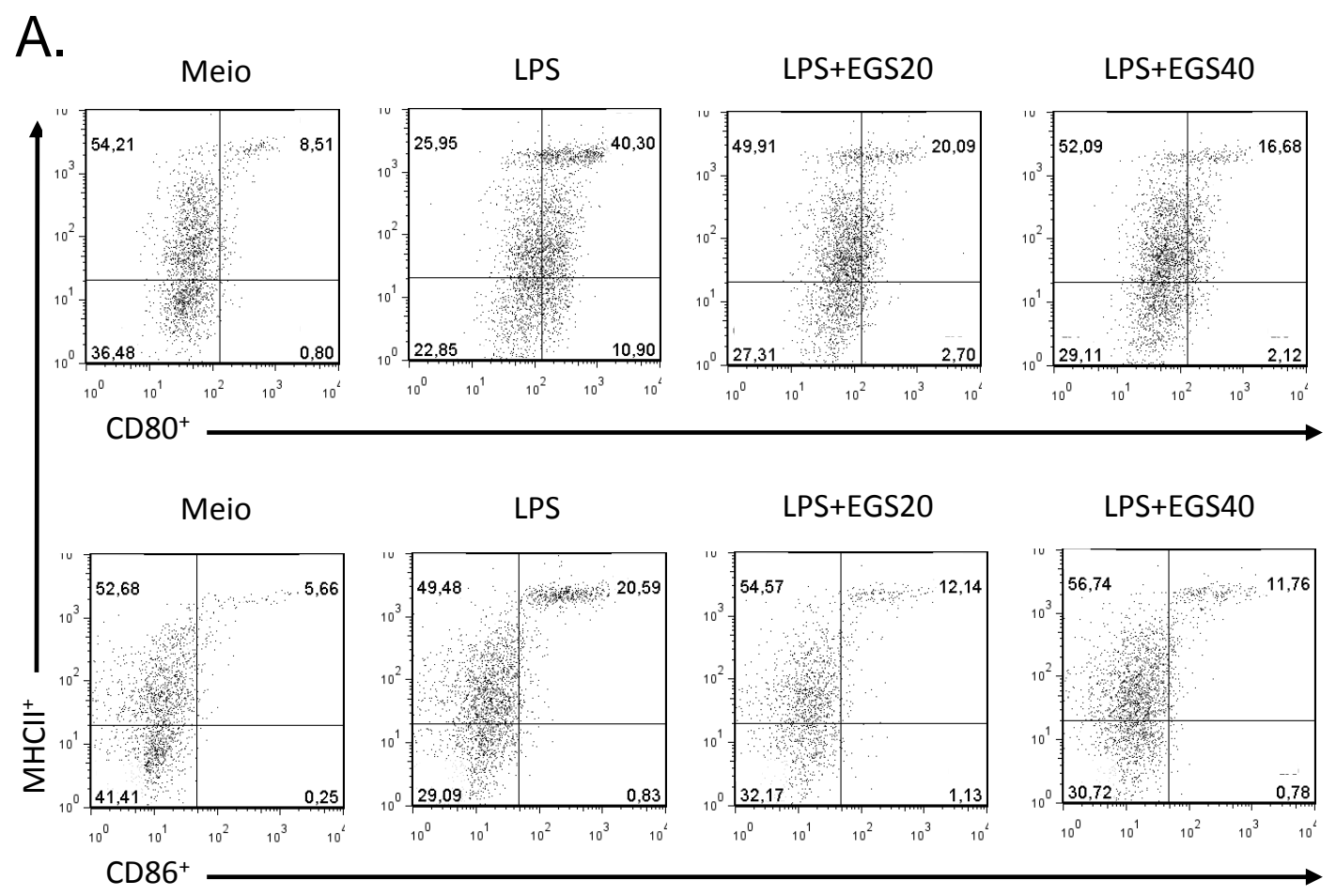

B.

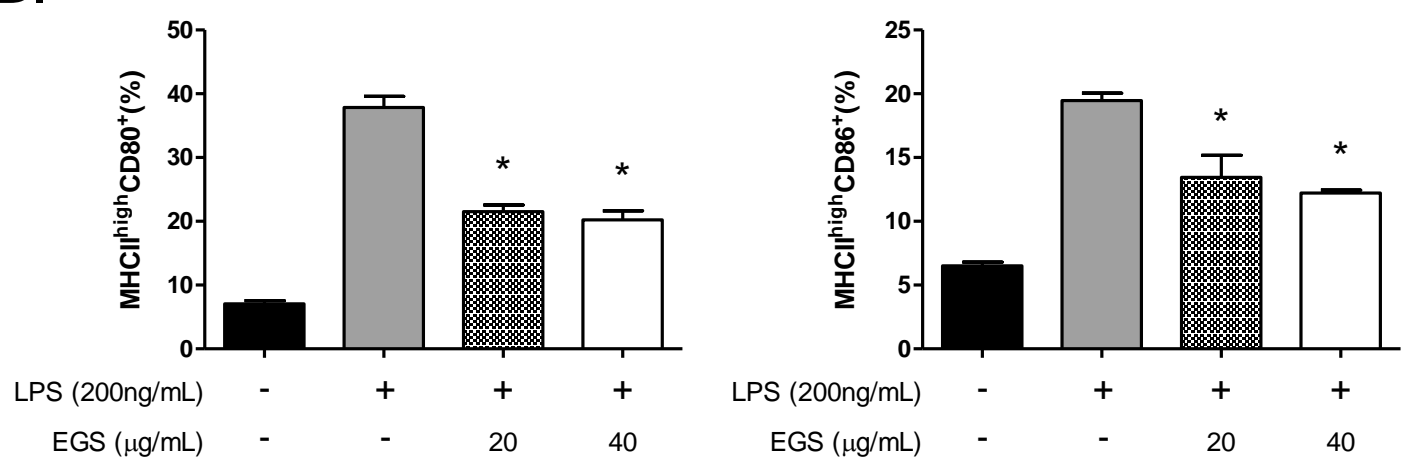

Figura 22 - Expressão de MHC de classe II, CD80 e CD86 em células CD11c ${ }^{+}$tratadas com EGS.Células $\left(1 \times 10^{6}\right.$ células $\left./ \mathrm{mL}\right)$ provenientes de cultura de medula óssea diferenciadas com GM-CSFforam pré-incubadas "overnight" na presença de meio ou EGS (20 e $40 \mu \mathrm{g} / \mathrm{mL})$ e estimuladas ou não com uLPS $(200 \mathrm{ng} / \mathrm{mL})$ por $24 \mathrm{~h}$. As células aderentes foram coletadas e marcadas com CD11c, MHCII, CD80 e CD86 e sua expressão determinada por citometria de fluxo. (A) Dot Plots representativos para as marcações intracelulares. (B) Frequência de células dendríticas $\mathrm{MHCII}^{\text {high }} \mathrm{CD} 80^{+}$e MHCII ${ }^{\text {high }} \mathrm{CD} 86^{+}$. Os resultados estão expressos como a média \pm SEM. ${ }^{*} p<0,05$ versus grupo LPS. $n=4$ por grupo. 

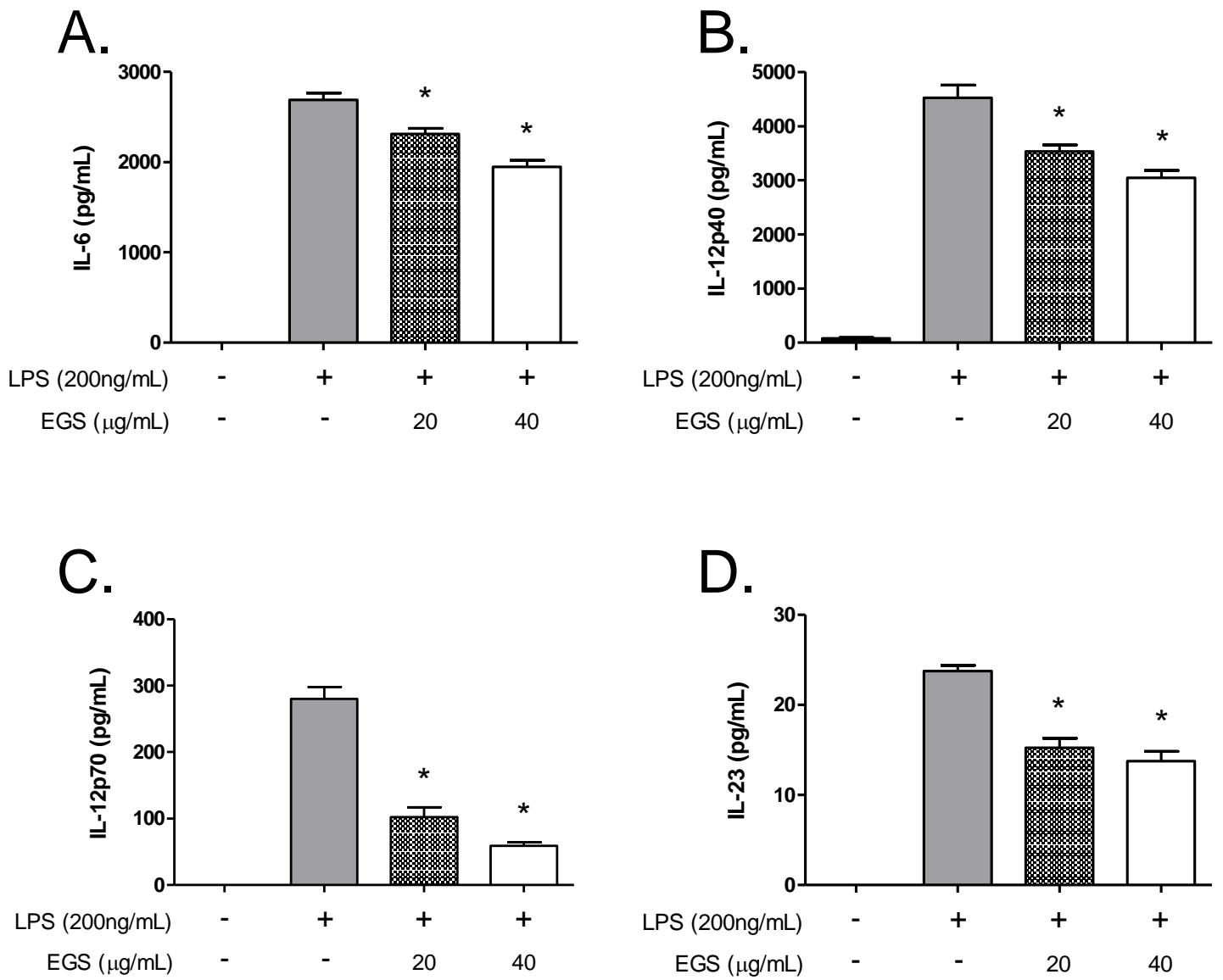

Figura 23 - Produção de citocinas por células dendríticas pré-incubadas com EGS de $\boldsymbol{A}$. aegypti e estimuladas com LPS. Células $\left(1 \times 10^{6}\right.$ células $\left./ \mathrm{mL}\right)$ provenientes de cultura de medula óssea diferenciadas com GM-CSF foram pré-incubadas "overnight" na presença de meio ou EGS (20 e $40 \mu \mathrm{g} / \mathrm{mL})$ e estimuladas ou não com LPS (200 ng/mL) por 24 h.O sobrenadante foi coletado e as citocinas (A) IL6, (B) IL-12p40, (C) IL-12p70 e (D) IL-23 foram determinadas. Os resultados estão expressos como a média \pm SEM. ${ }^{*} p<0,05$ versus grupo LPS. $n=4$ por grupo. 
5 DISCUSSÃO 
O repertório salivar de artrópodes hematófagos representa valiosa fonte para descoberta de novas moléculas farmacologicamente ativas. Em especial, a modulação exercida sobre o sistema imune evidencia o grande potencial de moléculas que possam ser empregadas no tratamento de doenças onde o sistema imunológico do indivíduo é o causador do quadro patológico, como no caso das hipersensibilidades e das doenças autoimunes. Embora bem recente, esta abordagem já foi explorada com sucesso com a saliva de outros insetos hematófagos, onde foi demonstrada a presença de moléculas capazes de agir em diferentes modelos experimentais (29-32). Além disso, o número crescente de moléculas descobertas nos transcriptomas salivares dessas espécies evidencia que a saliva é uma fonte de mediadores com potencial farmacêutico contra doenças de caráter imunológico. Nesse contexto, nosso laboratório vem caracterizando o imunoma funcional da saliva de A. aegypti que visa mapear o papel imunomodulador das moléculas presentes na saliva do mosquito no hospedeiro vertebrado.

Neste trabalho exploramos o potencial terapêutico do EGS de A. aegypti e sua capacidade de modular o curso clínico da EAE. Os diferentes protocolos de tratamento utilizados evidenciaram que o tratamento intravenoso não é eficiente para modular os sinais clínicos da doença. Não temos explicação para essa ausência de efeito, mas é fato que a biodisponibilidade e metabolização do EGS administrado por essa ou por outras vias ainda é desconhecido. Isso também foi uma surpresa para nós, uma vez que o tratamento intravenoso com pequenas quantidades do EGS de $P$. papatasi foi eficiente para amenizar o quadro clínico e inflamatório da artrite induzida por colágeno (29). Porém, uma comparação mais aprofundada entre as duas preparações salivares não pode ser feita, uma vez que os modelos representam doenças autoimunes distintas e tratadas com componentes salivares de espécies filogeneticamente separadas por milhões de anos (146). Por outro lado, um protocolo de tratamento mais agressivo onde o EGS foi adicionado tanto na emulsão quanto administrado intraperitonealmente, demonstrou o potencial terapêutico dos componentes salivares de $A$. aegypti. E de maneira interessante, observamos que o EGS atua efetivamente na doença se for administrado na fase de indução da mesma, ou seja, na emulsão contendo o auto-antígeno $\left(\mathrm{MOG}_{\mathrm{p} 35-55}\right)$. Nessas condições, o EGS foi eficiente em amenizar os sintomas dos animais, sintomas estes decorrentes principalmente dos efeitos de linfócitos $\mathrm{T}$ auto-reativos presentes no SNC.

Um dos mecanismos capazes de atenuar a EAE é a depleção das células T autoreativas (79). Em um primeiro momento, imaginamos ser esse o mecanismo de ação do EGS, 
uma vez que já demonstramos que esses componentes são capazes de modular a resposta de linfócitos naïves, induzindo sua apoptose (28). Porém, o tratamento com a fração responsável por esta atividade não foi capaz de modular os sinais clínicos da doença de uma maneira tão significativa, mesmo quando utilizado de uma maneira mais agressiva (presente na emulsão e administrado intraperitonealmente por 10 dias). Consideramos o efeito observado irrelevante porque a quantidade da fração utilizada no tratamento foi de $2 \mu \mathrm{g} / \mathrm{animal}$, uma quantidade muito superior desse material do que seria de se esperar nos $10 \mu \mathrm{g} / \mathrm{animal}$ usados no tratamento com o EGS total. Muito provavelmente o que pode estar ocorrendo é que o efeito do EGS de induzir a apoptose nos linfócitos ocorra predominantemente em células naïve e, como durante a EAE há uma grande indução de células antígeno específicas, o EGS não seja capaz de induzir a apoptose destas células e com isso diminuir os sintomas da doença de forma mais robusta. De fato, dados do nosso grupo demonstraram que apesar do EGS induzir apoptose em células T naïve de maneira dependente de caspase-3 e caspase-8 (28), células de memória não são sensíveis a tais efeitos, provavelmente pelo aumento da expressão de moléculas anti-apoptóticas.

Outro mecanismo capaz de atenuar a EAE é a indução de uma resposta Th2 $(71,72,80,147)$. Diversos trabalhos já demonstraram que o desvio para a resposta $\mathrm{Th} 2$ é capaz de suprimir doenças autoimunes de padrões Th1/Th17. Além disso, já se sabe que as células Th2 podem ser capazes de diminuir a resposta inflamatória e também estão ligadas a regulação da resposta imune durante a EAE (148-152). O tratamento peritoneal realizado com EGS foi de fato capaz de induzir citocinas de um padrão Th2 como IL-4 e IL-5, porém, não foi capaz de alterar o curso clinico da doença. Entretanto, quando o tratamento peritoneal está associado com a presença do EGS também na emulsão, observamos uma redução ainda maior na sintomatologia. Isso significa que mesmo a indução da resposta Th2 pelo EGS não sendo capaz de atenuar a doença sozinha, quando ela ocorre de forma conjunta com o tratamento na emulsão, é capaz de causar inibição ainda maior da doença. De fato, já foi mostrado na literatura que a administração de IL-4 é capaz de prevenir a EAE (149).

A análise das células infiltrantes no SNC (linfócitos e macrófagos) nos mostrou que o tratamento com EGS não foi capaz de diminuir a frequência das células auto-reativas nem de macrófagos/micróglias ativados. Entretanto, ocorreu uma diminuição no número absoluto destas células quando comparado com o grupo sem tratamento. Isso nos mostrou que o EGS está agindo na fase de indução da resposta, modulando de alguma maneira a função das células dendríticas ou a sua comunicação com os linfócitos T. O início da resposta imune 
durante a EAE ocorre nos linfonodos, onde as APCs irão apresentar o antígeno ( $\left.\mathrm{MOG}_{\mathrm{p} 35-55}\right)$, para os linfócitos (153). As células dendríticas sofrem diversas mudanças quando ativadas via padrões moleculares associados a patógenos, como o aumento da expressão de MHC de classe II e de moléculas coestimuladoras (ex. CD80 e CD86). Essas moléculas são importantes para a sinapse imunológica entre as APCs e os linfócitos T, não só para a apresentação do antígeno como também na indução do segundo sinal para a produção de citocinas. Diversos trabalhos já demonstraram que a inibição dessas moléculas é capaz de suprimir a EAE (154-159). Vimos que nosso melhor tratamento para a EAE (EGS na emulsão) foi capaz de atuar nas células dendríticas como mostramos por experimentos in vitro, diminuindo a expressão dessas moléculas tão importantes durante a interação entre as APCs e os linfócitos T. O EGS foi capaz de diminuir a expressão de MHCII, CD80 e CD86, além de inibir a produção de citocinas importantes para a indução de um padrão de resposta Th1/Th17 como IL-6, IL-12 e IL-23. Esses resultados são diferentes daqueles descritos anteriormente por nosso grupo, onde o EGS não apresentou efeitos relevantes na diferenciação, maturação e função de células dendríticas (28). Isso pode ter ocorrido por uma série de motivos. Primeiro, trabalhamos com camundongos C57BL/6, enquanto nossos resultados anteriores foram observados com células provenientes de camundongos BALB/c. Segundo, nosso protocolo experimental utilizou células dendríticas com 8 dias uma vez que nos baseamos em outros trabalhos da literatura avaliando a atividade dessas células na EAE (160), enquanto nosso trabalho anterior utilizou células diferenciadas da medula óssea com 6 dias. É conhecido que células dendríticas em diferentes graus de diferenciação podem ter fenótipos e funções distintas (161-164). De fato, a inibição da resposta Th1/Th17 observado com o tratamento com EGS parece ser devido a uma ação indireta via células dendríticas, com a inibição das citocinas IL-6, IL-12 e IL-23, responsáveis por induzir os padrões Th1/Th17 do que um efeito direto sobre os linfócitos como inicialmente foi hipotetizado com base nos resultados de apoptose de linfócitos (28).

Um dado interessante que observamos com relação às citocinas analisadas in vivo, foi que o tratamento com EGS inibe a produção de citocinas dos padrões Th1 (IFN- $\gamma$ ) e Th17 (IL-17A), células importantes na patogênese e durante o curso da EAE $(136,165,166)$, além de induzir a produção de IL-10, uma citocinas reguladora e anti-inflamatória. A IL-10 é uma citocina capaz de limitar a EAE, diminuindo os sintomas e a sua progressão, além de inibir a produção e a ação de citocinas pró-inflamatórias como IL-6, IL-12, IFN- $\gamma$ provenientes das APCs no SNC (167-170). E de fato, observamos que o tratamento é capaz de induzir 
produção de IL-10 por células MOG específicas. Além disso, vimos uma alta produção de IL10 nas células que não receberam estímulo linfócito-específico, o que nos leva a crer que a produção de IL-10 também esteja acontecendo em outros tipos celulares como as APCs. Nesse sentido, já foi demonstrado que a IL-10 é capaz de causar a remissão da doença (171) ou até mesmo inibir a indução da EAE (172). Um trabalho recente mostra que células dendríticas ativadas com LPS não são capazes de induzir EAE, ao contrário de células dendríticas ativadas com toxina pertussis, devido ao estímulo com LPS induzir uma grande quantidade de IL-10 (173). Trabalhos recentes com populações de células reguladoras, também têm demonstrado que células produtoras de IL-10 tornam-se células reguladoras de um padrão Tr-1 (174,175), portanto, apesar de ainda termos células produtoras de IFN- $\gamma$ e IL17, essas mesmas células não seriam células patogênicas, uma vez que também produziriam IL-10.

Embora tenhamos conseguido desvendar os mecanismos pelos quais o EGS está atuando e diminuindo a resposta imune durante a EAE, não conseguimos isolar as moléculas responsáveis por tais atividades. Apesar de já termos fracionado o EGS em nosso laboratório, testar todas as prováveis frações in vivo é tarefa inviável devido ao grande número de animais usado em cada experimento (10 animais por grupo). Além disso, não possuímos um modelo in vitro robusto capaz de nos auxiliar no seleção das frações com as atividades propostas. Não podemos descartar, por exemplo, uma atividade dos componentes salivares de A. aegypti sobre catepsinas, cisteíno-proteases que participam do processamento antigênico (176-178). Demonstramos há alguns anos que um inibidor de catepsina S (SialoL1) presente na saliva do carrapato I. scapularis foi capaz de diminuir os sinais clínicos da EAE por um mecanismo relacionado à inibição do processamento e degradação da cadeia invariante na fenda das moléculas de MHC de classe II (31). Apesar de um trabalho anterior do grupo ter demonstrado que a função de apresentação de antígenos pelas células dendríticas não tenha sido afetado na presença de EGS de A. aegypti (28), não podemos descartar que alterações nas condições experimentais possam evidenciar um fenótipo diferente, como foi visto acima na questão das citocinas e moléculas coestimuladoras.

Como o efeito do EGS na EAE ocorreu predominantemente quando os componentes salivares foram adicionados à emulsão contendo $\mathrm{CFA}$ e $\mathrm{MOG}_{\mathrm{p} 35-55}$, nos questionamos se os antígenos presentes no extrato poderiam competir com o $\mathrm{MOG}_{\mathrm{p} 35-55}$ e assim diminuir a apresentação dos auto-antígenos e consequentemente, os sintomas da doença. $\mathrm{O}$ ensaio que incluiu a mesma quantidade de OVA na emulsão $(10 \mu \mathrm{g} / \mathrm{mL})$ sugere que essa possibilidade 
não procede. Além disso, a quantidade de cada um das dezenas de antígenos presentes no extrato é muito pequena, em geral $1 \%$ ou menos do total do conteúdo proteico do EGS. Seria difícil imaginar que alguns nanogramas de tais antígenos seriam capazes de bloquear a ligação de $150 \mu \mathrm{g}$ de $\mathrm{MOG}_{\mathrm{p} 35-55}$ de modo significativo.

Com este estudo, conseguimos demonstrar pela primeira vez que o EGS de A. aegypti é capaz de modular a EAE de diferentes maneiras. O EGS possui moléculas que agem tanto na fase de indução da doença, diminuindo a resposta de células dendríticas, como também de forma mais sistêmica, através da indução de uma resposta $\mathrm{Th} 2$, fazendo o desvio da resposta Th1/Th17 para um perfil Th2, além de induzir a produção de IL-10 e possivelmente com algum papel na indução da apoptose das células T. Com isso, a identificação dessas moléculas, pode criar no futuro, tratamentos eficientes para o controle da EM e de outras doenças autoimunes. 
6 CONCLUSÃO 
Com este estudo, concluímos que o os componentes salivares de A. aegypti são capazes de alterar o curso clínico da EAE, diminuindo seus sinais clínicos. Demonstramos que o EGS consegue suprimir a doença por quatro vias principais:

1) atuando diretamente em células dendríticas e diminuindo a expressão de MHC de classe II, CD80 e CD86, além de diminuir a produção de citocinas responsáveis pela indução das respostas Th1 e Th17;

2) indução de células produtoras de IL-10 ex vivo;

3) diminuição da frequência de linfócitos T naïve responsivos, diminuindo assim a resposta proliferativa durante a fase da apresentação antigênica;

4) indução sistêmica de células com perfil Th2 com produção de IL-4 e IL-5, sugerindo um desvio do perfil Th1/Th17 de resposta imune.

A seguir, a Figura 24 apresenta um esquema com o resumo dessa modulação. 


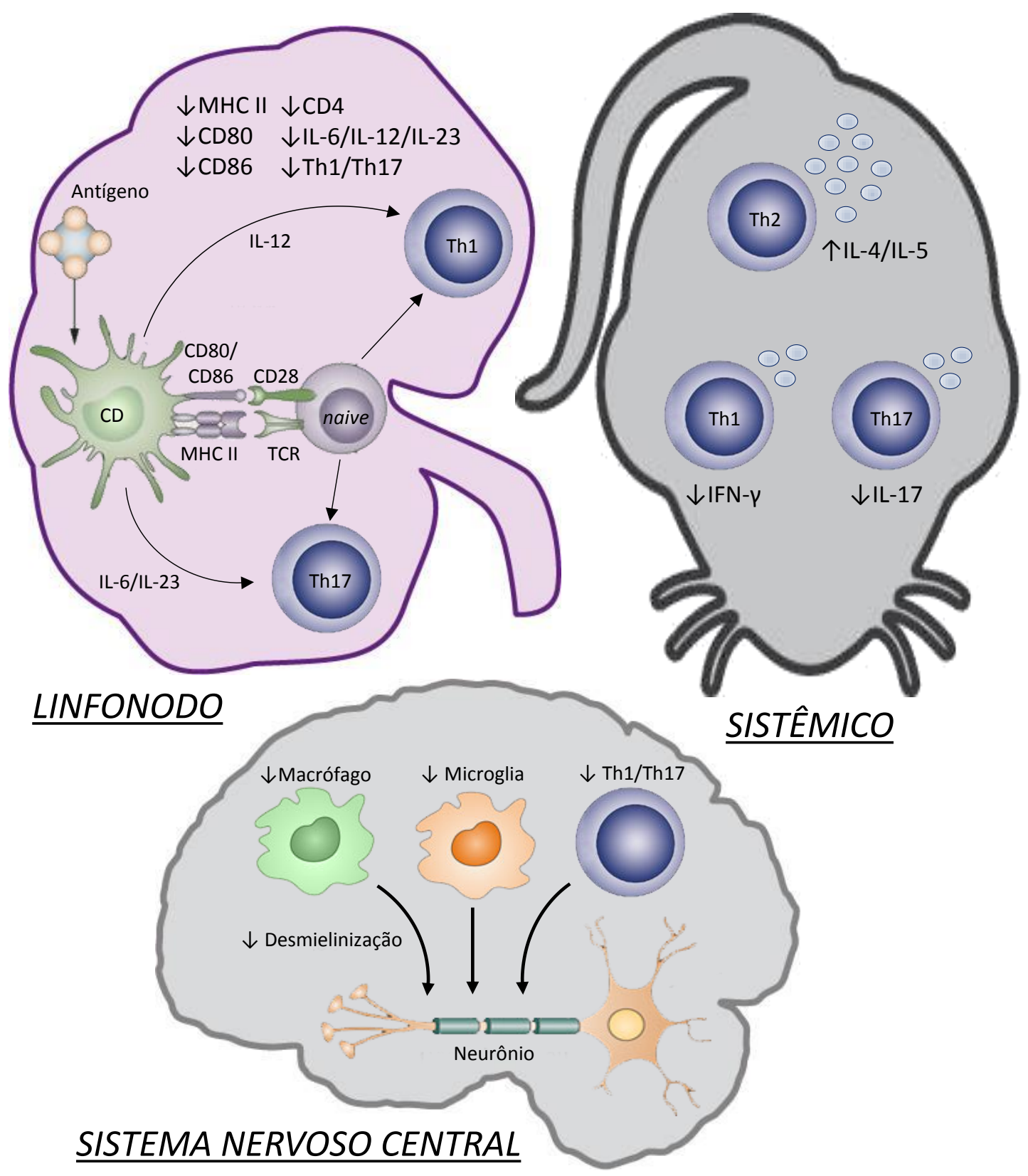

Figura 24 - Mecanismo de ação proposto para a ação do EGS na EAE. O EGS age primeiramente nos órgãos linfóides atuando diretamente nas células dendríticas, diminuindo a expressão de MHC de classe II e das moléculas coestimuladoras (CD80 e CD86) e a produção de citocinas (IL-6, IL-12p40, IL-12p70 e IL-23). Como consequência, há um menor número de subpopulações de células $\mathrm{T}$ (Th1 e Th17) e um aumento da subpopulação Th2 induzida pelo EGS intraperitonealmente. No SNC há um menor infiltrado de células inflamatórias, tanto, as subpopulações Th1 como Th17 além de macrófagos infiltrantes e como consequência um menor dano aos neurônios com menor desmielinização e portanto quadro clínico mais brando. 
1. Brusca RC, Brusca GJ. Invertebrates. Sinauer Associates, Incorporated; 2003.

2. Ødegaard F. How many species of arthropods? Erwin's estimate revised. Biol J Linn Soc [Internet]. 2000 Dec [cited 2013 Sep 19];71(4):583-97. Available from: http://linkinghub.elsevier.com/retrieve/pii/S0024406600904681

3. Ribeiro JM. Blood-feeding arthropods: live syringes or invertebrate pharmacologists? Infect Agents Dis. 1995 Sep;4(3):143-52.

4. World Health Organization [Internet]. Organização Mundial da Saude. 2014. Available from: http://www.who.int/mediacentre/factsheets/fs094/en/

5. Auerbach PM. Wilderness Medicine. Elsevier/Mosby; 2011.

6. Barrett ADT, Higgs S. Yellow fever: a disease that has yet to be conquered. Annu Rev Entomol. 2007 Jan;52:209-29.

7. Black WC, Bennett KE, Gorrochótegui-Escalante N, Barillas-Mury C V, FernándezSalas I, de Lourdes Muñoz M, et al. Flavivirus susceptibility in Aedes aegypti. Arch Med Res. 2002;33(4):379-88.

8. Gubler DJ. Epidemic dengue/dengue hemorrhagic fever as a public health, social and economic problem in the 21st century. Trends Microbiol. 2002 Feb;10(2):100-3.

9. Gubler DJ. The global emergence/resurgence of arboviral diseases as public health problems. Arch Med Res. 2002;33(4):330-42.

10. Bhatt S, Gething PW, Brady OJ, Messina JP, Farlow AW, Moyes CL, et al. The global distribution and burden of dengue. Nature. Nature Publishing Group; 2013 Apr;496(7446):504-7.

11. Secretária Estadual da Saúde do Estado de São Paulo [Internet]. Secretária Estadual da Saúde - SP - Centro de Vigilãncia Epidemiológica. 2014. Available from: http://www.cve.saude.sp.gov.br/htm/zoo/den14_import_autoc.htm

12. Secretária Estadual da Saúde do Estado de São Paulo [Internet]. Secretária Estadual da Saúde - SP - Centro de Vigilãncia Epidemiológica. 2013. Available from: http://www.cve.saude.sp.gov.br/htm/zoo/den13_import_autoc.htm

13. Secretária Municipal da Saúde [Internet]. Secretária Municipal da Saúde - SP. 2014. Available from: www.prefeitura.sp.gov.br/cidade/secretarias/saude/

14. Ribeiro JM. Role of saliva in blood-feeding by arthropods. Annu Rev Entomol. 1987 Jan;32:463-78.

15. Ribeiro JM, Sarkis JJ, Rossignol PA, Spielman A. Salivary apyrase of Aedes aegypti: characterization and secretory fate. Comp Biochem Physiol B. 1984 Jan;79(1):81-6. 
16. Calvo E, Tokumasu F, Marinotti O, Villeval J-L, Ribeiro JMC, Francischetti IMB. Aegyptin, a novel mosquito salivary gland protein, specifically binds to collagen and prevents its interaction with platelet glycoprotein VI, integrin alpha2beta1, and von Willebrand factor. J Biol Chem. 2007 Sep;282(37):26928-38.

17. Calvo E, Tokumasu F, Mizurini DM, McPhie P, Narum DL, Ribeiro JMC, et al. Aegyptin displays high-affinity for the von Willebrand factor binding site (RGQOGVMGF) in collagen and inhibits carotid thrombus formation in vivo. FEBS J. 2010 Jan;277(2):413-27.

18. Champagne DE, Ribeiro JM. Sialokinin I and II: vasodilatory tachykinins from the yellow fever mosquito Aedes aegypti. Proc Natl Acad Sci U S A. 1994 Jan;91(1):13842.

19. Stark KR, James AA. A factor Xa-directed anticoagulant from the salivary glands of the yellow fever mosquito Aedes aegypti. Exp Parasitol. 1995 Nov;81(3):321-31.

20. Lino CNR. Characterization of the biological activity of Aedes aegypti salivary serpin AET-7393. Universidade de São Paulo; 2013.

21. Bissonnette EY, Rossignol PA, Befus AD. Extracts of mosquito salivary gland inhibit tumour necrosis factor alpha release from mast cells. Parasite Immunol. 1993 Jan;15(1):27-33.

22. Schneider BS, Soong L, Coffey LL, Stevenson HL, McGee CE, Higgs S. Aedes aegypti saliva alters leukocyte recruitment and cytokine signaling by antigenpresenting cells during West Nile virus infection. PLoS One. 2010 Jan;5(7):e11704.

23. Wanasen N, Nussenzveig RH, Champagne DE, Soong L, Higgs S. Differential modulation of murine host immune response by salivary gland extracts from the mosquitoes Aedes aegypti and Culex quinquefasciatus. Med Vet Entomol. 2004 Jun;18(2):191-9.

24. Wasserman HA, Singh S, Champagne DE. Saliva of the Yellow Fever mosquito, Aedes aegypti, modulates murine lymphocyte function. Parasite Immunol. 2004;26(6-7):295306.

25. Schneider BS, McGee CE, Jordan JM, Stevenson HL, Soong L, Higgs S. Prior exposure to uninfected mosquitoes enhances mortality in naturally-transmitted West Nile virus infection. PLoS One. 2007 Jan;2(11):e1171.

26. Schneider BS, Soong L, Zeidner NS, Higgs S. Aedes aegypti salivary gland extracts modulate anti-viral and TH1/TH2 cytokine responses to sindbis virus infection. Viral Immunol. 2004 Jan;17(4):565-73.

27. Barros MS de. Standardization of a model of allergic inflammation by exposure to Aedes aegypti mosquito bites. Universidade de São Paulo; 2012. 
28. Bizzarro B, Barros MS, Maciel C, Gueroni DI, Lino CN, Campopiano J, et al. Effects of Aedes aegypti salivary components on dendritic cell and lymphocyte biology. Parasit Vectors. 2013 Jan;6:329.

29. Carregaro V, Sá-Nunes A, Cunha TM, Grespan R, Oliveira CJF, Lima-Junior DS, et al. Nucleosides from Phlebotomus papatasi salivary gland ameliorate murine collageninduced arthritis by impairing dendritic cell functions. J Immunol. 2011 Oct;187(8):4347-59.

30. Grespan R, Lemos HP, Carregaro V, Verri WA, Souto FO, de Oliveira CJF, et al. The protein LJM 111 from Lutzomyia longipalpis salivary gland extract (SGE) accounts for the SGE-inhibitory effects upon inflammatory parameters in experimental arthritis model. Int Immunopharmacol. 2012 Apr;12(4):603-10.

31. Sá-Nunes A, Bafica A, Antonelli LR, Choi EY, Francischetti IMB, Andersen JF, et al. The immunomodulatory action of sialostatin $\mathrm{L}$ on dendritic cells reveals its potential to interfere with autoimmunity. J Immunol [Internet]. 2009 Jun 15 [cited 2014 Jul 20];182(12):7422-9. Available from: http://www.pubmedcentral.nih.gov/articlerender.fcgi?artid=2694955\&tool=pmcentrez \&rendertype $=$ abstract

32. Juncadella IJ, Bates TC, Suleiman R, Monteagudo-Mera A, Olson CM, Navasa N, et al. The tick saliva immunosuppressor, Salp15, contributes to Th17-induced pathology during Experimental Autoimmune Encephalomyelitis. Biochem Biophys Res Commun. 2010 Nov;402(1):105-9.

33. Goverman J. Autoimmune $\mathrm{T}$ cell responses in the central nervous system. Nat Rev Immunol. 2009 Jun;9(6):393-407.

34. Associação Brasileira de Esclerose Múltipla [Internet]. Associação Brasileira de Esclerose Múltipla. 2014. Available from: www.datasus.gov.br

35. Ministério da Saúde [Internet]. Ministério da Saúde. 2014. Available from: http://portal.saude.gov.br

36. Dyment DA, Ebers GC, Sadovnick AD. Genetics of multiple sclerosis. Lancet Neurol. $2004 \mathrm{Feb} ; 3(2): 104-10$.

37. Ascherio A, Munger KL. Environmental risk factors for multiple sclerosis. Part I: the role of infection. Ann Neurol. 2007 Apr;61(4):288-99.

38. Kurtzke JF, Priester WA. Dogs, distemper, and multiple sclerosis in the United States. Acta Neurol Scand. 1979 Jan;60(5):312-9.

39. Kurtzke JF, Beebe GW, Norman JE. Epidemiology of multiple sclerosis in U.S. veterans: 1. Race, sex, and geographic distribution. Neurology. 1979 Sep;29(9 Pt 1):1228-35.

40. Kurtzke JF, Hyllested K. Multiple sclerosis in the Faroe Islands: I. Clinical and epidemiological features. Ann Neurol. 1979 Jan;5(1):6-21. 
41. Goodin DS, Ebers GC, Johnson KP, Rodriguez M, Sibley WA, Wolinsky JS. The relationship of MS to physical trauma and psychological stress: report of the Therapeutics and Technology Assessment Subcommittee of the American Academy of Neurology. Neurology. 1999 Jun;52(9):1737-45.

42. Confavreux C, Suissa S, Saddier P, Bourdès V, Vukusic S. Vaccinations and the risk of relapse in multiple sclerosis. Vaccines in Multiple Sclerosis Study Group. N Engl J Med. 2001 Feb;344(5):319-26.

43. Bach J-F. The effect of infections on susceptibility to autoimmune and allergic diseases. N Engl J Med. 2002 Sep;347(12):911-20.

44. Gilden DH. Infectious causes of multiple sclerosis. Lancet Neurol. 2005 Mar;4(3):195202.

45. Hawkes $\mathrm{CH}$. Smoking is a risk factor for multiple sclerosis: a metanalysis. Mult Scler. 2007 Jun;13(5):610-5.

46. Ramagopalan S V, Handel AE, Giovannoni G, Rutherford Siegel S, Ebers GC, Chaplin G. Relationship of UV exposure to prevalence of multiple sclerosis in England. Neurology. 2011 Apr;76(16):1410-4.

47. Levin LI, Munger KL, Rubertone M V, Peck CA, Lennette ET, Spiegelman D, et al. Temporal relationship between elevation of epstein-barr virus antibody titers and initial onset of neurological symptoms in multiple sclerosis. JAMA. 2005 May;293(20):2496-500.

48. Levin LI, Munger KL, O’Reilly EJ, Falk KI, Ascherio A. Primary infection with the Epstein-Barr virus and risk of multiple sclerosis. Ann Neurol. 2010 Jun;67(6):824-30.

49. Ramagopalan S V, Sadovnick a D. Epidemiology of multiple sclerosis. Neurol Clin. Elsevier Ltd; 2011 May;29(2):207-17.

50. Noseworthy JH, Lucchinetti C, Rodriguez M, Weinshenker BG. Multiple sclerosis. N Engl J Med. 2000 Sep;343(13):938-52.

51. Stefani MLFC| AF| MA. Rotinas em neurologia e neurocirurgia. Artmed; 2008.

52. Polman $\mathrm{CH}$, Reingold SC, Edan G, Filippi M, Hartung H-P, Kappos L, et al. Diagnostic criteria for multiple sclerosis: 2005 revisions to the "McDonald Criteria". Ann Neurol. 2005 Dec;58(6):840-6.

53. Weiner HL. Multiple sclerosis is an inflammatory T-cell-mediated autoimmune disease. Arch Neurol. 2004 Oct;61(10):1613-5.

54. Compston A, Coles A. Multiple sclerosis. Lancet. 2008 Oct;372(9648):1502-17.

55. Frohman EM, Racke MK, Raine CS. Multiple sclerosis--the plaque and its pathogenesis. N Engl J Med. 2006 Mar;354(9):942-55. 
56. Wuest SC, Edwan JH, Martin JF, Han S, Perry JSA, Cartagena CM, et al. A role for interleukin-2 trans-presentation in dendritic cell-mediated $\mathrm{T}$ cell activation in humans, as revealed by daclizumab therapy. Nat Med. 2011 May;17(5):604-9.

57. Prineas JW, Parratt JDE. Oligodendrocytes and the early multiple sclerosis lesion. Ann Neurol. 2012 Jul;72(1):18-31.

58. Bielekova B, Goodwin B, Richert N, Cortese I, Kondo T, Afshar G, et al. Encephalitogenic potential of the myelin basic protein peptide (amino acids 83-99) in multiple sclerosis: results of a phase II clinical trial with an altered peptide ligand. Nat Med. 2000 Oct;6(10):1167-75.

59. Bielekova B, Catalfamo M, Reichert-Scrivner S, Packer A, Cerna M, Waldmann TA, et al. Regulatory CD56(bright) natural killer cells mediate immunomodulatory effects of IL-2Ralpha-targeted therapy (daclizumab) in multiple sclerosis. Proc Natl Acad Sci U S A. 2006 Apr;103(15):5941-6.

60. Kaur G, Trowsdale J, Fugger L. Natural killer cells and their receptors in multiple sclerosis. Brain. 2013 Sep;136(Pt 9):2657-76.

61. Tullman MJ. Overview of the epidemiology, diagnosis, and disease progression associated with multiple sclerosis. Am J Manag Care. 2013 Feb;19(2 Suppl):S15-20.

62. Lucchinetti C, Brück W, Parisi J, Scheithauer B, Rodriguez M, Lassmann H. Heterogeneity of multiple sclerosis lesions: implications for the pathogenesis of demyelination. Ann Neurol. 2000 Jun;47(6):707-17.

63. Srivastava R, Aslam M, Kalluri SR, Schirmer L, Buck D, Tackenberg B, et al. Potassium channel KIR4.1 as an immune target in multiple sclerosis. N Engl J Med. 2012 Jul;367(2):115-23.

64. Oksenberg JR, Panzara MA, Begovich AB, Mitchell D, Erlich HA, Murray RS, et al. Selection for T-cell receptor $\mathrm{V}$ beta-D beta-J beta gene rearrangements with specificity for a myelin basic protein peptide in brain lesions of multiple sclerosis. Nature. 1993 Mar;362(6415):68-70.

65. Zhang J, Markovic-Plese S, Lacet B, Raus J, Weiner HL, Hafler DA. Increased frequency of interleukin 2-responsive $\mathrm{T}$ cells specific for myelin basic protein and proteolipid protein in peripheral blood and cerebrospinal fluid of patients with multiple sclerosis. J Exp Med. 1994 Mar;179(3):973-84.

66. Langrish CL, Chen Y, Blumenschein WM, Mattson J, Basham B, Sedgwick JD, et al. IL-23 drives a pathogenic $\mathrm{T}$ cell population that induces autoimmune inflammation. $\mathrm{J}$ Exp Med. 2005 Jan;201(2):233-40.

67. Kebir H, Kreymborg K, Ifergan I, Dodelet-Devillers A, Cayrol R, Bernard M, et al. Human TH17 lymphocytes promote blood-brain barrier disruption and central nervous system inflammation. Nat Med. 2007 Oct;13(10):1173-5. 
68. Tzartos JS, Friese MA, Craner MJ, Palace J, Newcombe J, Esiri MM, et al. Interleukin17 production in central nervous system-infiltrating $\mathrm{T}$ cells and glial cells is associated with active disease in multiple sclerosis. Am J Pathol. 2008 Jan;172(1):146-55.

69. Rojas JI, Romano M, Ciapponi A, Patrucco L, Cristiano E. Interferon Beta for primary progressive multiple sclerosis. Cochrane database Syst Rev. 2010 Jan;(1):CD006643.

70. Lublin FD, Reingold SC, Cohen J a, Cutter GR, Sørensen PS, Thompson AJ, et al. Defining the clinical course of multiple sclerosis: The 2013 revisions. Neurology. 2014 May;

71. Gold R. Oral therapies for multiple sclerosis: a review of agents in phase III development or recently approved. CNS Drugs. 2011 Jan;25(1):37-52.

72. Castro-Borrero W, Graves D, Frohman TC, Flores AB, Hardeman P, Logan D, et al. Current and emerging therapies in multiple sclerosis: a systematic review. Ther Adv Neurol Disord. 2012 Jul;5(4):205-20.

73. O'Connor P, Wolinsky JS, Confavreux C, Comi G, Kappos L, Olsson TP, et al. Randomized trial of oral teriflunomide for relapsing multiple sclerosis. N Engl J Med. 2011 Oct;365(14):1293-303.

74. Ransohoff RM. Natalizumab for multiple sclerosis. N Engl J Med. 2007 Jun;356(25):2622-9.

75. Cohen JA, Chun J. Mechanisms of fingolimod's efficacy and adverse effects in multiple sclerosis. Ann Neurol. 2011 May;69(5):759-77.

76. Noda H, Takeuchi H, Mizuno T, Suzumura A. Fingolimod phosphate promotes the neuroprotective effects of microglia. J Neuroimmunol. 2013 Mar;256(1-2):13-8.

77. Linker RA, Lee D-H, Ryan S, van Dam AM, Conrad R, Bista P, et al. Fumaric acid esters exert neuroprotective effects in neuroinflammation via activation of the Nrf2 antioxidant pathway. Brain. 2011 Mar;134(Pt 3):678-92.

78. Albrecht P, Bouchachia I, Goebels N, Henke N, Hofstetter HH, Issberner A, et al. Effects of dimethyl fumarate on neuroprotection and immunomodulation. $\mathbf{J}$ Neuroinflammation. 2012 Jan;9:163.

79. Perumal JS, Foo F, Cook P, Khan O. Subcutaneous administration of alemtuzumab in patients with highly active multiple sclerosis. Mult Scler. 2012 Aug;18(8):1197-9.

80. Comi G, Pulizzi A, Rovaris M, Abramsky O, Arbizu T, Boiko A, et al. Effect of laquinimod on MRI-monitored disease activity in patients with relapsing-remitting multiple sclerosis: a multicentre, randomised, double-blind, placebo-controlled phase IIb study. Lancet. 2008 Jun;371(9630):2085-92.

81. Bielekova B, Richert N, Howard T, Blevins G, Markovic-Plese S, McCartin J, et al. Humanized anti-CD25 (daclizumab) inhibits disease activity in multiple sclerosis 
patients failing to respond to interferon beta. Proc Natl Acad Sci U S A. 2004 Jun;101(23):8705-8.

82. Hauser SL, Waubant E, Arnold DL, Vollmer T, Antel J, Fox RJ, et al. B-cell depletion with rituximab in relapsing-remitting multiple sclerosis. N Engl J Med. 2008 Feb;358(7):676-88.

83. Bar-Or A, Fawaz L, Fan B, Darlington PJ, Rieger A, Ghorayeb C, et al. Abnormal Bcell cytokine responses a trigger of T-cell-mediated disease in MS? Ann Neurol. 2010 Apr;67(4):452-61.

84. Mangiardi M, Crawford DK, Xia X, Du S, Simon-Freeman R, Voskuhl RR, et al. An animal model of cortical and callosal pathology in multiple sclerosis. Brain Pathol. 2011 May;21(3):263-78.

85. Hohlfeld R, Wekerle H. Immunological update on multiple sclerosis. Curr Opin Neurol. 2001 Jun;14(3):299-304.

86. Koritschoner R, Schweinburg F. Klinische und experimentelle Beobachtungen über Lähmungen nach Wutschutzimpfung. Z Immun exp ther. 42:217-83.

87. Rivers TM, Schwentker FF. ENCEPHALOMYELITIS ACCOMPANIED BY MYELIN DESTRUCTION EXPERIMENTALLY PRODUCED IN MONKEYS. J Exp Med [Internet]. 1935 Apr 30 [cited 2014 Oct 10];61(5):689-702. Available from: http://www.pubmedcentral.nih.gov/articlerender.fcgi?artid=2133246\&tool=pmcentrez \&rendertype $=$ abstract

88. Rivers TM, Sprunt DH, Berry GP. OBSERVATIONS ON ATTEMPTS TO PRODUCE ACUTE DISSEMINATED ENCEPHALOMYELITIS IN MONKEYS. J Exp Med [Internet]. 1933 Jun 30 [cited 2014 Oct 10];58(1):39-53. Available from: http://www.pubmedcentral.nih.gov/articlerender.fcgi?artid=2132279\&tool=pmcentrez \&rendertype $=$ abstract

89. Kabat EA, Wolf A, Bezer AE. THE RAPID PRODUCTION OF ACUTE DISSEMINATED ENCEPHALOMYELITIS IN RHESUS MONKEYS BY INJECTION OF HETEROLOGOUS AND HOMOLOGOUS BRAIN TISSUE WITH ADJUVANTS. J Exp Med [Internet]. 1947 Jan 1 [cited 2014 Oct 10];85(1):117-30. Available from: http://www.pubmedcentral.nih.gov/articlerender.fcgi?artid=2135669\&tool=pmcentrez \&rendertype $=$ abstract

90. Kabat EA, Wolf A, Bezer AE. Rapid Production of Acute Disseminated Encephalomyelitis in Rhesus Monkeys by Injection of Brain Tissue With Adjuvants. Science [Internet]. 1946 Oct 18 [cited 2014 Oct 10];104(2703):362-3. Available from: http://www.ncbi.nlm.nih.gov/pubmed/17780100

91. Morgan IM. ALLERGIC ENCEPHALOMYELITIS IN MONKEYS IN RESPONSE TO INJECTION OF NORMAL MONKEY NERVOUS TISSUE. J Exp Med [Internet]. 1947 Jan 1 [cited 2014 Oct 10];85(1):131-40. Available from: 
http://www.pubmedcentral.nih.gov/articlerender.fcgi?artid=2135671\&tool=pmcentrez \&rendertype $=$ abstract

92. MORRISON LR. Disseminated encephalomyelitis experimentally produced by the use of homologous antigen. Arch Neurol Psychiatry [Internet]. 1947 Oct [cited 2014 Oct 10];58(4):391-416. Available from: http://www.ncbi.nlm.nih.gov/pubmed/20269877

93. FREUND J, STERN ER, PISANI TM. Isoallergic encephalomyelitis and radiculitis in guinea pigs after one injection of brain and Mycobacteria in water-in-oil emulsion. $\mathrm{J}$ Immunol [Internet]. 1947 Oct [cited 2014 Oct 10];57(2):179-94. Available from: http://www.ncbi.nlm.nih.gov/pubmed/20266867

94. OLITSKY PK, YAGER RH. Experimental disseminated encephalomyelitis in white mice. J Exp Med [Internet]. 1949 Sep [cited 2014 Oct 10];90(3):213-24. Available from:

http://www.pubmedcentral.nih.gov/articlerender.fcgi?artid=2135907\&tool=pmcentrez \&rendertype $=$ abstract

95. LEE JM, OLITSKY PK. Simple method for enhancing development of acute disseminated encephalomyelitis in mice. Proc Soc Exp Biol Med [Internet]. 1955 Jun [cited 2014 Oct 10];89(2):263-6. Available from: http://www.ncbi.nlm.nih.gov/pubmed/14395286

96. Munoz JJ, Bernard CC, Mackay IR. Elicitation of experimental allergic encephalomyelitis (EAE) in mice with the aid of pertussigen. Cell Immunol [Internet]. 1984 Jan [cited 2014 Oct 10];83(1):92-100. Available from: http://www.ncbi.nlm.nih.gov/pubmed/6607126

97. OLITSKY PK, TAL C. Acute disseminated encephalomyelitis produced in mice by brain proteolipide (Folch-Lees). Proc Soc Exp Biol Med [Internet]. 1952 Jan [cited 2014 Oct 10];79(1):50-3. Available from: http://www.ncbi.nlm.nih.gov/pubmed/14892035

98. Kies MW, Alvord EC. Encephalitogenie activity in guinea pigs of water-soluble protein fractions of nervous tissue. In: Kies MW, Alvord EC, editors. "Allergic" encephalomyelitis. Springfield: Charles C Thomas; 1959. p. 293-9.

99. Kies MW, Murphy JB, Alvord EC. Fractionation of guinea pig brain proteins with encepahlitogenic activity. Fed Proc. 1960;19:207.

100. Eylar EH, Caccam J, Jackson JJ, Westall FC, Robinson AB. Experimental allergic encephalomyelitis: synthesis of disease-inducing site of the basic protein. Science [Internet]. 1970 Jun 5 [cited 2014 Oct 10];168(3936):1220-3. Available from: http://www.ncbi.nlm.nih.gov/pubmed/5442707

101. Linington C, Berger T, Perry L, Weerth S, Hinze-Selch D, Zhang Y, et al. T cells specific for the myelin oligodendrocyte glycoprotein mediate an unusual autoimmune inflammatory response in the central nervous system. Eur J Immunol [Internet]. 1993 Jun [cited 2014 Oct 10];23(6):1364-72. Available from: http://www.ncbi.nlm.nih.gov/pubmed/7684687 
102. Amor S, Groome N, Linington C, Morris MM, Dornmair K, Gardinier M V, et al. Identification of epitopes of myelin oligodendrocyte glycoprotein for the induction of experimental allergic encephalomyelitis in SJL and Biozzi $\mathrm{AB} / \mathrm{H}$ mice. J Immunol [Internet]. 1994 Nov 15 [cited 2014 Oct 10];153(10):4349-56. Available from: http://www.ncbi.nlm.nih.gov/pubmed/7525700

103. Johns TG, Kerlero de Rosbo N, Menon KK, Abo S, Gonzales MF, Bernard CC. Myelin oligodendrocyte glycoprotein induces a demyelinating encephalomyelitis resembling multiple sclerosis. J Immunol [Internet]. 1995 May 15 [cited 2014 Oct 10];154(10):5536-41. Available from: http://www.ncbi.nlm.nih.gov/pubmed/7537310

104. Stevens DB, Chen K, Seitz RS, Sercarz EE, Bronstein JM. Oligodendrocyte-specific protein peptides induce experimental autoimmune encephalomyelitis in SJL/J mice. J Immunol [Internet]. 1999 Jun 15 [cited 2014 Oct 10];162(12):7501-9. Available from: http://www.ncbi.nlm.nih.gov/pubmed/10358205

105. Berger T, Weerth S, Kojima K, Linington C, Wekerle H, Lassmann H. Experimental autoimmune encephalomyelitis: the antigen specificity of $\mathrm{T}$ lymphocytes determines the topography of lesions in the central and peripheral nervous system. Lab Invest [Internet]. 1997 Mar [cited 2014 Oct 10];76(3):355-64. Available from: http://www.ncbi.nlm.nih.gov/pubmed/9121118

106. Kojima K, Berger T, Lassmann H, Hinze-Selch D, Zhang Y, Gehrmann J, et al. Experimental autoimmune panencephalitis and uveoretinitis transferred to the Lewis rat by $\mathrm{T}$ lymphocytes specific for the S100 beta molecule, a calcium binding protein of astroglia. J Exp Med [Internet]. 1994 Sep 1 [cited 2014 Oct 10];180(3):817-29. Available from: http://www.pubmedcentral.nih.gov/articlerender.fcgi?artid=2191664\&tool=pmcentrez \&rendertype $=$ abstract

107. Määttä JA, Käldman MS, Sakoda S, Salmi AA, Hinkkanen AE. Encephalitogenicity of myelin-associated oligodendrocytic basic protein and 2',3'-cyclic nucleotide 3'phosphodiesterase for BALB/c and SJL mice. Immunology [Internet]. 1998 Nov [cited 2014 Oct 10];95(3):383-8. Available from: http://www.pubmedcentral.nih.gov/articlerender.fcgi?artid=1364404\&tool=pmcentrez \&rendertype $=$ abstract

108. Thoua NM, van Noort JM, Baker D, Bose A, van Sechel AC, van Stipdonk MJ, et al. Encephalitogenic and immunogenic potential of the stress protein alphaB-crystallin in Biozzi ABH (H-2A(g7)) mice. J Neuroimmunol [Internet]. 2000 Apr 3 [cited 2014 Oct 10];104(1):47-57. Available from: http://www.ncbi.nlm.nih.gov/pubmed/10683514

109. BELL J, PATERSON PY. Rapid induction of allergic encephalomyelitis in rats without the use of mycobacteria. Science. 1960 May;131(3411):1448.

110. WAKSMAN BH, ARBOUYS S, ARNASON BG. The use of specific "lymphocyte" antisera to inhibit hypersensitive reactions of the "delayed" type. J Exp Med. 1961 Dec;114:997-1022. 
111. Gonatas NK, Howard JC. Inhibition of experimental allergic encephalomyelitis in rats severely depleted of T cells. Science. 1974 Nov;186(4166):839-41.

112. Ortiz-Ortiz L, Weigle WO. Cellular events in the induction of experimental allergic encephalomyelitis in rats. J Exp Med. 1976 Sep;144(3):604-16.

113. Ben-Nun A, Wekerle H, Cohen IR. Vaccination against autoimmune encephalomyelitis with T-lymphocyte line cells reactive against myelin basic protein. Nature. 1981 Jul;292(5818):60-1.

114. Zamvil SS, Steinman L. The T lymphocyte in experimental allergic encephalomyelitis. Annu Rev Immunol. 1990 Jan;8:579-621.

115. Kojima K, Berger T, Lassmann H, Hinze-Selch D, Zhang Y, Gehrmann J, et al. Experimental autoimmune panencephalitis and uveoretinitis transferred to the Lewis rat by $\mathrm{T}$ lymphocytes specific for the $\mathrm{S} 100$ beta molecule, a calcium binding protein of astroglia. J Exp Med. 1994 Sep;180(3):817-29.

116. Litzenburger T, Fässler R, Bauer J, Lassmann H, Linington C, Wekerle H, et al. B lymphocytes producing demyelinating autoantibodies: development and function in gene-targeted transgenic mice. J Exp Med. 1998 Jul;188(1):169-80.

117. Almolda B, Gonzalez B, Castellano B. Antigen presentation in EAE: role of microglia, macrophages and dendritic cells. Front Biosci (Landmark Ed. 2011 Jan;16:1157-71.

118. Leonard JP, Waldburger KE, Goldman SJ. Prevention of experimental autoimmune encephalomyelitis by antibodies against interleukin 12. J Exp Med. 1995 Jan;181(1):381-6.

119. Rose LM, Alvord EC, Hruby S, Jackevicius S, Petersen R, Warner N, et al. In vivo administration of anti-CD4 monoclonal antibody prolongs survival in longtailed macaques with experimental allergic encephalomyelitis. Clin Immunol Immunopathol. 1987 Dec;45(3):405-23.

120. Sedgwick JD, Mason DW. The mechanism of inhibition of experimental allergic encephalomyelitis in the rat by monoclonal antibody against CD4. J Neuroimmunol. 1986 Dec;13(2):217-32.

121. Ruddle NH, Bergman CM, McGrath KM, Lingenheld EG, Grunnet ML, Padula SJ, et al. An antibody to lymphotoxin and tumor necrosis factor prevents transfer of experimental allergic encephalomyelitis. J Exp Med. 1990 Oct;172(4):1193-200.

122. Kuroda Y, Shimamoto Y. Human tumor necrosis factor-alpha augments experimental allergic encephalomyelitis in rats. J Neuroimmunol. 1991 Nov;34(2-3):159-64.

123. Abreu SL. Suppression of experimental allergic encephalomyelitis by interferon. Immunol Commun. 1982 Jan;11(1):1-7. 
124. Billiau A, Heremans H, Vandekerckhove F, Dijkmans R, Sobis H, Meulepas E, et al. Enhancement of experimental allergic encephalomyelitis in mice by antibodies against IFN-gamma. J Immunol. 1988 Mar;140(5):1506-10.

125. Voorthuis JA, Uitdehaag BM, De Groot CJ, Goede PH, van der Meide PH, Dijkstra CD. Suppression of experimental allergic encephalomyelitis by intraventricular administration of interferon-gamma in Lewis rats. Clin Exp Immunol. 1990 Aug;81(2):183-8.

126. Duong TT, St Louis J, Gilbert JJ, Finkelman FD, Strejan GH. Effect of anti-interferongamma and anti-interleukin-2 monoclonal antibody treatment on the development of actively and passively induced experimental allergic encephalomyelitis in the SJL/J mouse. J Neuroimmunol. 1992 Feb;36(2-3):105-15.

127. Lublin FD, Knobler RL, Kalman B, Goldhaber M, Marini J, Perrault M, et al. Monoclonal anti-gamma interferon antibodies enhance experimental allergic encephalomyelitis. Autoimmunity. 1993 Jan;16(4):267-74.

128. Krakowski M, Owens T. Interferon-gamma confers resistance to experimental allergic encephalomyelitis. Eur J Immunol. 1996 Jul;26(7):1641-6.

129. Willenborg DO, Fordham S, Bernard CC, Cowden WB, Ramshaw IA. IFN-gamma plays a critical down-regulatory role in the induction and effector phase of myelin oligodendrocyte glycoprotein-induced autoimmune encephalomyelitis. J Immunol. 1996 Oct;157(8):3223-7.

130. Constantinescu CS, Wysocka M, Hilliard B, Ventura ES, Lavi E, Trinchieri G, et al. Antibodies against IL-12 prevent superantigen-induced and spontaneous relapses of experimental autoimmune encephalomyelitis. J Immunol. 1998 Nov;161(9):5097-104.

131. Segal BM, Dwyer BK, Shevach EM. An interleukin (IL)-10/IL-12 immunoregulatory circuit controls susceptibility to autoimmune disease. J Exp Med. 1998 Feb;187(4):537-46.

132. Oppmann B, Lesley R, Blom B, Timans JC, Xu Y, Hunte B, et al. Novel p19 protein engages IL-12p40 to form a cytokine, IL-23, with biological activities similar as well as distinct from IL-12. Immunity. 2000 Nov;13(5):715-25.

133. Gran B, Zhang G-X, Yu S, Li J, Chen X-H, Ventura ES, et al. IL-12p35-deficient mice are susceptible to experimental autoimmune encephalomyelitis: evidence for redundancy in the IL-12 system in the induction of central nervous system autoimmune demyelination. J Immunol. 2002 Dec;169(12):7104-10.

134. Harrington LE, Hatton RD, Mangan PR, Turner H, Murphy TL, Murphy KM, et al. Interleukin 17-producing CD4+ effector T cells develop via a lineage distinct from the T helper type 1 and 2 lineages. Nat Immunol. 2005 Nov;6(11):1123-32.

135. Steinman L. A brief history of $\mathrm{T}(\mathrm{H}) 17$, the first major revision in the $\mathrm{T}(\mathrm{H}) 1 / \mathrm{T}(\mathrm{H}) 2$ hypothesis of T cell-mediated tissue damage. Nat Med. 2007 Feb;13(2):139-45. 
136. Cua DJ, Sherlock J, Chen Y, Murphy CA, Joyce B, Seymour B, et al. Interleukin-23 rather than interleukin-12 is the critical cytokine for autoimmune inflammation of the brain. Nature. 2003 Feb;421(6924):744-8.

137. Zhang G-X, Gran B, Yu S, Li J, Siglienti I, Chen X, et al. Induction of experimental autoimmune encephalomyelitis in IL-12 receptor-beta 2-deficient mice: IL-12 responsiveness is not required in the pathogenesis of inflammatory demyelination in the central nervous system. J Immunol. 2003 Feb;170(4):2153-60.

138. Chung Y, Chang SH, Martinez GJ, Yang XO, Nurieva R, Kang HS, et al. Critical regulation of early Th17 cell differentiation by interleukin-1 signaling. Immunity. 2009 Apr;30(4):576-87.

139. Bettini M, Vignali DAA. Regulatory T cells and inhibitory cytokines in autoimmunity. Curr Opin Immunol. 2009 Dec;21(6):612-8.

140. Chen Y, Kuchroo VK, Inobe J, Hafler DA, Weiner HL. Regulatory T cell clones induced by oral tolerance: suppression of autoimmune encephalomyelitis. Science. 1994 Aug;265(5176):1237-40.

141. Nicholson LB, Greer JM, Sobel RA, Lees MB, Kuchroo VK. An altered peptide ligand mediates immune deviation and prevents autoimmune encephalomyelitis. Immunity. 1995 Oct;3(4):397-405.

142. Brocke S, Gijbels K, Allegretta M, Ferber I, Piercy C, Blankenstein T, et al. Treatment of experimental encephalomyelitis with a peptide analogue of myelin basic protein. Nature. 1996 Jan;379(6563):343-6.

143. Kim EY, Moudgil KD. Regulation of autoimmune inflammation by pro-inflammatory cytokines. Immunol Lett. 2008 Oct;120(1-2):1-5.

144. Correale J, Villa A. Role of CD8+ CD25+ Foxp3+ regulatory T cells in multiple sclerosis. Ann Neurol. 2010 May;67(5):625-38.

145. EAE Induction by Active Immunization in C57BL/6 Mice. [Internet]. Hooke Laboratories. 2014 [cited 2014 Aug 7]. Available from: http://hookelabs.com/protocols/pdf/EAE Induction by Active Immunization in C57BL6 Mice.pdf

146. Grimaldi D, Engel MS. Evolution of the Insects [Internet]. Cambridge University Press; 2005 [cited 2014 Aug 7]. Available from: http://books.google.com/books?id=Q16J16wKb88C\&pgis=1

147. G. C. Oral laquinimod reduced relapse rate and delayed progression of disability in allegro. A phase III trial for relapsing-remitting multiple sclerosis. Neurology. 2011;76(9):7PP.001.

148. Karpus WJ, Gould KE, Swanborg RH. CD4+ suppressor cells of autoimmune encephalomyelitis respond to $\mathrm{T}$ cell receptor-associated determinants on effector cells 
by interleukin-4 secretion. Eur J Immunol [Internet]. 1992 Jul [cited 2014 Jul 21];22(7):1757-63. Available from: http://www.ncbi.nlm.nih.gov/pubmed/1378016

149. Racke MK, Bonomo A, Scott DE, Cannella B, Levine A, Raine CS, et al. Cytokineinduced immune deviation as a therapy for inflammatory autoimmune disease. J Exp Med [Internet]. 1994 Nov 1 [cited 2014 Jul 21];180(5):1961-6. Available from: http://www.pubmedcentral.nih.gov/articlerender.fcgi?artid=2191757\&tool=pmcentrez \&rendertype $=$ abstract

150. Bielekova B, Lincoln A, McFarland H, Martin R. Therapeutic potential of phosphodiesterase-4 and -3 inhibitors in Th1-mediated autoimmune diseases. J Immunol [Internet]. 2000 Jan 15 [cited 2014 Jul 21];164(2):1117-24. Available from: http://www.ncbi.nlm.nih.gov/pubmed/10623864

151. Nagelkerken L. Role of Th1 and Th2 cells in autoimmune demyelinating disease. Braz J Med Biol Res [Internet]. 1998 Jan [cited 2014 Jul 21];31(1):55-60. Available from: http://www.ncbi.nlm.nih.gov/pubmed/9686179

152. Jäger A, Dardalhon V, Sobel RA, Bettelli E, Kuchroo VK. Th1, Th17, and Th9 effector cells induce experimental autoimmune encephalomyelitis with different pathological phenotypes. J Immunol [Internet]. 2009 Dec 1 [cited 2014 Jul 21];183(11):7169-77. Available from: http://www.pubmedcentral.nih.gov/articlerender.fcgi?artid=2921715\&tool=pmcentrez \&rendertype $=$ abstract

153. Germain RN. MHC-dependent antigen processing and peptide presentation: providing ligands for T lymphocyte activation. Cell [Internet]. 1994 Jan 28 [cited 2014 Jul 22];76(2):287-99. Available from: http://www.ncbi.nlm.nih.gov/pubmed/8293464

154. Steinman L, Rosenbaum JT, Sriram S, McDevitt HO. Prevention of EAE with monoclonal anti-I-A antibodies. Trans Am Neurol Assoc [Internet]. 1981 Jan [cited 2014 Jul 21];106:237-8. Available from: http://www.ncbi.nlm.nih.gov/pubmed/6960593

155. Adorini L, Nagy Z. Inhibition of T cell activation by MHC blockade. Int Rev Immunol [Internet]. 1990 Jan [cited 2014 Jul 21];6(1):23-35. Available from: http://www.ncbi.nlm.nih.gov/pubmed/2102903

156. Adorini L, Nagy ZA. Peptide competition for antigen presentation. Immunol Today [Internet]. 1990 Jan [cited 2014 Jul 21];11(1):21-4. Available from: http://www.ncbi.nlm.nih.gov/pubmed/2405874

157. Lamont AG, Sette A, Grey HM. Inhibition of antigen presentation in vitro and in vivo by MHC antagonist peptides. Int Rev Immunol [Internet]. 1990 Jan [cited 2014 Jul 21];6(1):49-59. Available from: http://www.ncbi.nlm.nih.gov/pubmed/1966393

158. Wraith DC, McDevitt HO, Steinman L, Acha-Orbea H. T cell recognition as the target for immune intervention in autoimmune disease. Cell [Internet]. 1989 Jun 2 [cited 2014 Jul 21];57(5):709-15. Available from: http://www.ncbi.nlm.nih.gov/pubmed/2655929 
159. Wraith DC, Smilek DE, Mitchell DJ, Steinman L, McDevitt HO. Antigen recognition in autoimmune encephalomyelitis and the potential for peptide-mediated immunotherapy. Cell [Internet]. 1989 Oct 20 [cited 2014 Jul 21];59(2):247-55. Available from: http://www.ncbi.nlm.nih.gov/pubmed/2478291

160. Lalor SJ, Dungan LS, Sutton CE, Basdeo SA, Fletcher JM, Mills KHG. Caspase-1processed cytokines IL-1beta and IL-18 promote IL-17 production by gammadelta and CD4 T cells that mediate autoimmunity. J Immunol [Internet]. 2011 May 15 [cited 2014 Jul 19];186(10):5738-48. Available from: http://www.ncbi.nlm.nih.gov/pubmed/21471445

161. Scheicher C, Mehlig M, Zecher R, Reske K. Dendritic cells from mouse bone marrow: in vitro differentiation using low doses of recombinant granulocyte-macrophage colony-stimulating factor. J Immunol Methods [Internet]. 1992 Oct 2 [cited 2014 Aug 8];154(2):253-64. Available from: http://www.ncbi.nlm.nih.gov/pubmed/1401959

162. Lutz MB, Rössner S. Factors influencing the generation of murine dendritic cells from bone marrow: the special role of fetal calf serum. Immunobiology [Internet]. $2007 \mathrm{Jan}$ [cited 2014 Aug 8];212(9-10):855-62. Available from: http://www.ncbi.nlm.nih.gov/pubmed/18086384

163. Son Y-I, Egawa S, Tatsumi T, Redlinger RE, Kalinski P, Kanto T. A novel bulkculture method for generating mature dendritic cells from mouse bone marrow cells. $\mathbf{J}$ Immunol Methods [Internet]. 2002 Apr 1 [cited 2014 Aug 8];262(1-2):145-57. Available from: http://www.ncbi.nlm.nih.gov/pubmed/11983228

164. Lutz MB, Kukutsch N, Ogilvie AL, Rössner S, Koch F, Romani N, et al. An advanced culture method for generating large quantities of highly pure dendritic cells from mouse bone marrow. J Immunol Methods [Internet]. 1999 Feb 1 [cited 2014 Jul 28];223(1):77-92. Available from: http://www.ncbi.nlm.nih.gov/pubmed/10037236

165. Cua DJ, Sherlock J, Chen Y, Murphy CA, Joyce B, Seymour B, et al. Interleukin-23 rather than interleukin-12 is the critical cytokine for autoimmune inflammation of the brain. Nature [Internet]. 2003 Feb 13 [cited 2014 Jul 20];421(6924):744-8. Available from: http://www.ncbi.nlm.nih.gov/pubmed/12610626

166. Murphy AC, Lalor SJ, Lynch MA, Mills KHG. Infiltration of Th1 and Th17 cells and activation of microglia in the CNS during the course of experimental autoimmune encephalomyelitis. Brain Behav Immun [Internet]. 2010 May [cited 2014 Jul 10];24(4):641-51. Available from: http://www.ncbi.nlm.nih.gov/pubmed/20138983

167. D'Andrea A, Aste-Amezaga M, Valiante NM, Ma X, Kubin M, Trinchieri G. Interleukin 10 (IL-10) inhibits human lymphocyte interferon gamma-production by suppressing natural killer cell stimulatory factor/IL-12 synthesis in accessory cells. J Exp Med [Internet]. 1993 Sep 1 [cited 2014 Jul 22];178(3):1041-8. Available from: http://www.pubmedcentral.nih.gov/articlerender.fcgi?artid=2191152\&tool=pmcentrez \&rendertype $=$ abstract

168. De Waal Malefyt R, Abrams J, Bennett B, Figdor CG, de Vries JE. Interleukin 10(IL10) inhibits cytokine synthesis by human monocytes: an autoregulatory role of IL-10 
produced by monocytes. J Exp Med [Internet]. 1991 Nov 1 [cited 2014 Jul 22];174(5):1209-20. Available

from: http://www.pubmedcentral.nih.gov/articlerender.fcgi?artid=2119001\&tool=pmcentrez \&rendertype $=$ abstract

169. Moore KW, O’Garra A, de Waal Malefyt R, Vieira P, Mosmann TR. Interleukin-10. Annu Rev Immunol [Internet]. 1993 Jan [cited 2014 Jul 22];11:165-90. Available from: http://www.ncbi.nlm.nih.gov/pubmed/8386517

170. De Waal Malefyt R, Haanen J, Spits H, Roncarolo MG, te Velde A, Figdor C, et al. Interleukin 10 (IL-10) and viral IL-10 strongly reduce antigen-specific human T cell proliferation by diminishing the antigen-presenting capacity of monocytes via downregulation of class II major histocompatibility complex expression. J Exp Med [Internet]. 1991 Oct 1 [cited 2014 Jul 22];174(4):915-24. Available from: http://www.pubmedcentral.nih.gov/articlerender.fcgi?artid=2118975\&tool=pmcentrez \&rendertype $=$ abstract

171. Kennedy MK, Torrance DS, Picha KS, Mohler KM. Analysis of cytokine mRNA expression in the central nervous system of mice with experimental autoimmune encephalomyelitis reveals that IL-10 mRNA expression correlates with recovery. J Immunol [Internet]. 1992 Oct 1 [cited 2014 Jul 22];149(7):2496-505. Available from: http://www.ncbi.nlm.nih.gov/pubmed/1527389

172. Cua DJ, Hutchins B, LaFace DM, Stohlman SA, Coffman RL. Central nervous system expression of IL-10 inhibits autoimmune encephalomyelitis. J Immunol [Internet]. 2001 Jan 1 [cited 2014 Jul 22];166(1):602-8. Available from: http://www.ncbi.nlm.nih.gov/pubmed/11123343

173. Zhou H, Wang Y, Lian Q, Yang B, Ma Y, Wu X, et al. Differential IL-10 production by DCs determines the distinct adjuvant effects of LPS and PTX in EAE induction. Eur J Immunol [Internet]. 2014 May [cited 2014 Jul 22];44(5):1352-62. Available from: http://www.ncbi.nlm.nih.gov/pubmed/24496948

174. Andrade RM, Hygino J, Kasahara TM, Vieira MM, Xavier LF, Blanco B, et al. High IL-10 production by aged AIDS patients is related to high frequency of Tr-1 phenotype and low in vitro viral replication. Clin Immunol [Internet]. 2012 Oct [cited 2014 Jul 22];145(1):31-43. Available from: http://www.ncbi.nlm.nih.gov/pubmed/22922271

175. Carrier Y, Whitters MJ, Miyashiro JS, LaBranche TP, Ramon HE, Benoit SE, et al. Enhanced GITR/GITRL interactions augment IL-27 expression and induce IL-10producing Tr-1 like cells. Eur J Immunol [Internet]. 2012 Jun [cited 2014 Jul 22];42(6):1393-404. Available from: http://www.ncbi.nlm.nih.gov/pubmed/22678896

176. Beers C, Burich A, Kleijmeer MJ, Griffith JM, Wong P, Rudensky AY. Cathepsin S controls MHC class II-mediated antigen presentation by epithelial cells in vivo. J Immunol [Internet]. 2005 Feb 1 [cited 2014 Aug 8];174(3):1205-12. Available from: http://www.ncbi.nlm.nih.gov/pubmed/15661874

177. Costantino CM, Ploegh HL, Hafler DA. Cathepsin S regulates class II MHC processing in human CD4+ HLA-DR+ T cells. J Immunol [Internet]. 2009 Jul 15 [cited 2014 Aug 
7];183(2):945-52.

Available

from:

http://www.pubmedcentral.nih.gov/articlerender.fcgi?artid=2752291\&tool=pmcentrez \&rendertype $=$ abstract

178. Stoeckle C, Quecke P, Rückrich T, Burster T, Reich M, Weber E, et al. Cathepsin S dominates autoantigen processing in human thymic dendritic cells. J Autoimmun [Internet]. 2012 Jun [cited 2014 Aug 3];38(4):332-43. Available from: http://www.ncbi.nlm.nih.gov/pubmed/22424724 